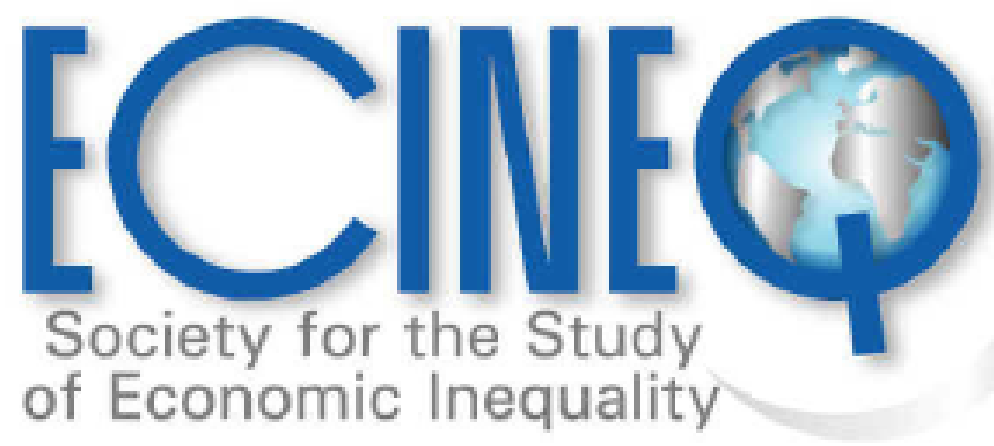

Working Paper Series

Top Expenditure Distribution in Arab Countries and the Inequality Puzzle

Vladimir Hlasny 


\title{
Top Expenditure Distribution in Arab Countries and the Inequality Puzzle
}

\author{
Vladimir Hlasny \\ Ewha Womans University
}

\begin{abstract}
This study was motivated by reports of a mismatch between inequality experienced on the streets across the Arab region, and that estimated in household expenditure surveys. The study uses eleven surveys from Egypt, Jordan, Palestine, Sudan and Tunisia to investigate whether the dispersion of top expenditures and measurement errors in them bias the measurement of inequality. The expenditure distributions are corrected by replacing potentially mismeasured values with those drawn from parametric distributions. Across all surveys, expenditure inequality is found to be at or below that found in emerging countries worldwide. The Gini is consistently 0.30-0.32 in Egypt, 0.35-0.37 in Jordan, and 0.38-0.43 in Palestine, Sudan and Tunisia. Several surveys include outliers raising inequality estimates. The Egyptian, Palestinian, and Tunisian surveys exhibit smoother top tails of expenditures, approximable by parametric distributions. Across years leading up to the Arab Spring, the estimates in these countries show falling inequality, suggesting that data problems are not behind the Arab inequality puzzle.
\end{abstract}

Keyword: Top expenditures, economic inequality, Pareto law, Arab region.

JEL Cassification: D31, D63, N35. 


\title{
Top Expenditure Distribution in Arab Countries and the Inequality Puzzle
}

\author{
Vladimir Hlasny*
}

\begin{abstract}
This study was motivated by reports of a mismatch between inequality experienced on the streets across the Arab region, and that estimated in household expenditure surveys. The study uses eleven surveys from Egypt, Jordan, Palestine, Sudan and Tunisia to investigate whether the dispersion of top expenditures and measurement errors in them bias the measurement of inequality. The expenditure distributions are corrected by replacing potentially mismeasured values with those drawn from parametric distributions. Across all surveys, expenditure inequality is found to be at or below that found in emerging countries worldwide. The Gini is consistently 0.30-0.32 in Egypt, 0.35-0.37 in Jordan, and 0.38-0.43 in Palestine, Sudan and Tunisia. Several surveys include outliers raising inequality estimates. The Egyptian, Palestinian, and Tunisian surveys exhibit smoother top tails of expenditures, approximable by parametric distributions. Across years leading up to the Arab Spring, the estimates in these countries show falling inequality, suggesting that data problems are not behind the Arab inequality puzzle.
\end{abstract}

JEL: D31, D63, N35.

Keywords: Top expenditures, economic inequality, Pareto law, Arab region.

* Economics Department, Ewha Womans University, Seoul Korea 120750. Email:

vhlasny@gmail.com. The paper is scheduled to be published in the Journal of Economic and Social Measurement. An earlier version appeared as a working paper of the United Nations Economic and Social Commission for Western Asia (Hlasny and Intini 2015). 


\section{Introduction}

In 2011 a series of revolutions shook the Arab region bringing about political changes in a number of countries. Worldwide attention turned to explaining the causes of these revolutions, and their repercussions. The prevalent theory since the days of the revolutions has held that inequality played a central role in the stirring up of popular discontent. The extent to which different dimensions of inequality were responsible for regime falls in Egypt, Libya, Tunisia and Yemen and other significant political changes in Bahrain, Jordan, Morocco, and Syria - and the acuteness of the different dimensions of inequality in the first place, are the subject of an active academic discourse (AfDB 2012; Ncube and Anyanwu 2012; Tessler et al. 2012; Al-Shawarby 2014; Azour 2014; Gatward et al. 2015; Ramadan et al. 2018).

The true level, manifestation and trend of inequalities in the lead up to the Arab Spring are all points of contention. Perceptions on the street and by the region's commentators are that inequality and lack of access to career opportunities are problems that played a crucial role in triggering the uprisings (Verme 2014; Teti et al. 2017). Grievances held by the middle class against the privileged elites were also specifically cited as culprits (Tobin 2012). This narrative is rooted in regional history. Public outcries about inequality, lack of freedoms and cronyism were not confined to the years leading up to the Arab Spring, but can be traced back at least three decades to movements against authoritarianism (Hinnebusch 2006), austere neoliberal reforms (Joya et al. 2011; Bogaert 2013) and a "fusion between neoliberal and authoritarian forces" (Dahi and Munif 2012:323). The protests against oppression can be traced even longer to the 'Great' revolutions of the first half the $20^{\text {th }}$ century freeing the region of the oppression under the old social structures including colonialism, monarchy and feudalism (Achcar 2013). ${ }^{1}$

However, the foregone conclusions about high inequality leading to the Arab Spring are in contrast to objective measurements of inequality using household surveys, a phenomenon dubbed the Arab inequality puzzle (Ianchovichina 2017). Bibi and Nabli (2010) reviewed the available evidence of inequality in the region and concluded that Arab countries in particular fall within the range of countries with moderate inequality of household incomes and expenditures, when compared to other regions such as East Asia, Latin America, South Asia and Sub Saharan Africa. Inequality measures based on both the Gini coefficient and the aggregate share of the top to bottom deciles often measured in terms of consumption expenditures - have been relatively low and declining (Page 2007).

The low inequality estimates in household surveys do not appear to be due to poor data quality. While there are presently few parametric tests of the properties of income, expenditure and wealth distributions in the region (as noted by Bibi and Nabli 2009), several recent studies have re-

\footnotetext{
${ }^{1} \mathrm{I}$ am grateful to an anonymous referee for making this important point.
} 
estimated inequality using parametric methods robust to various measurement issues pertaining to data quality, survey representation and non-response.

A world-wide historic study using an assumption of lognormal income distributions anchored by national accounts statistics (Pienkovskiy and Sala-i-Martin 2009) concluded that over the prior decades the Arab region had seen progress in reducing poverty rates and converging toward the world average welfare level and contribution to a "global middle class" (p.29). More relevant to our analysis, several studies have analyzed the top ends of individual countries' income distributions using external data on real estate postings (Van der Weide et al. 2018), national accounts and tax microdata (Assouad et al. 2015; Alvaredo et al. 2017), or parametric values from other mostly developed countries (Alvaredo and Piketty 2014). Using stylized parametric assumptions, or parameter values rather atypical of the region, they estimated higher degrees of national and cross-country inequality (Verme and Hlasny 2016).

Alvaredo and Piketty (2014) estimated inequality using a mix of Pareto distributions for top incomes and log-normal distributions for the rest of incomes. In Egypt as well as in the rest of the Arab region, this approach yielded higher estimates of inequality, suggesting systematic underreporting of top incomes, but the new national estimates were still moderate. On the other hand, between-country gaps in income distributions gave rise to high estimates of inequality at the pan-Arab level. Assouad (2015), applying the same methodology used by Alvaredo and Piketty to the individual tax returns and national accounts data in Lebanon, found one of the highest income concentrations among all the countries included in the World Top Income Database due to the disproportional effect of profits and rents in the top quantiles. Extrapolating these high estimates to the rest of the Arab region yielded high measures of national and particularly region-wide inequality.

Using within-survey information alone, Hlasny and Verme (2018) found that replacing actual top incomes or expenditures in the Egyptian household survey with Pareto parametric estimates did not affect the computed Gini noticeably regardless how data were weighted, apparently on account of the high quality of the data. Hlasny and Verme (2015) evaluated the dispersion of top incomes in several countries worldwide by comparing the actual dispersion to that predicted under the Pareto or the four-parameter generalized beta type-II (GB2) distributions. They found that the use of the Pareto distributions resulted in larger corrections as compared to the use of GB2 distributions but the differences were modest. In Egypt, the observed top $0.1 \%$ of incomes were found to be extreme or overstated (commanding a downward correction). However, the following $1 \%$ of incomes were found to follow the expected distributions more closely.

Focusing on the opposite tail of income distributions across a large set of Mediterranean surveys, Hlasny et al. (2020) assessed the presence and dispersion of non-positive incomes, and corrected the distribution using non-parametric and parametric methods. They found that negative and zero incomes are quite prevalent in the region, and are associated with self-employment earnings or with large tax or social-security adjustments. Households with non-positive incomes do not appear 
to be materially deprived, and their various socio-economic outcomes would predict much higher, positive income levels. Replacing non-positive incomes with the predicted positive incomes results in estimating an even lower degree of inequality.

This review suggests that income and consumption are prone to various measurement errors. The challenges are more severe still for households' wealth, which is an important determinant of workers' career outcomes (AlAzzawi and Hlasny 2019). Among the handful of existing studies, Hlasny and AlAzzawi (2019) estimate the distribution of durable-asset wealth across three Arab countries and across up to three survey waves, taking into account an extensive list of productive and non-productive assets. They found that the distribution of asset ownership was closely associated with the distribution of households' income and other socioeconomic outcomes. El Enbaby and Galal (2015) assessed inequality of opportunity for wealth acquisition and for earnings in Egypt during 1998-2012, showed their distributions, and discussed the complementary relationship between them.

This study adds to the literature by evaluating the dispersion of top expenditure observations in five countries in the Arab region using several alternative modeling specifications, and testing whether the potential mismeasurement of top expenditures could be driving the Arab inequality puzzle. The first contribution is to describe the top of the expenditure distributions in several Arab countries, including the rarely studied Palestine and Sudan, and provide parametric measures of the degree of dispersion of top expenditures. The second contribution is to deal with the suspected top expenditure issues by replacing actual top observations with values predicted under the Pareto distribution of type I - theoretical distribution used commonly as a good approximation to true population distributions across countries and years (Cowell and Victoria-Feser 2007; Van Kerm 2007; Lakner and Milanovic 2013). Going beyond the analysis by Hlasny and Verme $(2015,2018)$, several robustness tests are performed with respect to model specification.

By design, values drawn from the Pareto distribution are not subject to measurement errors, data censoring, or year-to-year sampling errors. They allow us to produce more accurate estimates of inequality, and changes in inequality across survey waves. By comparing the fit of the Pareto distributions to the actual patterns of dispersion of top expenditures, we can assess how adequately rich households are represented in Arab region surveys, and how sensitive the observed levels and trends in inequality are to measurement and sampling errors. Ultimately, the methods and findings in this study will serve to advance the toolbox for scholars and policymakers in the Arab region for working with regional economic distributions.

The paper is organized as follows. Section two briefly describes the data, empirical issues and correction methods taken up in the analysis. Section three presents the main results and section four discusses their significance with respect to the broader problem of evaluating economic inequality across the Arab region and over time. 


\section{Survey data, right-tail measurement issues, and correction methods}

The central aim of this study is to advance our understanding of the distribution of welfare among the peoples of the Arab region, using recently developed estimation methods and a newly available set of high-quality, harmonized household surveys. Expenditure per capita is used as a welfare aggregate (Deaton 1997:148,243-244). The reason for preferring expenditures over incomes is that the set of surveys used in this study are for emerging economies with significant rural sectors, where households earn incomes in kind, and engage in household production. The corresponding streams of consumption and welfare are better captured through questions about implicit consumption expenditures than about incomes.

The reliance on expenditures also facilitates comparison with other countries in the region as well as worldwide for whom income microdata are unavailable, are mismeasured or are not as yet analyzed carefully. Another reason for using expenditures is that expenditure data may be more precise given that income may be underreported, and given that expenditure is smoother than income over time, especially in developing and rural areas. Moreover, expenditure data in the Arab region have been found to exhibit lower inequality than incomes (Bibi and Nabli 2010), potentially presenting an even greater puzzle to observers of the recent political developments and changes in the region. The relatively narrow distribution of top expenditures may be on account of high saving elasticity among the rich, or may potentially indicate measurement issues that are more serious than those for top incomes (e.g., imputed rent, expenditures abroad, illicit goods and services).

\section{Available data}

Most Arab countries conduct household income and expenditure surveys (HHIES) periodically to collect evidence regarding the distribution and components of incomes and expenditures of their population. However, not all countries make the survey micro-data publically available in their entirety or at all. This study relies on a set of HHIESs harmonized and released to the public by Economic Research Forum (ERF) in collaboration with national statistical agencies: the Egyptian Household Expenditure, Income and Consumption Survey; the Jordanian Household Expenditure and Income Survey; the Palestinian Expenditure and Consumption Survey; the Sudanese National Baseline Household Survey; and the Tunisian National Survey on Household Budget, Consumption and Standard of Living. These are high quality, well-documented surveys that have been validated and used successfully in a number of existing studies (Krafft et al. 2017; Ramadan et al. 2018; Hlasny et al. 2020). All HHIES surveys are nationally representative, and thus comparable across countries and years, but individual households cannot be tracked over time.

All recent HHIESs available at the time of writing are used, including the surveys for Egypt 2008, 2010 and 2012; Jordan 2006 and 2010; Palestine 2007, 2010 and 2011; Sudan 2009; and Tunisia 2005 and 2010. The Egyptian surveys were administered during April '08-March '09, July '10June ' 11 , and July ' $12-$ June ' 13 , that is two years before the uprising, in its midst, and during the flux one year after the uprising when the Muslim Brotherhood was promoting a new national 
constitution. The Jordanian surveys were collected in the 12 months following April ' 06 , and those following April ' 10 - for the most part before public protests in the country became widespread in the spring of 2011 and led to constitutional reforms. In Palestine, the surveys were collected throughout the years 2007, 2010 and 2011, at the time of relaxation of the Israeli security regime and prior to the September 2012 surge of major protests against domestic economic policy. In Sudan, the survey took place in the summer of 2009, three years prior to the start of Arab-Spring inspired protests against the government's austerity plans. Finally, the Tunisian surveys were administered during May '05-May '06, and June '10-May '11. Fieldwork for the second survey was thus at its height in January 2011 when major public protests erupted, motivated by people's economic and democratic concerns, and led to the toppling of the country's president.

In the following analysis, the surveys are used one by one as cross-sectional samples. We are able to use multiple survey waves for four of the five included countries. This allows us to follow the evolution of expenditures and of inequality over time, and in the case of Egypt before and after the popular uprising. While the five countries do not represent the entire Arab region, they show a mosaic of the economic conditions and survey practices across the region. The surveys differ in their sampling rate from the population, and cover a heterogeneous block of countries in terms of their economic development, demography and labor force composition, inequality, and political climate at the time of survey fieldwork. The essential information on survey sources and data distribution is provided in the supplementary materials.

Before any analysis with the available sample, it is useful to check whether extreme expenditure observations are simply errors such as data-entry errors or are true values incidentally very distant from the central moments of the expenditure distribution. The eleven surveys differ significantly in the level and the dispersion of the highest several expenditures. The Egyptian data exhibit modest dispersion. The single highest expenditure exceeds the one ranked twentieth by merely 190 percent in 2008, 210 percent in 2010, and 120 percent in $2012 .^{2}$ The Jordanian data show more substantial dispersion, and include an influential observation in the 2010 wave. In the 2006 wave, the highest observed expenditure per capita exceeds the second highest one by 64 percent, and the twentieth highest one by 354 percent. In the 2010 wave, on the other hand, the highest expenditure per capita is more than seven times as high as the one in the second place, and more than twelve times as high as the one ranked twentieth. ${ }^{3}$

\footnotetext{
${ }^{2}$ Table A1 (and A2) lists the top twenty per-capita expenditure (disposable income, respectively) observations in each survey, representing 0.18-0.31 percent of all households. Several observations can be made: 1) Similar degrees of dispersion are evident across different versions of the Egyptian '08 HIECS: the 50\% random extraction provided through ERF, the $25 \%$ and $50 \%$ extractions provided directly by the Egyptian Central Agency for Public Mobilization and Statistics. In the full 100\% sample of the ' 08 HIECS (restricted-access), the gap between the richest and second richest household is 54\%, and that between the richest and the $20^{\text {th }}$ richest is $282 \%(34 \%$ and $694 \%$, respectively, for income). 2) In the Jordanian and Palestinian surveys, top expenditures exceed top disposable incomes. Many of these observations are for the same households, reflecting either negative saving rates, high imputed consumption of durables purchased in prior years, or some misreporting of expenditures or income.

${ }^{3}$ This observation is for a three-member household, so the conversion to per-capita terms does not explain the unusual value. Rather, the household includes two earners, one of a very high age. Using an alternative adult-equivalence scale
} 
In Palestine 2010, similarly, the highest one or two expenditures appear extreme. In the 2007 and 2011 waves, the single highest expenditure is 29-43 percent higher than the second highest expenditure, and 189-262 percent higher than the one ranked twentieth. In 2010, however, an outlying top expenditure is 134 percent higher than the second highest one, and more than seven times as high as the twentieth highest one. It is likely that the small sample sizes in Jordan ' 10 and Palestine " 10 are partially responsible for the presence of outliers.

In Sudan, the highest observed expenditure per capita exceeds the second highest one by 29 percent, and the twentieth by 189 percent, a medium degree of top expenditure gaps. In both waves of the Tunisian survey, the household with the highest expenditure per capita surpasses the expenditure of the second richest household by a mere 17-23 percent. Similarly, it surpasses the expenditure of the twentieth household by only 211-213 percent. Rather than having a single outlier, the Sudanese and Tunisian surveys have 3-4 outlying households - their expenditures are clustered nearby each other, while they exceed the following values by 50 percent. On the other hand, no further clustering of observations is found lower down the expenditure distribution.

Assessing the aggregate-expenditure shares of the richest households, we find that they are higher in Jordan, Palestine and Sudan and lower in Egypt and Tunisia (last row in table A1). Since it is unclear whether the dispersion of top expenditures in one survey (Jordan, or Palestine) is too wide due to measurement issues, or the dispersion in another survey (Tunisia) is too narrow due to underreporting, we take an agnostic view of the validity of each observation, and let parametric estimation on the entire distribution of top expenditures tell us which observations step out of line relative to the predicted pattern. ${ }^{4}$

Table 1 provides additional information on the actual distribution of top expenditures: the share of aggregate expenditures accounted for by the top 0.1 percent of observations (or 7-11 households across surveys) to as many as 20 percent of observations (or 780-2,662 households) are shown in brackets. These results confirm a disproportionate concentration of wealth among the superwealthy 0.2 percent of households (19-21 units) in Jordan ' 10 and in Sudan, where they command over 2.9-3.0 percent of aggregate expenditures. Tunisia ' 05 is nearly at that level of concentration among the uppermost expenditure households. Regarding expenditure shares among the following

\footnotetext{
giving lesser weight to the elderly would further increase the expenditure per capita of this household to $\$ 324,719$. Yet, under this alternative scale, Jordan's Gini would fall by 2 percentage points. Evaluation of individual expenditure components does not reveal the existence of any data-entry errors for this household. The household's possession of various household durables confirms the household's level of wealth. Correspondingly, expenditure on furniture, housing equipment, appliances, transportation vehicles, culture and recreation, energy, miscellaneous goods and various fees are very high. Expenditures on health and medical treatment abroad are also high. Finally, because of its rarity, this household has an above-average sampling weight, implying that it is quite influential in any estimation of population statistics.

${ }^{4}$ We also estimate the distributions on samples right-truncated below values deemed as potentially contaminated by measurement issues. We again find that the topmost observations may be distributed too narrowly compared to what would be expected under the Pareto law (table A5). Armour et al. (2016) apply a similar method using known information on the number of top-coded observations; our method is not limited to the case of topcoding, but also allows for general mismeasurement, outliers, or nonresponse. Jenkins (2017) discusses the appropriate type of Pareto specification and cutoffs for estimation.
} 
20 percent of households, Sudan and Tunisia '05 exhibit disproportionate concentrations. The richest 1 percent (10\%, or 20\%) of households control 7.6-7.8 percent (30.8-32.4 or 46.3-48.0\%, respectively) of aggregate expenditures.

\section{Top income measurement issues}

The observations in the uppermost tail of expenditure distributions may reflect true values of expenditures in the population, and may be appropriate to include for the sake of measuring inequality in the population. Alternatively, extreme observations may arise due to various errors and, if included, should be corrected for the identified errors. In either case, the uppermost observations may introduce spurious volatility of inequality across survey waves.

It is well known that the inclusion of extreme observations tends to influence commonly used measures of inequality (Cowell and Flachaire, 2007). Some measures such as the Theil index and other Generalized Entropy indices are very sensitive to exact values of top observations, but even the Gini coefficient is not robust to them (Cowell and Victoria-Feser 1996). To evaluate how sensitive inequality measurement is to extreme expenditure observations, without judgment on their authenticity, we would want to identify which observations are outliers and estimate our measures of inequality with and without them. Neri et al. (2009), for example, define outliers in the EU Surveys on Income and Living Conditions (SILC) as observations exceeding the median 4-5 times, and find that this comprises $0.1-0.2 \%$ of households.

In HHIESs measurement errors may arise for several reasons, including intentional misreporting, errors in recollection, or data entry errors. Across survey waves, expenditure distributions may also exhibit different upper tails on account of sampling variability. Top expenditures may generally also be deliberately obscured by national statistical agencies to comply with privacy norms or correct for measurement problems, but this is not the case with the survey samples at hand. Due to the potential measurement problems and sampling differences across survey waves in our set of Arab household surveys, our estimation of inequality levels and trends may be biased. We thus turn to a recently promulgated correction method that can address these issues.

\section{Replacement using values from a Pareto distribution}

To compare the actual distributions of top expenditures to distributions that may be predicted in the given countries, and study the presence of extreme values in our data, we follow an approach applied by Atkinson, Cowell, Jenkins, Piketty and others to summarize the dispersion of economic outcomes by a parametric distribution, report properties of the estimated distribution, and use the estimates to correct the observed top tail for suspected statistical problems (Atkinson et al. 2011; Armour et al. 2016). ${ }^{5}$

\footnotetext{
${ }^{5}$ Analysis is performed in Stata v.13 software on the Windows operating system.
} 
Inequality estimates imputed from parametric distributions can be less sensitive to extreme observations and sampling variations than non-parametric observations from actual survey data. Parametric estimates for the top tail could be combined with non-parametric statistics for the rest of the distribution to obtain estimates with better empirical properties (Cowell and Victoria-Feser 1996; Cowell and Victoria-Feser 2007). Burkhauser et al. (2012) compared four methods for dealing with under-representation or top-coding in the survey data - essentially replacing topcoded values using four alternative parametric estimators and combining the estimates with nontopcoded observations.

The following estimation approach is motivated by an empirical regularity that top observations across countries and years follow a particular pattern represented well by the Pareto distribution. The Pareto distribution is one of several distributions suggested by the Cowell et al. literature for evaluating potentially imprecise top incomes or expenditures vis-à-vis expected values. Arnold (2015) reviews the properties of the Pareto distribution as well as of the broader family of Pareto distributions. The Pareto distribution is highly skewed and heavy-tailed, and is thought to be suitable to model upper incomes, expenditures, wealth or other welfare aggregates (Levy and Solomon 1997; Davies et al. 2017; Vermeulen 2018). As expenditures grow larger, the number of observations declines following a law dictated by a constant Pareto coefficient $\theta$. The Pareto distribution can be described by its probability density function as follows:

$$
f(x)=\frac{\theta}{x^{\theta+1}}, 1 \leq x \leq \infty .
$$

Here $x$ is the variable of interest, which in our case will be expenditure per capita in international purchasing-power parity dollars. The Pareto coefficient $\theta$ can be estimated by maximum likelihood methods (Jenkins and Van Kerm 2007; Jenkins 2017:272) as

$$
\theta=\frac{1}{\log x_{(n-k+1)}-k^{-1} \sum_{i=0}^{k-1}\left(\log x_{(n-i)}\right)},
$$

where $x_{(j)}$ is the $j_{\text {th }}$ order statistic in the sample of expenditures $n$, and $k$ is the delineation of top expenditures such as the top 10\% of observations (Hill 1975:1166).

\section{Replacement using randomly drawn rather than predicted values}

Replacing observed expenditures with fitted values from the Pareto distribution yields measures of expenditure distribution and inequality that do not account for parameter-estimation error and sampling error in the available dataset. This problem is on top of the issue of combining standard errors of the parametric Gini among top expenditures and the nonparametric Gini among lower expenditures. An and Little (2007), and Jenkins et al. (2011) account for sampling error by drawing random values from the estimated distribution for all potentially imprecise top observations, combining them with actual lower-level values, and calculating a quasi-nonparametric inequality measure (that is, inequality measure estimated non-parametrically on partially synthetic data) with its bootstrap standard error. Repeating the exercise multiple times, we can note variability in the 
obtained inequality measure. Following Reiter (2003), as used by An and Little (2007) and Jenkins et al. (2011), the expected measure of inequality in such partially synthetic data can be computed as a simple mean of inequality measures from individual random draws, Giniquasi:

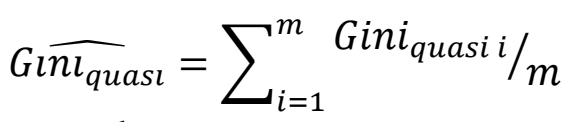

Its sampling variance can be computed as:

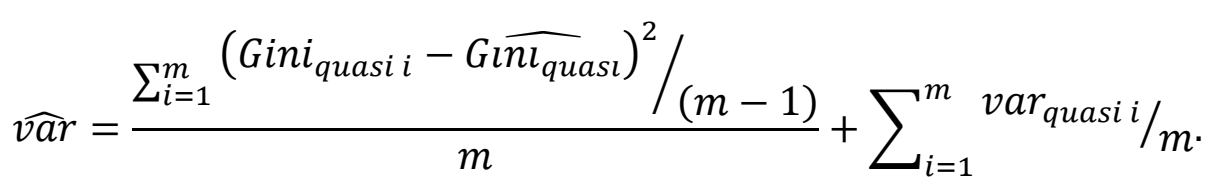

The first term here is the sampling variance across different draws from the Pareto distribution, and the second term is the mean sampling variance within an individual draw. $m$ is the number of repetitions and varquasi $i$ is the variance of the quasi-nonparametric Gini coefficient from an individual draw $i$. This methodology still ignores standard error from the estimation of parameters in the Pareto distribution. However, this is expected to be quite small compared to the sampling error, and can be ignored in large datasets where parameters have been estimated precisely (Jenkins et al. 2011).

The quasi-nonparametric Gini coefficient can be compared to an uncorrected nonparametric estimate. As long as it was correct to assume that top expenditures in the population are distributed as Pareto, a difference between the quasi non-parametric and non-parametric estimates would indicate that some observed high expenditures may have been generated by a statistical process other than Pareto, and that our inequality measure is sensitive to this. Quasi non-parametric Ginis that are lower than non-parametric Ginis can be interpreted as evidence that some top expenditures in the national samples are extreme compared to those generated under the Pareto distributions. A higher quasi non-parametric Gini would indicate that the observed top expenditures are lower than what would be generated under the Pareto distribution, potentially implying under-representation of rich units or underreporting of top expenditures in the sample.

In the following empirical analysis top expenditures are replaced by random draws from the Pareto distributions estimated on them. The reason for estimating the distributions on the same observations as those that will be replaced (rather than, say, estimating right-truncated Pareto distributions only on lower expenditure values deemed reliable) is that this approach allows us to remain agnostic regarding the validity of any individual observation. The approach does not require us to decide a priori which observations to use for estimation, and which observations to replace. Consequently, this approach can be viewed as addressing the problem when some expenditures are randomly under- or over-reported, or rank-proximity swapped. To the extent that different survey waves manage to cover different top-expenditure households through random sampling, this approach also mitigates the problem of overestimation of the variation in inequality 
across survey waves due to sampling errors. However, this approach cannot address problems of stand-alone systematic underreporting or top-coding of expenditures.

For the choice of an inequality index, this study uses the Gini coefficient as the primary measure, for its properties of being well understood and easily estimable under both parametric and nonparametric distributions, widely reported, and less sensitive to extreme observations than other indices. The results of inequality corrections in this study can thus be viewed as conservative estimates for the true effects of extreme observations on inequality measurement in general, under the baseline hypothesis that top-income issues do not affect inequality measurement in the Arab region. To the extent that the estimated Gini is affected by measurement issues, we may safely conclude that the consequences for other inequality measures would be as large or larger. For comparison, Table A4 reports the top expenditure shares in the actual and corrected distributions.

\section{Results}

Table 1 presents quasi-nonparametric estimates of Gini coefficients, obtained by replacing top expenditure observations with random values drawn from smooth Pareto distributions estimated among these top observations. The first row in table 1 shows the benchmark nonparametric estimates of the Gini for each survey. The following rows present the quasi-nonparametric estimates from the distributions of household expenditures per capita when the top 0.1-20.0 percent of values are replaced by numbers drawn randomly from the corresponding Pareto distributions.

Table 1 shows that the correction for potentially mismeasured top expenditures varies across the eleven surveys. In the three Egyptian surveys, the replacement of top 0.1-5 percent of expenditure observations leads to a small but systematic increase in the Gini of $0.3-0.4$ percentage points. This suggests that the reported expenditure values are distributed slightly more narrowly compared to what one would expect following the Pareto law. Thus, we do not find evidence that the topmost $0.1 \%$ of expenditures are extreme or command a downward correction, as Hlasny and Verme (2018) found for incomes in 2008.

In Jordan '06 and in all waves of the Palestinian, Sudanese and Tunisian data, when 5 percent or fewer observations are replaced, the estimated quasi-nonparametric Ginis are nearly identical to the nonparametric statistics (differing by -0.2 up to +0.3 pc.pt.). In Jordan ' 10 , the replacement of top expenditures leads to a drop in the Gini by 0.8 percentage points, presumably on account of the single outlying expenditure observation. Replacing this outlier and the following 34-88 expenditures (0.5-2\% of the overall sample) decreases the estimated Gini from 36.2 to 35.4.

[Table 1 to appear here]

Across all eleven surveys, when 10-20\% of observations are replaced with Pareto random draws, the estimated quasi-nonparametric Ginis consistently exceed the nonparametric values by up to 
0.4 percentage points in Egypt, 1.2 in Jordan, 1.9 in Palestine, 0.6 in Sudan, and 1.6 in Tunisia. This suggests that in this range of expenditures, observed expenditures per capita are dispersed more narrowly than would be predicted under smooth Pareto distributions (relative to the dispersion of the topmost $0.1-5 \%$ of expenditures). This is most significant in Jordan ' 06 and in all waves of the Palestinian and Tunisian surveys. Because this replacement of 10-20\% of observations with randomly drawn values involves a large number of observations. This finding cannot be due to a few unlucky observations or a few unlucky draws but reflects a systematic departure of the observed distributions to the theoretically expected ones.

Finally worth noting, in all but the Egyptian surveys, the Gini corrections rise nearly monotonically as we replace more expenditures from only top 1 percent to top 20 percent. In the three Egyptian surveys, on the other hand, the corrections are systematically highest when 5 percent of expenditures are replaced. This suggests that in Egypt it is particularly the top ventile of expenditures (relative to the top $1 \%$, or to the second ventile) that are distributed too narrowly compared to what the Pareto law would predict, while in other countries it may be the second ventile and second decile where the actual dispersion is too narrow. Figure 1 illustrates these trends with their confidence intervals.

[Figure 1 to appear here]

Another measure of dispersion among top expenditures and a measure of the share of aggregate expenditures accounted for by them is the inverted Pareto-Lorenz coefficient, computed as $\beta=$ $\theta /(\theta-1)$ (Atkinson et al. 2011). This coefficient reflects a property of the Pareto law that the ratio of mean expenditure above a threshold for the delineation of top expenditures $(\bar{x})$ to that threshold is constant. The coefficient measures the thickness of the upper tail, and has been found to vary across countries and even over time. Variation in $\beta$ can be explained by changing economic and demographic factors in the population, which affect the topmost expenditures differently than the expenditures of households lower in the distribution (refer to the demographic decomposition of inequality by Ramadan et al. 2018). Estimation in table 1 yields inverted Pareto-Lorenz coefficients of 1.30-1.71 in Egypt, 1.31-1.92 in Palestine, 1.58-2.15 in Sudan, and 1.33-1.92 in Tunisia. In Jordan, the inverted Pareto-Lorenz coefficients are 1.24-1.77 in the 2006 wave and 1.25-3.49 in 2010. These results support our findings that the dispersion of top expenditures is widest in Jordan '10 and in Sudan, and least wide in Egypt, followed by Palestine and Tunisia.

In all surveys except Jordan '10 and Sudan '09, the inverted Pareto-Lorenz coefficient increases nearly monotonically as a greater percentage of top observations are used for estimation and are replaced. This suggests that as more of lower expenditures are added to the analysis, the degree of dispersion at the top increases as does the expenditure share of the topmost observations. In Egypt and Tunisia, the increase in the inverted Pareto-Lorenz coefficient is timid as 1-20 percent of top expenditures are added (the coefficient stagnates at 1.6-1.7 in Egypt '08 and '10), suggesting that a Pareto distribution with a single parameter may describe that entire range of top expenditures adequately. On the other hand, in Jordan '10, the inverted Pareto-Lorenz coefficient falls 
drastically from 3.49 when only the top $0.5 \%$ of observations are evaluated to 1.25 when top $1 \%$ are evaluated. This is clearly due to the single highest influential observation.

Our analysis disagrees with an observation made by Burkhauser et al. (2012), and Alvaredo and Piketty (2014) that the inverted Pareto-Lorenz coefficient tends to fall as more of top observations are evaluated. Using figure 1, we conclude that extreme observations are not problematic for inequality measurement in our sample of surveys (with the exception of a handful of observations in Jordan ' 10 and Palestine ' 10 ). Instead, it is the rather narrow dispersion of expenditures between the $80^{\text {th }}$ and the $95^{\text {th }}$ percentile (or the top ventile in Egypt) that causes a divergence from what would be expected under the Pareto law.

These findings also suggest that the exact cutoff for expenditures used in the analysis affects the estimated shape of the top expenditure distribution. Different surveys display different sensitivity to the choice. The estimated Pareto coefficient varies by less than 0.4 percentage points in Egypt '08 and ' 10 and in Sudan; by 0.7-0.9 in Egypt '12, Jordan '06 and Tunisia; by 0.8-1.2 in Palestine; and by as much as $2.7(\theta \in[2.27,4.94])$ in Jordan ' 10 depending whether at most $1 \%$ of the richest households or as many as $20 \%$ are evaluated.

The estimated measures of inequality are also affected by the chosen cutoff for top expenditures. The correction for potentially imprecise top expenditures ranges $-0.01-0.43$ percentage points of the Gini in Egypt; -0.81-1.23 percentage points in Jordan; -0.08-1.95 percentage points in Palestine; -0.19-0.65 percentage points in Sudan; -0.05-1.56 percentage points in Tunisia. ${ }^{6}$ While not trivial, these differences in corrections are modest in size, particularly in view of the size of standard errors on all the Ginis (0.28-2.00). Consequently, individual specifications of the top income distribution (nonparametric, or Pareto parametric distributions estimated from different cutoff points) cannot be clearly rejected in favor of one another. Confidence intervals around the various Pareto estimates and the nonparametric estimates of the Ginis overlap, implying that neither set of estimates can be clearly rejected regardless whether Pareto or nonparametric (or another) type of estimation was appropriate. Figure 1 illustrates. ${ }^{7}$

To evaluate whether it was appropriate to model the top expenditures as Pareto distributed, we can compare the estimated Pareto coefficients across different delineations of top expenditures. We can also draw the Hill plots of the estimated distributions, showing how the estimated Pareto parameter changes as one changes the cutoff for top expenditures to a particular percentile (Drees et al. 2000). The fit of the Pareto distributions can also be evaluated from the size of standard errors on the Pareto coefficients. If the standard error is large, the estimated Pareto distribution is not

\footnotetext{
6 These corrections are the differences between nonparametric and quasi-nonparametric Ginis. The quasinonparametric Ginis from random draws differ by up to 0.89 percentage points in absolute value from non-randomized smooth-distribution Ginis in Jordanian surveys, by up to 0.45 percentage points in Sudan, and by up to 1.08 percentage points in Tunisian surveys (mean difference in absolute value across these eleven surveys is 0.27 pc.pt.).

${ }^{7}$ While Pareto distribution has been accepted as providing a good fit for income and expenditure distributions, other more flexible statistical distributions have been suggested as providing a potentially better fit, such as the fourparameter GB2 distribution. Table A6, figure A2 and the associated text review the results.
} 
very predictive of the dispersion of top expenditures, and alternative Pareto coefficients cannot be effectively tested against one another. Another parametric distribution may represent the dispersion pattern better.

Table 1 shows that the Pareto distributions fitted to top expenditures vary across different delineations of the top expenditures. When the distributions are fitted only among the top 1 percent or fewer observations, the Pareto coefficients vary between 2.5 and 4.0 in Egypt, 1.4-5.3 in Jordan, 3.0-4.2 in Palestine, 1.9-2.5 in Sudan, and 2.5-4.1 in Tunisia. When the fitting is among top 220 percent of observations, the Pareto coefficients are notably lower and tighter (see bottom rows of table 1), at 2.4-2.6 in Egypt, 2.3-3.9 in Jordan, 2.1-3.0 in Palestine, 2.3-2.7 in Sudan, and 2.13.2 in Tunisia (refer to figure A3). In all surveys but Sudan, the coefficients drift downward near monotonically as a greater share of expenditures are used for fitting.

Coefficient standard errors indicate that there is more noise around the estimates when the sample sizes are small, particularly in the Jordanian samples. This suggests that the uppermost observations are not distributed as smoothly as to reflect the Pareto law. The small samples and the presence of outliers may also give rise to estimation bias (Jenkins 2017:272). The estimates become precise only when at least 2 percent of top observations (47-790 observations or more in our samples) are used for estimation. Using 95\% confidence intervals, Pareto coefficients estimated on top 2 percent of expenditures are significantly higher than those estimated on top 20 percent of expenditures in Jordan ' 10 , Palestine ' 10 , and Tunisia ' 05 and ' $10 .{ }^{8}$

One motivation for replacing actual top expenditures with synthetic values is to mitigate the sampling error in inequality measurement due to sampling variability across survey waves. Under the conjecture that the true Gini coefficient is stable across nearby years ( $\mathrm{Li}$ et al. 1998), we could expect the quasi-nonparametric Gini to be more stable than the observable nonparametric Gini. Indeed, in most model specifications for Egypt and Jordan, and in one half of model specifications for Palestine and Tunisia (refer to table 1), the quasi-nonparametric Ginis exhibit less variation

\footnotetext{
${ }^{8}$ Figures A4 and A5 compare actual top expenditures to those predicted under the Pareto distributions estimated among the top 5 or 20 percent of expenditures. Figure A4 again shows the influence of outliers in Jordan ' 10 and Palestine '10, the narrow dispersion in the tails in Egypt, and the good fit of this particular Pareto distribution (estimated among the top 5\%) in Egypt '10, Jordan '06, Palestine '07 and Sudan '09. When the Pareto distributions are estimated among the top 20\% of expenditures, the degree of fit further improves in Egypt but deteriorates in other countries.

The Hill plots (figure A6) show volatile behavior among the topmost 0.2 percent of expenditures in all surveys (682 observations in our samples). Beyond this share, the plots for the Egyptian and Palestinian surveys (top row) are near-stationary at a single parameter value across the top $0.5-20 \%$ of expenditure observations. Hill plots for the Jordanian, Sudanese and Tunisian surveys (bottom row), on the other hand, slope downward throughout most the range of top expenditures. These Hill plots indicate that a one-parameter Pareto distribution is adequate at approximating the observed top-expenditure distributions in Egypt and Palestine, but not in the other three countries, particularly past 5\% of the topmost expenditures. Only in Sudan '09 and Tunisia '05 the plots are relatively stable and hump-shaped (rather than falling monotonically) until top 5\% of the respective samples, suggesting that even in these surveys Pareto approximation may be possible among the top 5\% of expenditures.
} 
over time than the nonparametric Ginis. At the same time, the quasi-nonparametric Ginis carry standard errors that are only 20 percent higher than the nonparametric standard errors, and are of the same size in Sudan '09 and lower in Jordan '10. This suggests that the method advanced in this study may have distinct benefits over traditional nonparametric estimation of the Gini and its trend over time, particularly in datasets where there are clear outliers.

Finally worth noting, the Pareto and inverted Pareto-Lorenz coefficients and Ginis can be compared to those in prior studies worldwide. Using Atkinson et al.'s (2011: figures) estimates, the top expenditures in the five Arab countries considered here have lower inverted Pareto coefficients - and thus exhibit lower dispersion and lower aggregate expenditure shares - than incomes in Argentina, India and even Singapore over the past two decades. They are on par with the inverted Pareto coefficients for incomes in Mediterranean Europe (France, Italy, Portugal, Spain). Even restricting attention to prior estimates for expenditures (Hlasny and Verme 2018: figure 1), our five countries exhibit an inverted Pareto coefficient below the median of emerging economies worldwide, or 1.7 (1.8 for income). Even the highest estimates of the inverted Pareto coefficients in our study, when estimated on fully 20 percent of top expenditures, range between 1.64 and 1.92, around the worldwide emerging-countries' median.

\section{Discussion}

This study has aimed to evaluate the patterns of dispersion of top expenditures in eleven recent surveys from five Arab countries, and their implications for the measurement of inequality in the region and in emerging countries worldwide. We have attempted to correct the inequality estimates for potentially mismeasured top expenditures. Inspection of the eleven surveys indicates that the topmost expenditures in the Egyptian surveys are distributed fairly narrowly, followed by the Tunisian and Sudanese surveys, while in the Jordanian and Palestinian surveys they are quite dispersed. The 2010 waves of the Jordanian and Palestinian surveys contain clear outliers affecting the measurement of inequality. We thus attempted to correct for such values that are potentially non-representative of the underlying population using values drawn from the expected Pareto distribution.

In our study using only survey data on expenditures, the Gini coefficient is estimated consistently between 0.30 and 0.32 in Egypt, 0.35 to 0.37 in Jordan, and 0.38 to 0.43 in Palestine, Sudan and Tunisia. Replacing observed top expenditures with synthetic values helped to refine the Ginis systematically albeit modestly. Across all surveys, replacing the top 20 percent of expenditures yielded higher Ginis suggesting that in that range of expenditures actual values are dispersed more narrowly than predicted under smooth Pareto distributions (relative to the dispersion of the topmost $0.1-5 \%$ of expenditures).

We also found that different countries exhibit different sensitivity to the correction of potentially contaminated top expenditures. In Egypt, followed by Palestine and Tunisia, the estimated inverted 
Pareto-Lorenz coefficient is near invariant to the cutoff for the delineation of top expenditures, suggesting that Pareto distributions may describe the top expenditures rather well in support of the Pareto law. In Jordan and Sudan the inverted Pareto-Lorenz coefficient fluctuates, suggesting that Pareto distributions do not track the upper tail too closely. Modeling top expenditures in these countries may require a more complex parametric form.

Our estimates of the dispersion of top expenditures (using inverted Pareto coefficients), or all expenditures (using the Ginis) are below or at the mean of the range put forward by Atkinson et al. (2011) and Hlasny and Verme (2018) for income and expenditure distributions in emerging countries. Particularly in Egypt, inequality is low and falling. Top expenditures in Egypt are distributed rather smoothly and Pareto-like. The falling inequality is thus not due to the presence or absence of extreme observations in any year. The same can be said about the falling inequality in Tunisia, and subject to larger standard errors in Palestine. Trend in Jordan, however, hinges on the inclusion of a few outliers.

Generally, whether the observed or the synthetically derived Ginis are closer to the true degree of inequality in the five countries is unclear, as it depends on the source of the observed dispersion of top expenditures. Differences across the various Gini estimates are also modest in view of their differences across countries. Indeed, nonparametric Ginis vary by as much as 11.8 percentage points across the five countries (29.6 in Egypt '12 to 41.4 in Tunisia '05). The width of confidence intervals around all estimates - shown in table 1 and figure 1 - implies that neither set of pointestimates can be clearly favored over others.

These conclusions are based on the assumption that the expenditures on which parametric distributions were estimated are not systematically understated. Allowing for this potential problem, the parametric approximations would themselves lead to underestimation. To the extent that there is no clear evidence in existing literature regarding systematic underreporting of expenditures in Arab countries, this method appears appropriate. In fact, claims of underreporting in regional household surveys typically involve incomes, and are based on suspicions rather than on information that underreporting takes place, how much underrepresentation there is, and through which channels it operates.

Alvaredo and Piketty (2014) and Alvaredo et al. (2017) used external data for the tops of income distributions in the region, and derived greater corrections and higher estimates of the Ginis. In the Arab region, however, external data such as national accounts and tax records are not well compatible with survey data on household expenditures, due to issues such as the size of the oil sector, unreported remittances from abroad, neighborhood and family transfers across households, and tax avoidance. Whether household-survey data alone or in combination with national accounts data can provide more relevant estimates of economic inequality is an open question. Moreover, economic inequality across households is also entangled with other dimensions of inequality, such as health inequality, inequality of opportunities, and inequality between countries. All these factors 
drive a wedge between people's perceptions and the reality of economic inequality, giving rise to what has been dubbed the Arab inequality puzzle.

Our findings regarding the extent of within-country inequality in expenditures thus address only a small part of the puzzle. It is widely recognized that expenditures are distributed more equally than incomes or wealth, due to households' propensity to save and borrow to smooth consumption (Heathcote et al. 2010; Fisher et al. 2015), and households' tendency to recall or report income incorrectly. (Indeed, using disposable incomes in place of expenditures raises the estimates of inequality in all surveys, but upholds the conclusion that inequality fell in Egypt and Palestine refer to table A3.) In the Arab region, moreover, consumption tends to be funded by incomes of extended families. Finally worth noting, inequality in households' expenditures may be systematically biased for inequality in households' true consumption and welfare, because of systematic differentials in access to free public goods. Poor households face an inadequate public provision of education, health services, and other infrastructure in their communities. They must pay out of pocket to compensate for lacking public transportation, car damage on poorly maintained roads, lack of health/property insurance, or property theft, something that wealthy households do not spend money on. Whether the observed expenditures or incomes are better measures of households' true welfare thus remains an open question.

Our central finding is that neither the uncorrected Ginis nor the parametric Ginis can be favored over each other on conceptual grounds. We may take our claim further and surmise as follows: under the assumption that nonparametric estimates are consistent for latent true Ginis but potentially inefficient due to a handful of outliers and measurement errors, and that the quasinonparametric estimates may be more efficient but potentially inconsistent due to misspecification, similarity of the two sets of estimates suggests that neither measurement errors nor specification errors are sufficiently grave to let us clearly reject either set of the Ginis. For the time being, we should take caution relying on a single estimate, instead considering multiple alternative estimates to construct intervals of plausible values of the countries' true degrees of economic inequality.

\section{References}

Achcar, Gilbert (2013) The People Want: A Radical Exploration of the Arab Uprising. Berkeley: University of California Press.

Africa Development Bank (AfDB, 2012), Jobs, Justice and the Arab Spring: Inclusive Growth in North Africa, North Africa Operations Department, www.afdb.org/en/documents/document/jobsjustice-and-the-arab-spring-inclusive-growth-in-north-africa-27978/.

AlAzzawi, Shireen, and Vladimir Hlasny (2019) Household asset wealth and female labor supply in MENA, Quarterly Review of Economics and Finance 73:3-13.

Al-Shawarby, S. (2014), The Measurement of Inequality in the Arab Republic of Egypt: A Historical Survey. Chapter 1 in P. Verme et al., eds., Inside Inequality in the Arab Republic of Egypt: Facts and Perceptions across People, Time and Space, Washington: World Bank. 
Alvaredo, Facundo, and Thomas Piketty (2014) Measuring Top Incomes and Inequality in the Middle East: Data Limitations and Illustration with the Case of Egypt. Economic Research Forum, Working Paper 832, May.

Alvaredo, Facundo, Lydia Assouad, and Thomas Piketty (2017) Measuring Inequality in the Middle East 1990-2016: The World's Most Unequal Region? CEPR Discussion Paper No. DP12405, October.

An, D. and Little, R.J.A. (2007) Multiple imputation: an alternative to top coding for statistical disclosure control, Journal of the Royal Statistical Society A 170:923-940.

Armour, Philip, Richard V. Burkhauser, and Jeff Larrimore (2016). Using the Pareto Distribution to Improve Estimates of Topcoded Earnings, Economic Inquiry 54(2):1263-1273.

Arnold, Barry C. (2008) Pareto Distributions. 2nd edition. New York: CRC Press.

Assouad, Lida (2015), Top Income and Personal Taxation in Lebanon. An Exploration of Individual Tax Records, Master's Thesis, Paris School of Economics.

Atkinson, A.B., Piketty, T. and Saez, E. (2011) Top incomes in the long run of history, Journal of Economic Literature 49:3-71.

Azour, J. (2014), Social Justice in the Arab World. E/ESCWA/SDD/2014/Background Paper.

Bibi, S., and Nabli, M.K. (2009) Income Inequality in the Arab Region: Data and Measurement, Patterns and Trends, Middle East Development Journal 1(2):275-314.

Bibi, S., and Nabli, M.K. (2010) Equity and Inequality in the Arab Region, ERF Policy Research Report No.33.

Bogaert, Koenraad (2013) Contextualizing the Arab revolts: the politics behind three decades of neoliberalism in the Arab world, Middle East Critique 22(3):213-234.

Burkhauser, R.V., Feng, S., Jenkins, S.P. and Larrimore, J. (2012) Recent trends in top income shares in the United States: Reconciling estimates from March CPS and IRS tax return data, Review of Economics and Statistics 94(2):371-388.

Cowell, F. A. (2011). Measuring Inequality ( $3^{\text {rd }}$ ed.). Oxford: Oxford University Press.

Cowell, F.A. and Victoria-Feser, M.-P. (1996) Poverty measurement with contaminated data: A robust approach, European Economic Review 40:1761-1771.

Cowell, F.A. and Victoria-Feser, M.-P. (2007) Robust Lorenz curves: a semiparametric approach, Journal of Economic Inequality 5:21-35.

Cowell, F.A. and Flachaire, E. (2007) Income distribution and inequality measurement: The problem of extreme values, Journal of Econometrics 141(2):1044-1072.

Dahi, Omar S., and Yasser Munif (2012) Revolts in Syria: tracking the convergence between authoritarianism and neoliberalism, Journal of Asian and African Studies 47(4):323-332.

Davies, J. and Lluberas, R., and Shorrocks, A.F. (2017), Estimating the Level and Distribution of Global Wealth, 2000-2014, Review of Income and Wealth 63(4):731-59.

Deaton, A. (1997), The analysis of household surveys: a microeconometric approach to development policy, Washington: World Bank.

Drees, H., de Haan, L., and Resnick, S.I. (2000) How to make a Hill plot. Annals of Statistics 28:254-274.

El Enbaby, Hoda, and Rami Galal (2015). Inequality of opportunity in individuals' wages andhouseholds' assets in Egypt. ERF working paper 942.

Fisher, J., Johnson, D., and Smeeding, T. (2015) Inequality of Income and Consumption: Measuring the Trends in Inequality from 1984-2011 for the Same Individuals. Review of Income and Wealth 61(4):630-650. 
Gatward, I. (2015), Economic Opportunity and Inequality as Contributing Factors to the Arab Spring: The Cases of Tunisia and Egypt. Boston College Electronic Thesis or Dissertation.

Heathcote, J., Perri, F., and Violante, G. (2010) Unequal We Stand: An Empirical Analysis of Economic Inequality in the US, 1967-2006, Review of Economic Dynamics 13(1):15-51.

Hill, Bruce M. (1975) A Simple General Approach to Inference About the Tail of a Distribution, Annals of Statistics 3(5):1163-1174.

Hinnebusch, Raymond (2006) Authoritarian persistence, democratization theory and the Middle East: an overview and critique, Democratization 13(3):373-395.

Hlasny, Vladimir, and Shireen AlAzzawi (2019) Asset inequality in MENA: the missing dimension? Quarterly Review of Economics and Finance 73:44-55.

Hlasny, Vladimir, Lidia Ceriani, and Paolo Verme (2020) Bottom incomes and the measurement of poverty and inequality, ERF-LIS Working Paper.

Hlasny, Vladimir, and Vito Intini (2015) Representativeness of top expenditures in Arab region household surveys. UN ESCWA/EDID Working Paper 11.

Hlasny, V., and Verme, P. (2015) Top Incomes and the Measurement of Inequality: A Comparative Analysis of Correction Methods Using EU, US and Egyptian Survey Data, ECINEQ working paper 145.

Hlasny, V., and Verme, P. (2018) Top Incomes and the Measurement of Inequality in Egypt, World Bank Economic Review 32(2):428-455.

Ianchovichina, Elena (2017), Eruptions of Popular Anger: The Economics of the Arab Spring and Its Aftermath, MENA Development Report, Washington: World Bank.

Jenkins, S.P. (2017), Pareto distributions, top incomes, and recent trends in UK income inequality, Economica 84(334):261-289.

Jenkins, S.P., Burkhauser, R.V., Feng, S., and Larrimore, J. (2011) Measuring inequality using censored data: a multiple-imputation approach to estimation and inference, Journal of the Royal Statistical Society 174(1):63-81.

Jenkins, S.P., and Van Kerm, P. (2007), Paretofit: Stata module to fit a Type 1 Pareto distribution. https://ideas.repec.org/c/boc/bocode/s456832.html.

Joya, Angela, Patrick Bond, Rami El-Amine, Adam Hanieh, and Mostafa Henaway (2011) The Arab revolts against neoliberalism, Center for Social Justice.

Krafft, C., R. Assaad, H. Nazier, R. Ramadan, A. Vahidmanesh, and S. Zouari, S. (2017), Estimating Poverty and Inequality in the Absence of Consumption Data: an Application to the Middle East and North Africa, Economic Research Forum Working Paper 1100.

Lakner, C. and Milanovic, B. (2013) Global income distribution from the fall of the Berlin Wall to the great recession, World Bank Policy Research working paper series \#6719.

Levy, Moshe, Sorin Solomon, (1997), New evidence for the power-law distribution of wealth, Physica A: Statistical Mechanics and its Applications 242(1-2):90-94.

Li, Hongyi, Lyn Squire, and Heng-fu Zou (1998), Explaining International and Intertemporal Variations in Income Inequality, Economic Journal 108(446):26-43.

Ncube, M., and Anyanwu, J.C. (2012) Inequality and Arab Spring Revolutions in North Africa and the Middle East, African Development Bank: Africa Economic Brief 3(7):1-23.

Neri, L., Gagliardi, F., Ciampalini, G., Verma, V. and Betti, G. (2009) Outliers at upper end of income distribution (EU-SILC 2007), DMQ Working Paper n. 86, November.

Pinkovskiy, Maxim, and Xavier Sala-i-Martin (2009), Parametric Estimations of the World Distribution of Income, NBER Working Paper 15433, October. 
Ramadan, Racha, Vladimir Hlasny and Vito Intini (2018) Inter-group expenditure gaps in the Arab region and their determinants: application to Egypt, Jordan, Palestine and Tunisia, Review of Income and Wealth 64(s1):S145-S188.

Reiter, J.P. (2003) Inference for partially synthetic, public use microdata sets. Survey Methodology 29:181-188.

Tessler, M., A. Jamal and M. Robbins (2012), New Findings on Arabs and Democracy, Journal of Democracy 23(4):89-103.

Teti, Andrea, Pamela Abbott, and Francesco Cavatorta (2017) The Arab Uprisings in Egypt, Jordan and Tunisia: Social, Political and Economic Transformations. Springer.

Tobin, Sarah A. (2012) Jordan's Arab Spring: the middle class and anti-revolution, Middle East Policy 19(1):96-109.

Van der Weide, Roy, Christoph Lakner and Elena Ianchovichina (2018), Is Inequality Underestimated in Egypt? Evidence from House Prices, Review of Income and Wealth 64(s1):S55-S79.

Van Kerm, Philippe (2007) Extreme incomes and the estimation of poverty and inequality indicators from EU-SILC, IRISS Working Paper Series 2007-01, CEPS/INSTEAD internal doc. \#07-07-0335-E, February.

Verme, Paolo (2014) Facts and perceptions of inequality, Ch. 3 in P. Verme et al., eds., Inside Inequality in the Arab Republic of Egypt: Facts and Perceptions across People, Time and Space, Washington: World Bank Studies.

Verme, Paolo, and Vladimir Hlasny (2016), Top Incomes, inequality and the Egyptian case, World Bank Let's Talk Development blog, 11 Nov 2016, http://blogs.worldbank.org/developmenttalk/eastasiapacific/top-incomes-inequality-andegyptian-case.

Vermeulen, P. (2018), How fat is the top tail of the wealth distribution? Review of Income and Wealth 64(2):357-387. 
Table 1. Quasi-nonparametric estimates of Gini coefficients: Pareto distribution

\begin{tabular}{|c|c|c|c|c|c|c|c|c|c|c|c|}
\hline & \multicolumn{3}{|c|}{ Egypt '08 } & \multicolumn{3}{|c|}{ Egypt '10 } & \multicolumn{3}{|c|}{ Egypt '12 } & \multicolumn{2}{|c|}{ Jordan '06 } \\
\hline $\begin{array}{l}\text { Correction } \\
\text { for extreme } \\
\text { observations }\end{array}$ & $\begin{array}{l}\text { Observ. } \\
\text { replaced } \\
\text { [expend. } \\
\text { share] }\end{array}$ & $\begin{array}{c}\text { Pareto } \\
\text { coef. } \theta \\
\text { (s.e.) }\end{array}$ & $\begin{array}{l}\text { Gini } \\
\text { (s.e.) }\end{array}$ & $\begin{array}{l}\text { Observ. } \\
\text { replaced } \\
\text { [expend. } \\
\text { share] }\end{array}$ & $\begin{array}{c}\text { Pareto } \\
\text { coef. } \theta \\
\text { (s.e.) }\end{array}$ & $\begin{array}{l}\text { Gini } \\
\text { (s.e.) }\end{array}$ & $\begin{array}{l}\text { Observ. } \\
\text { replaced } \\
\text { [expend. } \\
\text { share] }\end{array}$ & $\begin{array}{l}\text { Pareto } \\
\text { coef. } \theta \\
\text { (s.e.) }\end{array}$ & $\begin{array}{l}\text { Gini } \\
\text { (s.e.) }\end{array}$ & $\begin{array}{l}\text { Observ. } \\
\text { replaced } \\
\text { [expend. } \\
\text { share] }\end{array}$ & $\begin{array}{c}\text { Pareto } \\
\text { coef. } \theta \\
\text { (s.e.) }\end{array}$ \\
\hline $\begin{array}{l}\text { non-param. } \\
\text { estimation }\end{array}$ & $\begin{array}{l}0 \text { out of } \\
23,428\end{array}$ & & $\begin{array}{l}31.32 \\
(0.28)\end{array}$ & $\begin{array}{c}0 \text { out of } \\
7,719\end{array}$ & & $\begin{array}{l}31.42 \\
(0.49)\end{array}$ & $\begin{array}{c}0 \text { out of } \\
7,528\end{array}$ & & $\begin{array}{l}29.60 \\
(0.42)\end{array}$ & $\begin{array}{c}0 \text { out of } \\
2,897\end{array}$ & \\
\hline quasi-nonparar & etr. estimat & n, top $\mathrm{k} \%$ & eplaced & & & & & & & & \\
\hline $\mathrm{k}=0.1 \% \times \mathrm{n}$ & $\begin{array}{c}43 \\
{[1.42 \%]}\end{array}$ & $\begin{array}{c}3.258 \\
(0.637) \\
\end{array}$ & $\begin{array}{l}31.31 \\
(0.28) \\
\end{array}$ & $\begin{array}{c}12 \\
{[1.42 \%]}\end{array}$ & $\begin{array}{c}3.377 \\
(0.644) \\
\end{array}$ & $\begin{array}{l}31.45 \\
(0.52) \\
\end{array}$ & $\begin{array}{c}12 \\
{[0.92 \%]}\end{array}$ & $\begin{array}{c}3.964 \\
(0.867) \\
\end{array}$ & $\begin{array}{l}29.62 \\
(0.43) \\
\end{array}$ & $\begin{array}{c}8 \\
{[1.44 \%]}\end{array}$ & $\begin{array}{c}3.429 \\
(1.977)\end{array}$ \\
\hline $\mathrm{k}=0.2 \% \times \mathrm{n}$ & $\begin{array}{c}82 \\
{[2.28 \%]}\end{array}$ & $\begin{array}{c}3.071 \\
(0.406)\end{array}$ & $\begin{array}{l}31.34 \\
(0.29)\end{array}$ & $\begin{array}{c}27 \\
{[2.29 \%]}\end{array}$ & $\begin{array}{c}2.749 \\
(0.503)\end{array}$ & $\begin{array}{l}31.47 \\
(0.54)\end{array}$ & $\begin{array}{c}27 \\
{[1.70 \%]}\end{array}$ & $\begin{array}{c}4.290 \\
(0.913)\end{array}$ & $\begin{array}{l}29.62 \\
(0.43) \\
\end{array}$ & $\begin{array}{c}9 \\
{[2.07 \%]}\end{array}$ & $\begin{array}{c}5.258 \\
(3.616) \\
\end{array}$ \\
\hline $\mathrm{k}=0.5 \% \times \mathrm{n}$ & $\begin{array}{c}207 \\
{[4.24 \%]}\end{array}$ & $\begin{array}{c}2.819 \\
(0.221)\end{array}$ & $\begin{array}{l}31.38 \\
(0.30)\end{array}$ & $\begin{array}{c}59 \\
{[4.24 \%]}\end{array}$ & $\begin{array}{c}3.061 \\
(0.439)\end{array}$ & $\begin{array}{l}31.46 \\
(0.54)\end{array}$ & $\begin{array}{c}59 \\
{[3.39 \%]}\end{array}$ & $\begin{array}{c}3.962 \\
(0.552)\end{array}$ & $\begin{array}{l}29.60 \\
(0.43)\end{array}$ & $\begin{array}{c}34 \\
{[4.23 \%]}\end{array}$ & $\begin{array}{c}2.431 \\
(0.463)\end{array}$ \\
\hline $\mathrm{k}=1 \% \times \mathrm{n}$ & $\begin{array}{c}393 \\
{[6.68 \%]}\end{array}$ & $\begin{array}{c}2.701 \\
(0.151)\end{array}$ & $\begin{array}{c}31.41 \\
(0.32)\end{array}$ & $\begin{array}{c}123 \\
{[6.59 \%]}\end{array}$ & $\begin{array}{c}2.531 \\
(0.248) \\
\end{array}$ & $\begin{array}{l}31.51 \\
(0.56) \\
\end{array}$ & $\begin{array}{c}116 \\
{[5.72 \%]}\end{array}$ & $\begin{array}{c}3.312 \\
(0.280) \\
\end{array}$ & $\begin{array}{l}29.69 \\
(0.47)\end{array}$ & $\begin{array}{c}67 \\
{[6.49 \%]}\end{array}$ & $\begin{array}{r}2.981 \\
(0.531)\end{array}$ \\
\hline $\mathrm{k}=2 \% \times \mathrm{n}$ & $\begin{array}{c}790 \\
{[10.34 \%]}\end{array}$ & $\begin{array}{c}2.563 \\
(0.103)\end{array}$ & $\begin{array}{l}31.48 \\
(0.34)\end{array}$ & $\begin{array}{c}245 \\
{[10.24 \%]}\end{array}$ & $\begin{array}{c}2.550 \\
(0.186)\end{array}$ & $\begin{array}{l}31.53 \\
(0.57)\end{array}$ & $\begin{array}{c}232 \\
{[9.26 \%]}\end{array}$ & $\begin{array}{c}3.047 \\
(0.205) \\
\end{array}$ & $\begin{array}{l}29.71 \\
(0.49)\end{array}$ & $\begin{array}{c}132 \\
{[10.22 \%]}\end{array}$ & $\begin{array}{c}2.721 \\
(0.311)\end{array}$ \\
\hline $\mathrm{k}=5 \% \times \mathrm{n}$ & $\begin{array}{c}1,966 \\
{[18.02 \%]}\end{array}$ & $\begin{array}{c}2.402 \\
(0.061)\end{array}$ & $\begin{array}{c}31.68 \\
(0.37)\end{array}$ & $\begin{array}{c}605 \\
{[17.87 \%]}\end{array}$ & $\begin{array}{c}2.428 \\
(0.115)\end{array}$ & $\begin{array}{l}31.71 \\
(0.64) \\
\end{array}$ & $\begin{array}{c}591 \\
{[16.80 \%]}\end{array}$ & $\begin{array}{c}2.539 \\
(0.110) \\
\end{array}$ & $\begin{array}{l}30.02 \\
(0.60)\end{array}$ & $\begin{array}{c}285 \\
{[18.57 \%]}\end{array}$ & $\begin{array}{c}2.706 \\
(0.193)\end{array}$ \\
\hline $\mathrm{k}=10 \% \times \mathrm{n}$ & $\begin{array}{c}3,744 \\
{[27.14 \%]}\end{array}$ & $\begin{array}{c}2.401 \\
(1.714)\end{array}$ & $\begin{array}{l}31.59 \\
(0.39)\end{array}$ & $\begin{array}{c}1,165 \\
{[27.12 \%]}\end{array}$ & $\begin{array}{c}2.457 \\
(0.085)\end{array}$ & $\begin{array}{l}31.62 \\
(0.67)\end{array}$ & $\begin{array}{c}1,150 \\
{[25.86 \%]}\end{array}$ & $\begin{array}{c}2.511 \\
(0.084)\end{array}$ & $\begin{array}{l}30.03 \\
(0.56)\end{array}$ & $\begin{array}{c}482 \\
{[28.54 \%]}\end{array}$ & $\begin{array}{c}2.664 \\
(0.149)\end{array}$ \\
\hline $\mathrm{k}=20 \% \times \mathrm{n}$ & $\begin{array}{c}6,778 \\
{[40.94 \%]}\end{array}$ & $\begin{array}{c}2.456 \\
(0.034)\end{array}$ & $\begin{array}{l}31.39 \\
(0.36) \\
\end{array}$ & $\begin{array}{c}2,173 \\
{[41.07 \%]}\end{array}$ & $\begin{array}{c}2.472 \\
(0.061)\end{array}$ & $\begin{array}{l}31.53 \\
(0.63) \\
\end{array}$ & $\begin{array}{c}2,082 \\
{[39.66 \%]}\end{array}$ & $\begin{array}{c}2.551 \\
(0.065)\end{array}$ & $\begin{array}{l}29.90 \\
(0.56) \\
\end{array}$ & $\begin{array}{c}848 \\
{[43.97 \%]}\end{array}$ & $\begin{array}{c}2.307 \\
(0.084)\end{array}$ \\
\hline $\begin{array}{l}\text { Mean (s.d.) if } \\
\mathrm{k} \leq 1 \% \times \mathrm{n}\end{array}$ & -- & $\begin{array}{c}2.962 \\
(0.250)\end{array}$ & $\begin{array}{l}31.36 \\
(0.04)\end{array}$ & -- & $\begin{array}{c}2.930 \\
(0.369)\end{array}$ & $\begin{array}{l}31.47 \\
(0.03)\end{array}$ & -- & $\begin{array}{c}3.882 \\
(0.410)\end{array}$ & $\begin{array}{l}29.63 \\
(0.04)\end{array}$ & -- & $\begin{array}{c}3.525 \\
(1.225)\end{array}$ \\
\hline $\begin{array}{l}\text { Mean (s.d.) if } \\
\mathrm{k} \geq 2 \% \times \mathrm{n}\end{array}$ & -- & $\begin{array}{c}2.456 \\
(0.076)\end{array}$ & $\begin{array}{l}31.54 \\
(0.13)\end{array}$ & -- & $\begin{array}{c}2.477 \\
(0.052)\end{array}$ & $\begin{array}{l}31.60 \\
(0.09)\end{array}$ & -- & $\begin{array}{c}2.662 \\
(0.257)\end{array}$ & $\begin{array}{l}29.92 \\
(0.15)\end{array}$ & -- & $\begin{array}{c}2.600 \\
(0.196)\end{array}$ \\
\hline
\end{tabular}


Table 1 (cont.). Quasi-nonparametric estimates of Gini coefficients: Pareto distribution

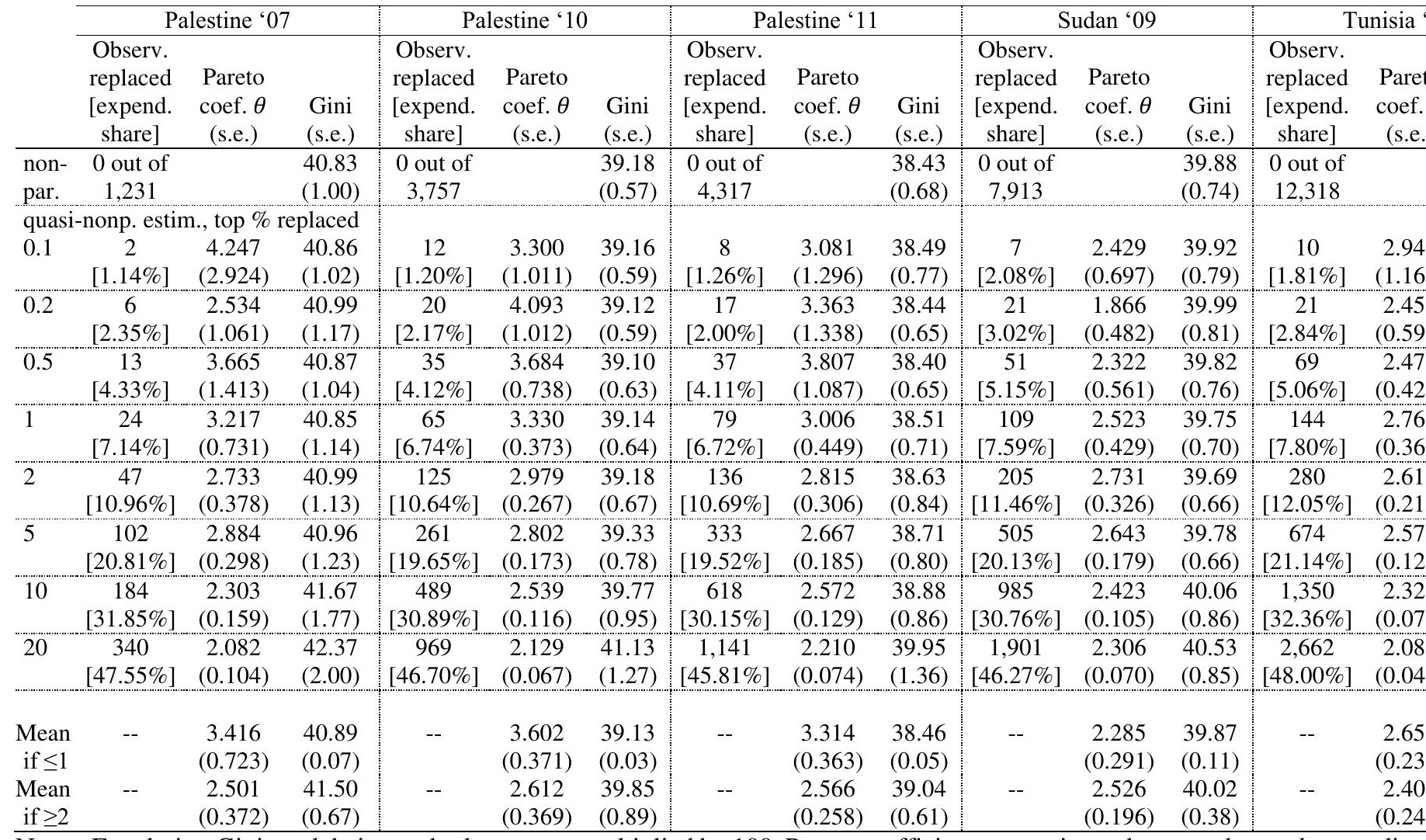

Notes: For clarity, Ginis and their standard errors are multiplied by 100. Pareto coefficients are estimated among the top $k$ expenditu likelihood methods (Jenkins and Van Kerm 2007). Quasi-nonparametric Gini coefficients are computed using 100 random draws

Pareto distributions. Numbers in square brackets show aggregate expenditure shares of the replaced observations, considering hous 
Figure 1. Gini uncorrected vs. corrected for potentially mismeasured highest expenditures
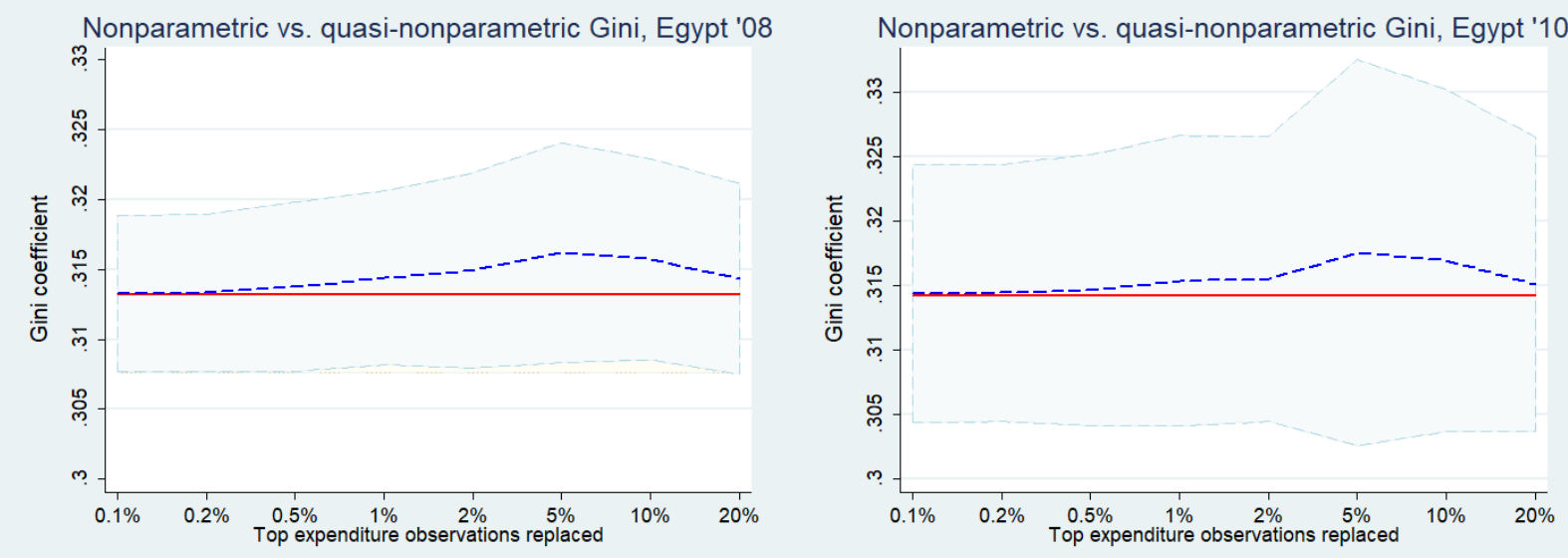

a. Egypt '08

b. Egypt ' 10
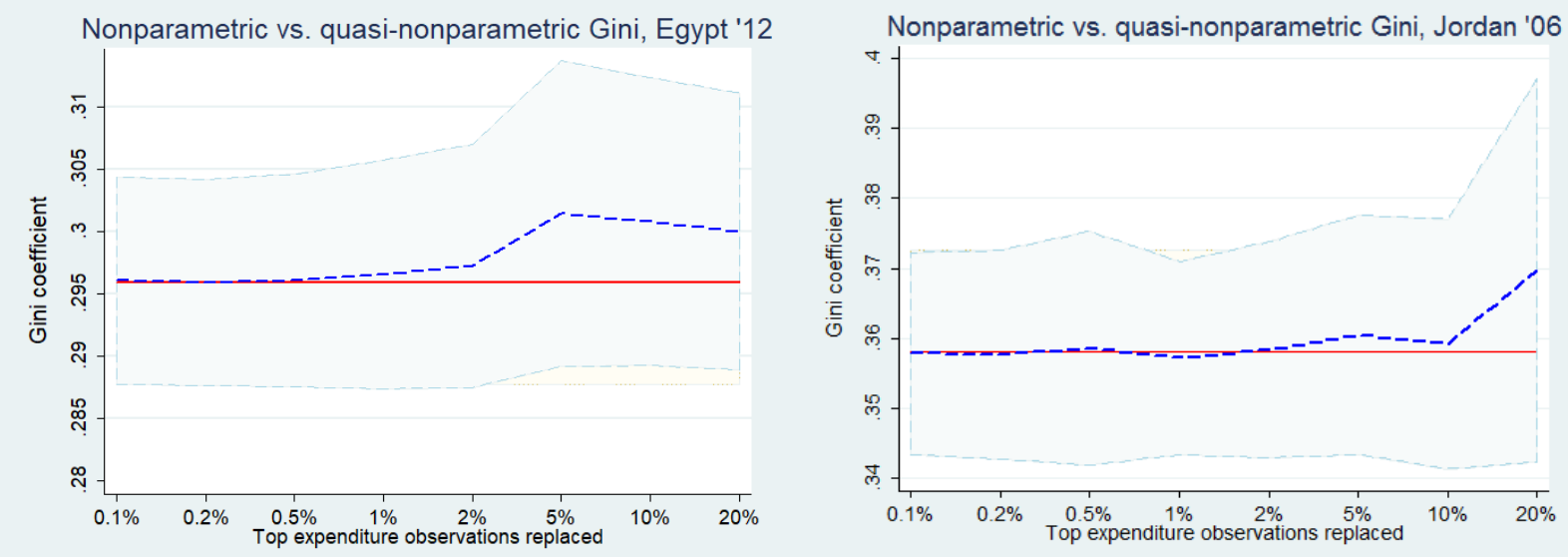

c. Egypt '12

d. Jordan '06

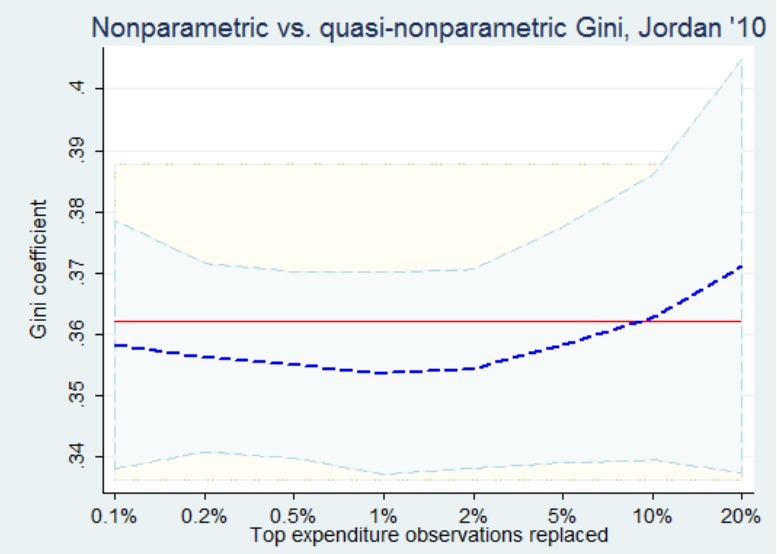

e. Jordan '10

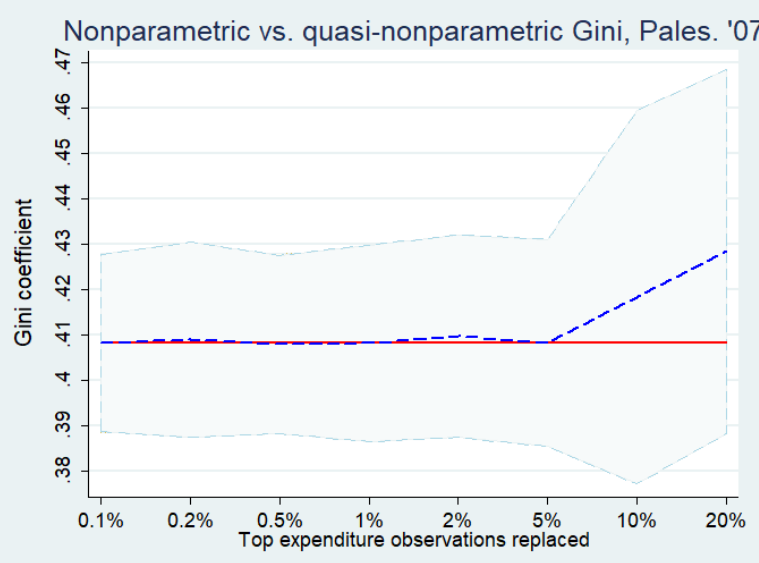

f. Palestine '07 
Figure 1 (cont.). Gini uncorrected vs. corrected for potentially mismeasured highest expenditures
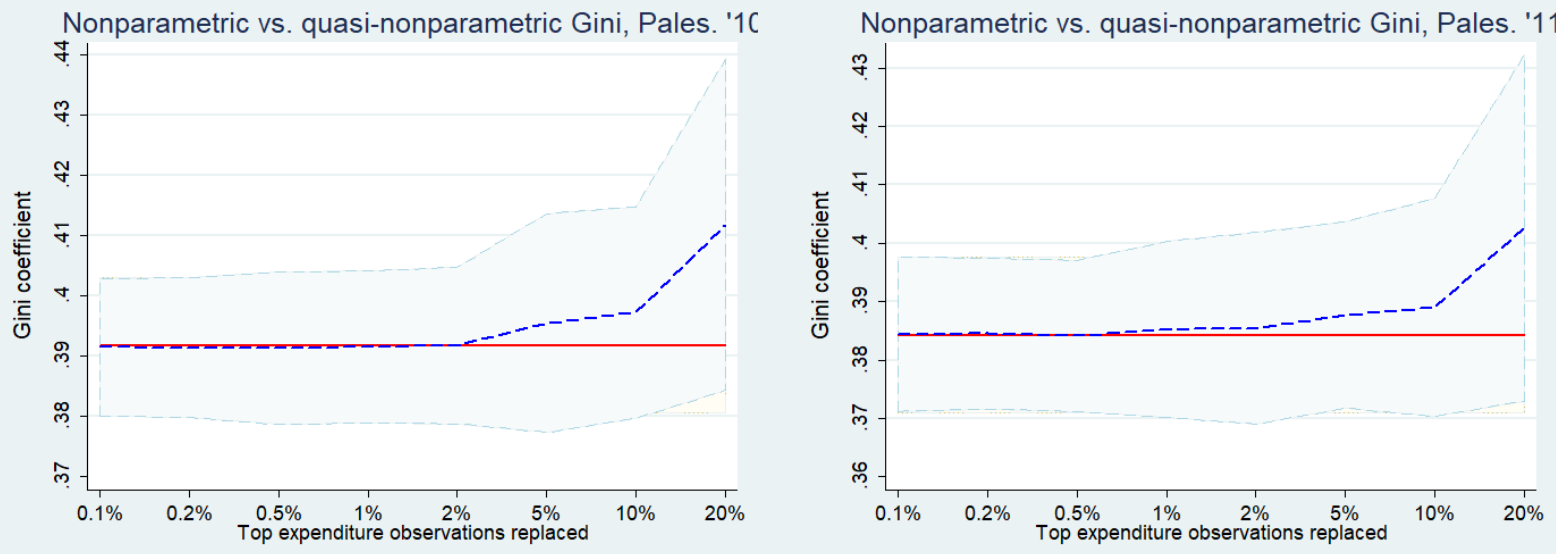

g. Palestine '10

h. Palestine '11
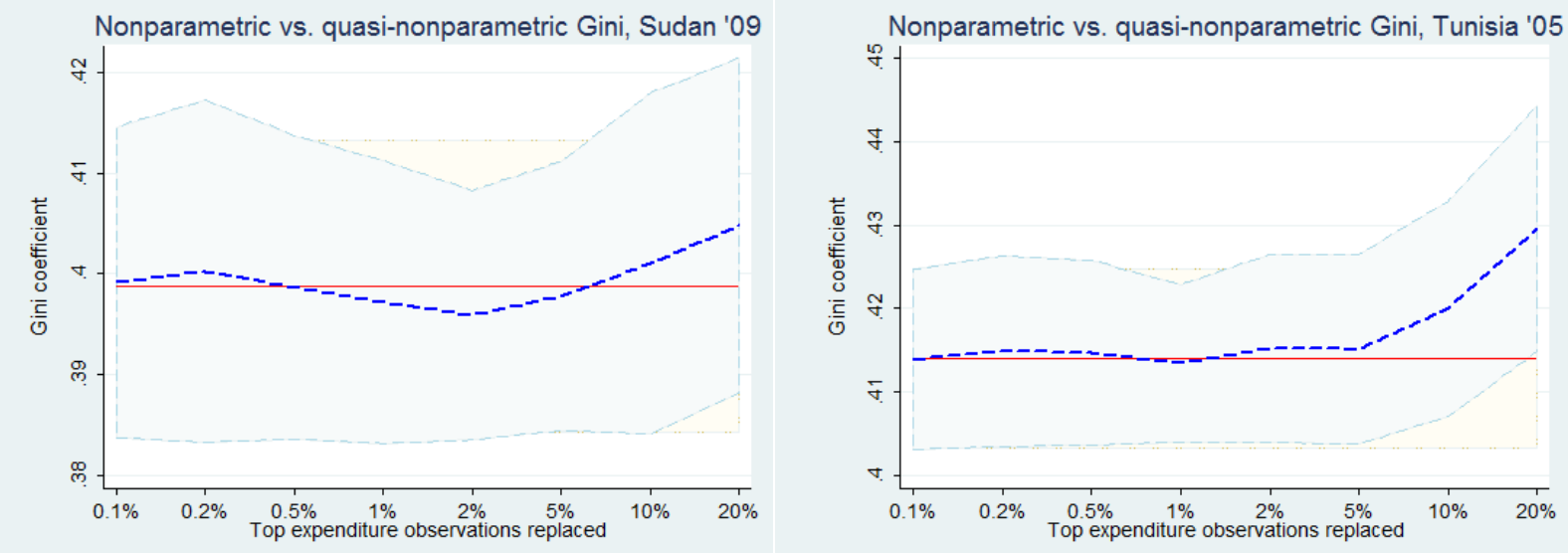

i. Sudan '09

j. Tunisia '05

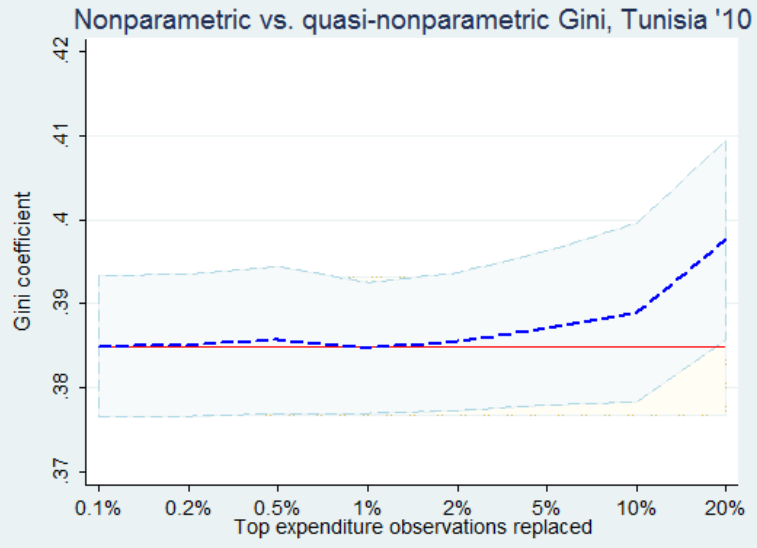

k. Tunisia' 10

Blue dashed lines show the estimated quasi-nonparametric Ginis and $95 \%$ confidence intervals using bootstrap standard errors aggregated across 100 random draws as in equation 3, for alternative delineations of top $k$ expenditures. Red solid lines show non-parametric Ginis with their 95\% confidence intervals using bootstrap standard errors. 


\section{Supplementary Materials}

\section{Available data}

This study relies on eleven household surveys harmonized and released to the public by Economic Research Forum (ERF) in collaboration with national statistical agencies: the Egyptian Household Expenditure, Income and Consumption Survey; the Jordanian Household Expenditure and Income Survey; the Palestinian Expenditure and Consumption Survey; the Sudanese National Baseline Household Survey; and the Tunisian National Survey on Household Budget, Consumption and Standard of Living.

Summary statistics help to check for any systematic differences across survey waves. In particular, the three Palestinian waves appear comparable to one another, representative of the same population, and reflecting on socio-economic developments in the territory during 2007-2011 rather than on survey-administration challenges or changes in the sampling frame. This helps to alleviate any concerns over the effect of the Israeli occupation and the 2006-2007 Gaza blockade on sampling quality. Similarly, the results for Egypt 2010 versus 2012, and Tunisia 2005 versus 2010 appear to reflect on socio-economic conditions in the country rather than on deteriorating sampling quality amidst the popular uprisings. Documentation for the Palestinian, Egyptian and Tunisian surveys does not indicate any security-related challenges.

Worth noting, the Egyptian 2008 survey made available to researchers has three times the sample size of the 2010 and 2012 waves, a potential comparability issue. Also notably, the Jordanian and Palestinian surveys have lower sample sizes than other surveys.

HHIES include information on households' basic demographic and employment status, income and its sources, asset ownership, and expenditures on various commodities. (The surveys for Tunisia and for Palestine '07 do not report total or disposable income.) This study uses only information on household size (hnum), total annual household expenditures per capita (totexp/hnum) and cross-sectional household sampling weights (hweight) in the surveys. ERF adds up expenditure items according to the Classification of Individual Consumption According to Purpose rules. Expenditures cover food and beverages, alcoholic drinks and smokes, clothes, textiles and shoes, residence and its accessories, furniture, durables, health care and services, transportation, telecommunications, culture and entertainment, education, restaurants and hotels, various services and commodities. The expenditure data are not subject to top-coding.

Expenditures are converted to per capita terms and standardized to real year-2005 purchasingpower parity international dollars (UNSD 2015). ${ }^{9}$ Household sampling weights in conjunction

\footnotetext{
${ }^{9}$ UNSD (2015) versus World Bank (2015) currency conversion factors yield analogous results: nonparametric and Pareto parametric Ginis retain their quantitative difference under both factors. Dividing by the count of household members is chosen in deference to previous literature to facilitate comparison of Ginis across studies. Using a modified OECD adult-equivalence scale, evaluated for Jordan 2010, leads to a 2 pc.pt. reduction in the estimated nonparametric and quasi-nonparametric Ginis (figure A1). Other qualitative results of this study are robust to this modification.
} 
with household size are used to assign greater weights to the parts of population where more individuals benefit from particular levels of expenditure per capita.

\section{Replacing using random draws from the right-truncated Pareto distribution}

Truncating the estimated Pareto distribution at the $95^{\text {th }}, 97^{\text {th }}$ or $99^{\text {th }}$ percentile of expenditure, and then replacing observations above that value with random draws from the estimated Pareto distribution, we get Ginis that are very close on either side of the original nonparametric statistics. For Egypt '08, the new corrected estimates are 30.09-31.80; for Egypt '10, 31.48-32.28; for Egypt '12, 29.07-30.29; for Jordan '06, 36.73-43.01; for Jordan '10, 37.54-42.96; for Palestine '07, 41.33-46.31; for Palestine '10, 41.80-48.32; for Palestine '11, 39.42-46.01; for Sudan, 40.1342.82; for Tunisia '05, 42.56-47.45; and for Tunisia '10, 39.36-47.81. In Jordan, Palestine and Tunisia, the truncated-Pareto estimates are consistently higher by $0.5-9$ pc.pt. than the noncorrected Ginis, and in Sudan the corrected estimation exceeds the uncorrected values by 0.5-3.0 pc.pt. These estimates are consistently slightly higher than the quasi-nonparametric estimates without truncation, suggesting that the topmost observations may be distributed too narrowly compared to what would be expected under the Pareto law. In Jordan, Palestine and Tunisia, the upward revisions of the Ginis become more substantial, of 3-8 pc.pt., when we replace 5\% of top expenditures.

\section{Replacing using random draws from the generalized beta type-II distribution}

While Pareto distribution approximates well the dispersal of top expenditures, it is not representative of expenditures in the middle or bottom of the expenditure distribution. Generalized beta distribution of the second kind (GB2), also known as the Feller-Pareto distribution, has been proposed as a suitable parametric form representing well the entire expenditure distributions (McDonald 1984). The upper tail of the distribution is heavy and decays like a power function. Four estimable parameters give the distribution flexibility to fit various empirical expenditure distributions. Cumulative distribution function of the GB2 distribution is

$$
F(x)=I\left(p, q, \frac{(x / b)^{a}}{1+(x / b)^{a}}\right)
$$

where $I(p, q, y)$ is the regularized incomplete beta function, and $y$ is the per-capita expenditure normalized to be in the unit interval. Parameters $a, p$, and $q$ are distributional shape parameters and $b$ a scale parameter. These parameters can be estimated by pseudo maximum likelihood. Other suitable candidates for a distribution function, the Singh-Maddala (1976) and the Dagum (1980) distributions, are limiting cases of the GB2 distribution with parameter $p$ ( $q$, respectively) restricted to one (McDonald 1984).

Gini index of expenditure inequality under the GB2 distribution can be computed by evaluating the generalized hypergeometric function ${ }_{3} F_{2}$ with the estimated parameters as arguments, and its standard error can be computed using the delta method (McDonald 1984; Jenkins 2009). 
The results show that the corrections under the GB2 distribution differ systematically from those under the Pareto distribution. In the Jordanian and Palestinian samples, the GB2 estimates consistently exceed the Pareto estimates by $0.02-1.52$ percentage points (except when $\mathrm{k} \geq 10 \%$ ). In the Sudanese and Tunisian samples, on the other hand, GB2 estimates are nearly universally lower by up to 1.7 percentage points. In Egypt, GB2 estimates tend to be lower in the 2008 and 2010 waves (up to 0.8 pc.pt. in magnitude), and higher in the 2012 wave (up to 0.6 pc.pt.). Hence, the estimated GB2 distributions predict wider dispersion of expenditures than the corresponding Pareto distributions in Egypt '12, Jordan and Palestine, but narrower dispersion in Egypt '08-'10, Sudan and Tunisia. These results suggest that our assumption about the distribution of true expenditures affects our correction for extreme observations. In absolute terms, however, the differences are modest, ranging from -1.7 to 1.5 percentage points across all surveys and topexpenditure delineations (mean - 0.03 pc.pt.; 0.39 pc.pt. in absolute value). All GB2 estimates are also within the confidence intervals of nonparametric Ginis. This may be viewed as confirming plausible distribution or acceptable quality of top expenditure observations in the eleven surveys.

Actual expenditures in Jordan and Palestine (Sudan and Tunisia) are dispersed slightly more narrowly (widely, respectively) than expenditures predicted under the respective GB2 distributions. Comparing the Pareto and the GB2 estimates of the Ginis, results also differed systematically across the eleven surveys. In Egypt 2008 and 2010, in Jordan and in Palestine, GB2 estimates consistently exceeded Pareto estimates by up to 1.5 percentage points, while in Egypt 2012, in Sudan and in Tunisia, GB2 estimates were nearly universally lower than Paretodistribution estimates by up to 1.7 percentage points. These Gini coefficient estimates and differences in them across the Pareto versus the GB2 specifications appear meaningful, as they are consistent across small changes in model specifications. They evolve nearly monotonically as more of top expenditures are analyzed. 
Table A1. Top twenty household expenditures per capita across national surveys

\begin{tabular}{|c|c|c|c|c|c|c|c|c|c|}
\hline $\begin{array}{l}\text { Rank in survey } \\
\text { sample }\end{array}$ & $\begin{array}{l}\text { Egypt } \\
\text { '08 }\end{array}$ & $\begin{array}{l}\text { Egypt } \\
' 10\end{array}$ & $\begin{array}{l}\text { Egypt } \\
\cdot 12\end{array}$ & $\begin{array}{c}\text { Jordan } \\
\text { '06 }\end{array}$ & $\begin{array}{c}\text { Jordan } \\
' 10 \\
\end{array}$ & $\begin{array}{c}\text { Palestine } \\
\text { '07 }\end{array}$ & $\begin{array}{c}\text { Palestine } \\
\text { '10 }\end{array}$ & $\begin{array}{c}\text { Palestine } \\
\text { '11 }\end{array}$ & \\
\hline 1 & $53,157.94$ & $42,165.61$ & $26,548.15$ & $67,948.41$ & $216,479.50$ & $71,114.78$ & $306,455.70$ & $114,961.80$ & 38 \\
\hline 2 & $44,649.02$ & $36,707.64$ & $23,906.70$ & $41,531.91$ & $30,406.46$ & $49,659.20$ & $131,242.00$ & $89,052.73$ & 30,0 \\
\hline 3 & $37,195.29$ & $29,176.12$ & $19,151.00$ & $34,790.27$ & $25,944.99$ & $41,153.54$ & $83,083.49$ & $80,502.95$ & \\
\hline 4 & $31,339.21$ & $24,892.83$ & $18,037.32$ & $30,315.73$ & $24,987.13$ & $40,396.23$ & $74,492.45$ & $62,696.21$ & \\
\hline 5 & $29,683.66$ & $24,584.93$ & $17,949.00$ & $27,772.65$ & $24,722.63$ & $31,365.09$ & $69,019.34$ & $59,075.16$ & 17,3 \\
\hline 6 & $24,938.04$ & $23,122.48$ & $17,488.60$ & $27,096.44$ & $23,521.76$ & $28,966.98$ & $64,400.47$ & $52,244.81$ & 167 \\
\hline 7 & $23,993.49$ & $21,897.13$ & $16,970.23$ & $25,220.63$ & $21,287.35$ & $28,400.31$ & $63,939.15$ & $50,660.85$ & \\
\hline 8 & $23,803.92$ & $21,571.85$ & $15,871.91$ & $25,209.04$ & $20,734.76$ & $27,966.27$ & $62,664.05$ & 9.43 & \\
\hline 9 & $23,713.33$ & $21,086.50$ & $15,857.55$ & $24,663.42$ & $20,729.18$ & $27,066.04$ & $56,308.49$ & $47,628.30$ & \\
\hline 10 & $22,857.74$ & 18,76 & $15,849.71$ & $23,070.90$ & $20,655.43$ & 25, & .13 & .38 & 13,9 \\
\hline 11 & $22,779.96$ & $17,616.72$ & $14,090.66$ & $22,990.89$ & $19,819.79$ & 24,2 & .57 & .34 & \\
\hline 12 & $20,508.14$ & $17,207.32$ & $13,862.28$ & $20,151.54$ & $19,717.65$ & $24,145.60$ & $50,257.55$ & $44,476.18$ & 13 \\
\hline 13 & $19,615.29$ & $15,696.35$ & $13,514.34$ & $18,677.11$ & $19,578.73$ & $23,711.70$ & $47,319.02$ & $43,918.68$ & 11, \\
\hline 14 & $19,205.29$ & 15,39 & $13,085.75$ & $18,194.18$ & 18,9 & $23,429.40$ & .83 & .55 & 10 \\
\hline 15 & $19,139.61$ & $14,819.35$ & $12,920.23$ & $17,871.50$ & $18,652.47$ & $23,016.04$ & $45,682.55$ & 43,0 & \\
\hline 16 & $18,973.53$ & $14,123.82$ & $12,865.81$ & $16,430.74$ & $18,596.38$ & $22,867.45$ & $45,245.55$ & $41,923.94$ & 10 \\
\hline 17 & $18,690.49$ & $14,096.90$ & $12,856.13$ & $16,030.26$ & $18,284.49$ & $22,126.96$ & & $41,459.91$ & \\
\hline 18 & $18,687.45$ & 13,75 & $12,582.74$ & $15,926.60$ & $18,181.84$ & & 42 , & 41,1 & \\
\hline 19 & $18,405.49$ & $13,746.32$ & $12,376.07$ & $15,828.49$ & $18,097.23$ & $21,112.26$ & $42,614.62$ & $40,604.36$ & 10 \\
\hline 20 & $18,277.65$ & $13,527.39$ & $12,139.60$ & $14,973.79$ & $17,902.55$ & $19,666.04$ & $41,933.96$ & $39,848.02$ & \\
\hline $1^{\text {st }} / 2^{\text {nd }} \mathrm{gap}$ & 19.06 & 14.87 & 11.05 & 63.61 & 611.95 & 43.21 & 133.50 & 29.09 & \\
\hline $1^{\text {st }} / 20^{\text {th }}$ gap $(\%)$ & 190.84 & 211.71 & 118.69 & 353.78 & $1,109.21$ & & & 188.50 & \\
\hline Cumul. de & $0.05 \%$ & $0.15 \%$ & $0.14 \%$ & $0.31 \%$ & $0.20 \%$ & $0.79 \%$ & $0.19 \%$ & $0.24 \%$ & \\
\hline Expend. share ${ }^{\mathrm{b}}$ & $0.81 \%$ & $1.89 \%$ & $1.34 \%$ & $3.18 \%$ & $2.95 \%$ & $6.13 \%$ & $2.17 \%$ & $2.47 \%$ & \\
\hline
\end{tabular}

Notes: Year-2005 purchasing-power parity international dollars (UNSD 2015). Expenditures exceeding the following values by 40

${ }^{\text {a }}$ Portion of the density of the entire survey sample, accounting for household sampling weights and household size.

${ }^{\mathrm{b}}$ Portion of the aggregate expenditure of the entire survey sample, accounting for household sampling weights. 
Table A2. Top twenty disposable household incomes per capita across national surveys

\begin{tabular}{|c|c|c|c|c|c|c|c|c|}
\hline $\begin{array}{l}\text { Rank in survey } \\
\text { sample }\end{array}$ & $\begin{array}{l}\text { Egypt } \\
\text { '08 }\end{array}$ & $\begin{array}{l}\text { Egypt } \\
\cdot 10\end{array}$ & $\begin{array}{l}\text { Egypt } \\
\cdot 12\end{array}$ & $\begin{array}{c}\text { Jordan } \\
\text { '06 }\end{array}$ & $\begin{array}{c}\text { Jordan } \\
' 10 \\
\end{array}$ & $\begin{array}{c}\text { Palestine } \\
' 10\end{array}$ & $\begin{array}{c}\text { Palestine } \\
\text { '11 }\end{array}$ & Sudan '09 \\
\hline 1 & $236,297.20$ & $179,448.10$ & $61,698.11$ & $67,948.41$ & $169,835.00$ & $88,018.87$ & $70,161.32$ & $163,716.20$ \\
\hline 2 & $231,226.40$ & $76,886.79$ & $60,731.13$ & $41,531.91$ & $61,415.25$ & $87,668.46$ & $65,247.64$ & $63,679.25$ \\
\hline 3 & $153,089.60$ & 160.38 & $52,806.61$ & $34,790.27$ & $44,740.11$ & $67,924.53$ &, 233.68 & $37,283.02$ \\
\hline 4 & $118,490.60$ & $44,253.39$ & $48,168.24$ & $30,315.73$ & $39,796.61$ & $57,311.32$ & $44,146.04$ & $28,724.53$ \\
\hline 5 & $64,093.16$ & $38,867.93$ & $45,283.02$ & $27,772.65$ & $37,728.81$ & $56,603.77$ & .09 & $28,301.89$ \\
\hline ( & $50,642.69$ & $38,301.89$ & $43,372.64$ & 27,096 & $37,436.44$ & & & $22,574.12$ \\
\hline 7 & & 07 & $40,030.19$ & 250 & & & & $17,688.68$ \\
\hline 8 & 47,22 & 35,4 & $35,510.61$ & 25,20 & & & & 18.74 \\
\hline 9 & $45,283.02$ & $31,226.42$ & $30,681.60$ & $24,663.42$ & $35,192.09$ & & & $15,547.17$ \\
\hline 10 & & 30, & 29,9 & & & & & 4.53 \\
\hline 11 & & 28 & 28,6 & 20 & & & & .85 \\
\hline 12 & 42,38 & $26,415.09$ & $28,301.89$ & 20,151 & 26,5 & & & $11,202.83$ \\
\hline 13 & & 25,2 & 28,3 & & & & & 06.29 \\
\hline 14 & & . & 27,4 & & & & & 1.89 \\
\hline 15 & & 2 & 27,16 & & & & & 16.98 \\
\hline 16 & $35,326.57$ & $23,584.91$ & $27,146.23$ & $16,430.74$ & $24,593.22$ & $37,940.25$ & $27,874.06$ & $10,553.91$ \\
\hline 17 & & & & & & & & $10,135.61$ \\
\hline 18 & & 72 & 26,8 & & 23, & & & 75.47 \\
\hline 19 & $30,944.34$ & $21,589.62$ & $25,633.42$ & 15,828 & 22,3 & 34 , & 27,17 & $9,748.43$ \\
\hline 20 & $30,566.04$ & $21,581.00$ & $25,174.53$ & $14,973.79$ & $20,101.70$ & $33,090.57$ & $26,671.70$ & $9,580.19$ \\
\hline $1^{\text {st }} / 2^{\text {nd }} \xi$ & 2.19 & & 1.59 & 74.4 & & 0 . & 7.53 & 157.1 \\
\hline $1^{\mathrm{st}} / 20^{\mathrm{th}} \mathrm{g}$ & 673.07 & & 145.08 & $1,250.98$ & & 165.99 & 163.06 & $1,608.90$ \\
\hline Cumul. dens & 0.05 & 0.14 & 0.17 & 0.3 & 0.61 & 0.24 & 0.24 & 0.2 \\
\hline $\begin{array}{l}\text { Expend. share } \\
(\%)\end{array}$ & 1.51 & 2.03 & 1.6 & 7.61 & 5.95 & 3.52 & 2.56 & 9.82 \\
\hline
\end{tabular}

Notes: Palestine ' 07 , and Tunisia ' 05 and ' 10 surveys do not cover incomes, only expenditures. Year-2005 purchasing-power parit 2015). Expenditures exceeding the following values by $40+\%$ in bold. 
Table A3. Quasi-nonparametric estimates of Gini coefficients for disposable household income per capita: Pa

\begin{tabular}{|c|c|c|c|c|c|c|c|c|c|c|c|c|}
\hline & \multicolumn{3}{|c|}{ Egypt '08 } & \multicolumn{3}{|c|}{ Egypt '10 } & \multicolumn{3}{|c|}{ Egypt '12 } & \multicolumn{3}{|c|}{ Jordan '06 } \\
\hline $\begin{array}{l}\text { Correction } \\
\text { for extreme } \\
\text { observations }\end{array}$ & $\begin{array}{l}\text { Observ. } \\
\text { replaced } \\
\text { [income } \\
\text { share] }\end{array}$ & $\begin{array}{c}\text { Pareto } \\
\text { coef. } \theta \\
\text { (s.e.) }\end{array}$ & $\begin{array}{l}\text { Gini } \\
\text { (s.e.) }\end{array}$ & $\begin{array}{l}\text { Observ. } \\
\text { replaced } \\
\text { [income } \\
\text { share] }\end{array}$ & $\begin{array}{c}\text { Pareto } \\
\text { coef. } \theta \\
\text { (s.e.) }\end{array}$ & $\begin{array}{l}\text { Gini } \\
\text { (s.e.) }\end{array}$ & $\begin{array}{l}\text { Observ. } \\
\text { replaced } \\
\text { [income } \\
\text { share] }\end{array}$ & $\begin{array}{c}\text { Pareto } \\
\text { coef. } \theta \\
\text { (s.e.) }\end{array}$ & $\begin{array}{l}\text { Gini } \\
\text { (s.e.) }\end{array}$ & $\begin{array}{l}\text { Observ. } \\
\text { replaced } \\
\text { [income } \\
\text { share] }\end{array}$ & $\begin{array}{c}\text { Pareto } \\
\text { coef. } \theta \\
\text { (s.e.) } \\
\end{array}$ & $\begin{array}{l}\text { Gini } \\
\text { (s.e.) }\end{array}$ \\
\hline $\begin{array}{l}\text { non-param. } \\
\text { estimation }\end{array}$ & $\begin{array}{l}0 \text { out of } \\
23,428\end{array}$ & & $\begin{array}{l}33.67 \\
(0.39)\end{array}$ & $\begin{array}{c}0 \text { out of } \\
7,719\end{array}$ & & & $\begin{array}{c}0 \text { out of } \\
7,528\end{array}$ & & & $\begin{array}{c}0 \text { out of } \\
2,897\end{array}$ & & \\
\hline \multicolumn{13}{|c|}{ quasi-nonparametr. Gini, top k\% replaced } \\
\hline $\mathrm{k}=0.1 \% \times \mathrm{n}$ & $\begin{array}{c}43 \\
{[2.19 \%]}\end{array}$ & $\begin{array}{c}2.181 \\
(0.426)\end{array}$ & $\begin{array}{l}33.57 \\
(0.38)\end{array}$ & $\begin{array}{c}16 \\
{[1.53 \%]}\end{array}$ & $\begin{array}{c}2.244 \\
(0.477)\end{array}$ & & $\begin{array}{c}10 \\
{[1.28 \%]}\end{array}$ & & & $\begin{array}{c}5 \\
{[3.39 \%]}\end{array}$ & & \\
\hline $\mathrm{k}=0.2$ & $\begin{array}{c}75 \\
{[3.18 \%]}\end{array}$ & & & $\begin{array}{c}25 \\
{[2.26 \%]}\end{array}$ & & & $\begin{array}{c}23 \\
{[2.13 \%]}\end{array}$ & & & $\begin{array}{c}8 \\
{[4.67 \%]}\end{array}$ & & \\
\hline $\mathrm{k}=0.5 \% \times \mathrm{n}$ & $\begin{array}{c}189 \\
{[5.37 \%]}\end{array}$ & $\begin{array}{l}2.356 \\
(0.193)\end{array}$ & & $\begin{array}{c}56 \\
{[4.31 \%]}\end{array}$ & $\begin{array}{c}3.128 \\
(0.446)\end{array}$ & & $\begin{array}{c}59 \\
{[3.84 \%]}\end{array}$ & & & $\begin{array}{c}36 \\
{[6.63 \%]}\end{array}$ & $\begin{array}{l}1 . \\
(0 .\end{array}$ & $\begin{array}{l}.06 \\
.44)\end{array}$ \\
\hline $\mathrm{k}=1 \% \times \mathrm{n}$ & $\begin{array}{c}383 \\
{[7.93 \%]}\end{array}$ & $\begin{array}{c}2.242 \\
(0.128)\end{array}$ & & $\begin{array}{c}112 \\
{[6.82 \%]}\end{array}$ & $\begin{array}{c}2.751 \\
(0.257)\end{array}$ & & $\begin{array}{c}119 \\
{[6.23 \%]}\end{array}$ & $\begin{array}{c}2.975 \\
(0.352)\end{array}$ & $\begin{array}{l}63 \\
66) \\
\end{array}$ & $\begin{array}{c}64 \\
{[9.11 \%]}\end{array}$ & $\begin{array}{l}2 . \\
(0 .\end{array}$ & $\begin{array}{l}9.78 \\
1.04)\end{array}$ \\
\hline $\mathrm{k}=2 \%$ & $\begin{array}{c}772 \\
{[11.63 \%]}\end{array}$ & $\begin{array}{c}2.261 \\
(0.095)\end{array}$ & $\begin{array}{l}33.63 \\
(0.47)\end{array}$ & $\begin{array}{c}237 \\
{[10.57 \%]}\end{array}$ & $\begin{array}{c}2.661 \\
(0.189)\end{array}$ & $\begin{array}{l}32.85 \\
(0.55)\end{array}$ & $\begin{array}{c}250 \\
{[9.76 \%]}\end{array}$ & $\begin{array}{l}2.750 \\
(0.216)\end{array}$ & $\begin{array}{l}31.70 \\
(0.59)\end{array}$ & $\begin{array}{c}126 \\
{[12.96 \%]}\end{array}$ & $\begin{array}{c}2.532 \\
(0.350)\end{array}$ & $\begin{array}{l}39.53 \\
(1.03)\end{array}$ \\
\hline $\mathrm{k}=5 \%$ & $\begin{array}{c}1,902 \\
{[19.50 \%]}\end{array}$ & $\begin{array}{c}2.321 \\
(0.063)\end{array}$ & $\begin{array}{l}33.59 \\
(0.41)\end{array}$ & $\begin{array}{c}612 \\
{[18.43 \%]}\end{array}$ & $\begin{array}{c}2.404 \\
(0.110)\end{array}$ & & $\begin{array}{c}592 \\
{[17.55 \%]}\end{array}$ & $\begin{array}{c}2.696 \\
(0.134) \\
\end{array}$ & $\begin{array}{l}76 \\
6) \\
\end{array}$ & $\begin{array}{c}253 \\
{[21.60 \%]}\end{array}$ & $\begin{array}{c}2.674 \\
(0.248)\end{array}$ & $\begin{array}{l}39.49 \\
(1.05)\end{array}$ \\
\hline $\mathrm{k}=10 \% \times \mathrm{n}$ & $\begin{array}{c}3,594 \\
{[28.68 \%]}\end{array}$ & $\begin{array}{c}2.315 \\
(0.045)\end{array}$ & $\begin{array}{l}33.59 \\
(0.41)\end{array}$ & $\begin{array}{c}1,161 \\
{[27.85 \%]}\end{array}$ & $\begin{array}{c}2.408 \\
(0.081)\end{array}$ & $\begin{array}{l}33.08 \\
(0.65)\end{array}$ & $\begin{array}{c}1,135 \\
{[27.04 \%]}\end{array}$ & $\begin{array}{l}2.497 \\
(0.084)\end{array}$ & $\begin{array}{l}32 \\
(0\end{array}$ & $\begin{array}{c}447 \\
{[31.97 \%]}\end{array}$ & $\begin{array}{c}2.411 \\
(0.133)\end{array}$ & $\begin{array}{l}39.87 \\
(1.17)\end{array}$ \\
\hline $\mathrm{k}=20 \% \times \mathrm{n}$ & $\begin{array}{c}6,596 \\
{[42.82 \%]}\end{array}$ & $\begin{array}{r}2.333 \\
(0.033)\end{array}$ & $\begin{array}{l}33.57 \\
(0.40)\end{array}$ & $\begin{array}{c}2,122 \\
{[41.98 \%]}\end{array}$ & $\begin{array}{c}2.452 \\
(0.061)\end{array}$ & $\begin{array}{l}32.86 \\
(0.59)\end{array}$ & $\begin{array}{c}2,066 \\
{[41.18 \%]}\end{array}$ & $\begin{array}{c}2.434 \\
(0.059)\end{array}$ & $\begin{array}{l}32.18 \\
(0.64)\end{array}$ & $\begin{array}{c}789 \\
{[47.22 \%]}\end{array}$ & $\begin{array}{l}2.215 \\
(0.090) \\
\end{array}$ & $\begin{array}{l}40.26 \\
(1.33)\end{array}$ \\
\hline $\begin{array}{l}\text { Mean (s.d.) if } \\
\mathrm{k} \leq 1 \% \times \mathrm{n}\end{array}$ & -- & $\begin{array}{c}2.34 \\
(0.18)\end{array}$ & $\begin{array}{l}33.60 \\
(0.10)\end{array}$ & -- & $\begin{array}{c}2.83 \\
(0.44)\end{array}$ & $\begin{array}{l}32.75 \\
(0.05)\end{array}$ & -- & $\begin{array}{l}2.81 \\
(0.19)\end{array}$ & $\begin{array}{l}31.63 \\
(0.03)\end{array}$ & -- & $\begin{array}{c}1.80 \\
(0.28)\end{array}$ & $\begin{array}{l}40.18 \\
(0.32)\end{array}$ \\
\hline $\begin{array}{l}\text { Mean (s.d.) if } \\
\mathrm{k} \geq 2 \% \times \mathrm{n}\end{array}$ & -- & $\begin{array}{r}2.31 \\
(0.03) \\
\end{array}$ & $\begin{array}{l}33.60 \\
(0.03) \\
\end{array}$ & -- & $\begin{array}{c}2.48 \\
(0.12) \\
\end{array}$ & $\begin{array}{l}33.00 \\
(0.17) \\
\end{array}$ & -- & $\begin{array}{c}2.59 \\
(0.15) \\
\end{array}$ & $\begin{array}{r}31.92 \\
(0.22) \\
\end{array}$ & -- & $\begin{array}{c}2.46 \\
(0.19) \\
\end{array}$ & $\begin{array}{l}39.79 \\
(0.36) \\
\end{array}$ \\
\hline
\end{tabular}

Notes: For clarity, Ginis and their standard errors are multiplied by 100. Pareto coefficients are estimated among the top $k$ income likelihood methods. Quasi-nonparametric Gini coefficients are computed using 100 random draws from the estimated respective $\mathrm{P}$ 
Table A3 (cont.). Quasi-nonparametric estimates of Gini coefficients for household disposable income per ca

\begin{tabular}{|c|c|c|c|c|c|c|c|c|c|}
\hline & \multicolumn{3}{|c|}{ Palestine ' 10} & \multicolumn{3}{|c|}{ Palestine '11 } & \multicolumn{3}{|c|}{ Sudan '09 } \\
\hline & $\begin{array}{c}\text { Observ. } \\
\text { replaced } \\
\text { [income } \\
\text { share] }\end{array}$ & $\begin{array}{c}\text { Pareto } \\
\text { coef. } \theta \\
\text { (s.e.) }\end{array}$ & $\begin{array}{l}\text { Gini } \\
\text { (s.e.) }\end{array}$ & $\begin{array}{c}\text { Observ. } \\
\text { replaced } \\
\text { [income } \\
\text { share] }\end{array}$ & $\begin{array}{c}\text { Pareto } \\
\text { coef. } \theta \\
\text { (s.e.) }\end{array}$ & $\begin{array}{l}\text { Gini } \\
\text { (s.e.) }\end{array}$ & $\begin{array}{c}\text { Observ. } \\
\text { replaced } \\
\text { [income } \\
\text { share] }\end{array}$ & $\begin{array}{c}\text { Pareto } \\
\text { coef. } \theta \\
\text { (s.e.) }\end{array}$ & $\begin{array}{l}\text { Gini } \\
\text { (s.e.) }\end{array}$ \\
\hline non-par. & $\begin{array}{c}0 \text { out of } \\
3,757\end{array}$ & & $\begin{array}{l}44.94 \\
(0.70)\end{array}$ & $\begin{array}{c}0 \text { out of } \\
4,317\end{array}$ & & $\begin{array}{l}43.32 \\
(0.60)\end{array}$ & $\begin{array}{c}0 \text { out of } \\
7,913\end{array}$ & & $\begin{array}{l}54.74 \\
(1.05)\end{array}$ \\
\hline \multicolumn{4}{|c|}{ quasi-nonparametric. Gini, top \% replaced } & & & & & & \\
\hline $\mathrm{k}=0.1 \% \times \mathrm{n}$ & $\begin{array}{c}8 \\
{[1.70 \%]}\end{array}$ & $\begin{array}{c}3.079 \\
(1.150)\end{array}$ & $\begin{array}{l}44.97 \\
(0.71)\end{array}$ & $\begin{array}{c}5 \\
{[1.22 \%]}\end{array}$ & $\begin{array}{l}10.130 \\
(8.183)\end{array}$ & $\begin{array}{l}43.32 \\
(0.61)\end{array}$ & $\begin{array}{c}10 \\
{[4.91 \%]}\end{array}$ & $\begin{array}{c}2.591 \\
(1.112)\end{array}$ & $\begin{array}{l}54.50 \\
(1.20)\end{array}$ \\
\hline $\mathrm{k}=0.2 \% \times \mathrm{n}$ & $\begin{array}{c}15 \\
{[2.80 \%]}\end{array}$ & $\begin{array}{c}3.053 \\
(0.960) \\
\end{array}$ & $\begin{array}{l}44.96 \\
(0.71) \\
\end{array}$ & $\begin{array}{c}14 \\
{[2.13 \%]}\end{array}$ & $\begin{array}{r}2.859 \\
(0.633) \\
\end{array}$ & $\begin{array}{l}38.44 \\
(0.65)\end{array}$ & $\begin{array}{c}19 \\
{[6.61 \%]}\end{array}$ & $\begin{array}{c}1.988 \\
(0.446)\end{array}$ & $\begin{array}{l}54.61 \\
(1.28)\end{array}$ \\
\hline $\mathrm{k}=0.5 \% \times \mathrm{n}$ & $\begin{array}{c}34 \\
{[5.27 \%]}\end{array}$ & $\begin{array}{c}2.328 \\
(0.426)\end{array}$ & $\begin{array}{l}44.94 \\
(0.46) \\
\end{array}$ & $\begin{array}{c}38 \\
{[3.93 \%]}\end{array}$ & $\begin{array}{c}3.213 \\
(0.638) \\
\end{array}$ & $\begin{array}{l}43.37 \\
(0.63)\end{array}$ & $\begin{array}{c}47 \\
{[10.54 \%]}\end{array}$ & $\begin{array}{c}1.859 \\
(0.279) \\
\end{array}$ & $\begin{array}{l}54.80 \\
(1.55) \\
\end{array}$ \\
\hline $\mathrm{k}=1 \% \times \mathrm{n}$ & $\begin{array}{c}60 \\
{[8.05 \%]}\end{array}$ & $\begin{array}{c}2.343 \\
(0.340) \\
\end{array}$ & $\begin{array}{l}45.05 \\
(0.85)\end{array}$ & $\begin{array}{c}75 \\
{[6.69 \%]}\end{array}$ & $\begin{array}{c}3.179 \\
(0.453)\end{array}$ & $\begin{array}{l}43.36 \\
(0.63)\end{array}$ & $\begin{array}{c}86 \\
{[15.11 \%]}\end{array}$ & $\begin{array}{c}1.622 \\
(0.169) \\
\end{array}$ & $\begin{array}{l}55.60 \\
(2.86)\end{array}$ \\
\hline $\mathrm{k}=2 \% \times \mathrm{n}$ & $\begin{array}{c}119 \\
{[12.23 \%]}\end{array}$ & $\begin{array}{c}2.558 \\
(0.284)\end{array}$ & $\begin{array}{l}44.94 \\
(0.89)\end{array}$ & $\begin{array}{c}137 \\
{[10.57 \%]}\end{array}$ & $\begin{array}{c}3.156 \\
(0.339)\end{array}$ & $\begin{array}{l}43.38 \\
(0.79)\end{array}$ & $\begin{array}{c}163 \\
{[20.30 \%]}\end{array}$ & $\begin{array}{c}1.759 \\
(0.158)\end{array}$ & $\begin{array}{l}55.01 \\
(2.08)\end{array}$ \\
\hline $\mathrm{k}=5 \% \times \mathrm{n}$ & $\begin{array}{c}278 \\
{[21.36 \%]}\end{array}$ & $\begin{array}{c}2.436 \\
(0.160) \\
\end{array}$ & $\begin{array}{l}45.13 \\
(1.00) \\
\end{array}$ & $\begin{array}{c}331 \\
{[19.93 \%]}\end{array}$ & $\begin{array}{c}2.768 \\
(0.182) \\
\end{array}$ & $\begin{array}{l}43.62 \\
(0.78) \\
\end{array}$ & $\begin{array}{c}403 \\
{[31.45 \%]}\end{array}$ & $\begin{array}{r}1.863 \\
(0.116) \\
\end{array}$ & $\begin{array}{l}54.74 \\
(1.44) \\
\end{array}$ \\
\hline $\mathrm{k}=10 \% \times \mathrm{n}$ & $\begin{array}{c}496 \\
{[32.83 \%]}\end{array}$ & $\begin{array}{c}2.750 \\
(0.148) \\
\end{array}$ & $\begin{array}{l}44.66 \\
(0.73)\end{array}$ & $\begin{array}{c}582 \\
{[31.13 \%]}\end{array}$ & $\begin{array}{c}2.715 \\
(0.132)\end{array}$ & $\begin{array}{l}43.64 \\
(0.79)\end{array}$ & $\begin{array}{c}838 \\
{[43.11 \%]}\end{array}$ & $\begin{array}{c}1.780 \\
(0.078)\end{array}$ & $\begin{array}{l}55.09 \\
(1.60)\end{array}$ \\
\hline $\mathrm{k}=20 \% \times \mathrm{n}$ & $\begin{array}{c}949 \\
{[49.82 \%]}\end{array}$ & $\begin{array}{c}2.249 \\
(0.073) \\
\end{array}$ & $\begin{array}{l}46.10 \\
(1.24)\end{array}$ & $\begin{array}{c}1,046 \\
{[48.15 \%]}\end{array}$ & $\begin{array}{c}2.415 \\
(0.083) \\
\end{array}$ & $\begin{array}{l}44.44 \\
(1.19)\end{array}$ & $\begin{array}{c}1,615 \\
{[58.03 \%]}\end{array}$ & $\begin{array}{c}1.714 \\
(0.055) \\
\end{array}$ & $\begin{array}{l}55.78 \\
(2.13) \\
\end{array}$ \\
\hline $\begin{array}{l}\text { Mean (s.d.) if } \\
\mathrm{k} \leq 1 \% \times \mathrm{n}\end{array}$ & -- & $\begin{array}{c}2.70 \\
(0.42)\end{array}$ & $\begin{array}{l}44.98 \\
(0.05)\end{array}$ & -- & $\begin{array}{c}4.85 \\
(3.53)\end{array}$ & $\begin{array}{l}42.12 \\
(2.46)\end{array}$ & -- & $\begin{array}{c}2.02 \\
(0.41)\end{array}$ & $\begin{array}{l}54.88 \\
(0.50)\end{array}$ \\
\hline $\begin{array}{l}\text { Mean (s.d.) if } \\
\mathrm{k} \geq 2 \% \times \mathrm{n}\end{array}$ & -- & $\begin{array}{c}2.50 \\
(0.21) \\
\end{array}$ & $\begin{array}{l}45.21 \\
(0.63) \\
\end{array}$ & -- & $\begin{array}{c}2.76 \\
(0.30) \\
\end{array}$ & $\begin{array}{l}43.77 \\
(0.46) \\
\end{array}$ & -- & $\begin{array}{c}1.78 \\
(0.06) \\
\end{array}$ & $\begin{array}{l}55.16 \\
(0.44) \\
\end{array}$ \\
\hline
\end{tabular}

Notes: Palestine ' 07 , and Tunisia ' 05 and ' 10 surveys do not cover incomes, only expenditures. For clarity, Ginis and their standar Pareto coefficients are estimated among the top $k$ income observations using maximum likelihood methods. Quasi-nonparametric $C$ using 100 random draws from the estimated respective Pareto distributions 
Table A4. Semiparametric estimates of Lorenz ordinates: Top 5\% of expenditures replaced with smooth Pare

\begin{tabular}{|c|c|c|c|c|c|c|c|c|c|}
\hline $\begin{array}{c}\text { Density of top } \\
\text { households }\end{array}$ & Egypt '08 & Egypt '10 & Egypt '12 & Jordan '06 & Jordan ' 10 & Palestine '07 & Palestine ' 10 & Palestine '11 & Sudan “ \\
\hline \multicolumn{10}{|c|}{ Lorenz ordinates (top expenditure shares) in actual distribution } \\
\hline $0.5 \%$ & $4.24 \%$ & $4.24 \%$ & $3.39 \%$ & $4.23 \%$ & $4.43 \%$ & $4.33 \%$ & $4.12 \%$ & $4.11 \%$ & 5 \\
\hline $1 \%$ & $6.68 \%$ & $6.59 \%$ & $5.72 \%$ & $6.49 \%$ & $6.47 \%$ & $7.14 \%$ & $6.74 \%$ & $6.72 \%$ & 7. \\
\hline $5 \%$ & $18.02 \%$ & $17.87 \%$ & $16.80 \%$ & $18.57 \%$ & $19.18 \%$ & $20.81 \%$ & $19.65 \%$ & $19.52 \%$ & 20.13 \\
\hline $10 \%$ & $27.14 \%$ & $27.12 \%$ & $25.86 \%$ & $28.54 \%$ & $29.41 \%$ & $31.85 \%$ & $30.89 \%$ & $30.15 \%$ & 30.7 \\
\hline \multicolumn{10}{|c|}{ Lorenz ordinates in semiparametric distribution } \\
\hline $0.5 \%$ & $6.83 \%$ & $6.37 \%$ & $5.90 \%$ & $7.08 \%$ & $5.62 \%$ & $6.45 \%$ & $5.60 \%$ & $6.26 \%$ & \\
\hline $1 \%$ & $10.25 \%$ & $9.58 \%$ & $8.99 \%$ & $10.96 \%$ & $8.78 \%$ & $10.14 \%$ & $8.75 \%$ & $9.65 \%$ & \\
\hline $5 \%$ & $26.22 \%$ & $24.68 \%$ & $23.84 \%$ & $30.25 \%$ & $24.71 \%$ & $29.03 \%$ & $24.64 \%$ & $26.41 \%$ & 23.32 \\
\hline $10 \%$ & $35.27 \%$ & $33.88 \%$ & $32.81 \%$ & $40.26 \%$ & $35.08 \%$ & $40.22 \%$ & $36.21 \%$ & $37.06 \%$ & 33. \\
\hline
\end{tabular}

Notes: Top expenditure shares in the actual distribution are computed nonparametrically. In the semiparametric distribution, they a on the actual aggregate expenditures, expenditure share of the bottom $95 \%$ of expenditures, the cutoff $\left(95^{\text {th }}\right.$ percentile) expendit coefficient, and the count of top-expenditure observations replaced. 
Table A5. Quasi-nonparametric estimates for household expenditure per capita: truncated Pareto distribution

\begin{tabular}{|c|c|c|c|c|c|c|c|c|c|c|c|}
\hline \multicolumn{3}{|c|}{ Egypt '08 } & \multicolumn{3}{|c|}{ Egypt ' 10} & \multicolumn{3}{|c|}{ Egypt '12 } & \multicolumn{3}{|c|}{ Jordan '06 } \\
\hline $\begin{array}{l}\text { Right } \\
\text { truncation }\end{array}$ & $\begin{array}{c}\text { Sample size } \eta \\
\kappa \text { obs. } \\
\text { replaced }\end{array}$ & $\alpha$ & Gini & $\begin{array}{c}\text { Sample size } \eta \\
\kappa \text { obs. } \\
\text { replaced }\end{array}$ & $\alpha$ & Gini & $\begin{array}{c}\text { Sample size } \eta \\
\kappa \text { obs. } \\
\text { replaced }\end{array}$ & $\alpha$ & Gini & $\begin{array}{c}\text { Sample size } \eta \\
\kappa \text { obs. } \\
\text { replaced }\end{array}$ & $\alpha$ \\
\hline \multicolumn{12}{|c|}{ Estimation on top $15-\mathrm{k}^{\text {th }}$ percentile of incomes } \\
\hline $\mathrm{k}=1 \%$ & $\begin{array}{c}\eta=4,920 \\
\kappa=394\end{array}$ & $\begin{array}{c}2.512 \\
(.062)\end{array}$ & $\begin{array}{l}31.80 \\
(.35)\end{array}$ & $\begin{array}{c}\eta=1,567 \\
\kappa=124\end{array}$ & $\begin{array}{l}2.406 \\
(.110)\end{array}$ & $\begin{array}{r}31.88 \\
(.54)\end{array}$ & $\begin{array}{c}\eta=1,511 \\
\kappa=117\end{array}$ & $\begin{array}{l}2.526 \\
(.121)\end{array}$ & $\begin{array}{r}30.27 \\
(.51)\end{array}$ & $\begin{array}{c}\eta=605 \\
\kappa=68\end{array}$ & $\begin{array}{l}2.210 \\
(.181)\end{array}$ \\
\hline $\mathrm{k}=3 \%$ & $\begin{array}{l}\eta=4,120 \\
\kappa=1,194\end{array}$ & $\begin{array}{c}2.676 \\
(.100)\end{array}$ & $\begin{array}{l}31.07 \\
(.29)\end{array}$ & $\begin{array}{c}\eta=1,326 \\
\kappa=365\end{array}$ & $\begin{array}{l}2.437 \\
(.180)\end{array}$ & $\begin{array}{r}31.65 \\
(.48)\end{array}$ & $\begin{array}{c}\eta=1,273 \\
\kappa=355\end{array}$ & $\begin{array}{l}2.610 \\
(.197)\end{array}$ & $\begin{array}{r}30.06 \\
(.49)\end{array}$ & $\begin{array}{l}\eta=499 \\
\kappa=174\end{array}$ & $\begin{array}{l}2.137 \\
(.276)\end{array}$ \\
\hline $\mathrm{k}=5 \%$ & $\begin{array}{l}\eta=3,347 \\
\kappa=1,967\end{array}$ & $\begin{array}{l}2.947 \\
(.157)\end{array}$ & $\begin{array}{l}30.09 \\
(.22)\end{array}$ & $\begin{array}{c}\eta=1,085 \\
\kappa=606\end{array}$ & $\begin{array}{c}2.402 \\
(.279) \\
\end{array}$ & $\begin{array}{r}31.90 \\
(.51) \\
\end{array}$ & $\begin{array}{c}\eta=1,036 \\
\kappa=592\end{array}$ & $\begin{array}{c}2.842 \\
(.296) \\
\end{array}$ & $\begin{array}{r}29.07 \\
(.41) \\
\end{array}$ & $\begin{array}{l}\eta=387 \\
\kappa=286\end{array}$ & $\begin{array}{l}1.607 \\
(.447) \\
\end{array}$ \\
\hline \multicolumn{12}{|c|}{ Estimation on top $20-\mathrm{k}^{\text {th }}$ percentile of incomes } \\
\hline $\mathrm{k}=1 \%$ & $\begin{array}{c}\eta=6,385 \\
\kappa=394\end{array}$ & $\begin{array}{c}2.512 \\
(.050)\end{array}$ & $\begin{array}{l}31.80 \\
(.35)\end{array}$ & $\begin{array}{c}\eta=2,050 \\
\kappa=124\end{array}$ & $\begin{array}{c}2.459 \\
(.090)\end{array}$ & $\begin{array}{r}31.81 \\
(.53)\end{array}$ & $\begin{array}{c}\eta=1,966 \\
\kappa=117\end{array}$ & $\begin{array}{l}2.547 \\
(.097)\end{array}$ & $\begin{array}{r}30.24 \\
(.51)\end{array}$ & $\begin{array}{c}\eta=781 \\
\kappa=68\end{array}$ & $\begin{array}{c}2.049 \\
(.139)\end{array}$ \\
\hline $\mathrm{k}=3 \%$ & $\begin{array}{l}\eta=5,585 \\
\kappa=1,194\end{array}$ & $\begin{array}{c}2.610 \\
(.073)\end{array}$ & $\begin{array}{l}31.20 \\
(.30)\end{array}$ & $\begin{array}{c}\eta=1,809 \\
\kappa=365\end{array}$ & $\begin{array}{c}2.511 \\
(.133)\end{array}$ & $\begin{array}{r}31.48 \\
(.47)\end{array}$ & $\begin{array}{c}\eta=1,728 \\
\kappa=355\end{array}$ & $\begin{array}{c}2.599 \\
(.142)\end{array}$ & $\begin{array}{r}30.08 \\
(.49)\end{array}$ & $\begin{array}{l}\eta=675 \\
\kappa=174\end{array}$ & $\begin{array}{l}1.938 \\
(.203)\end{array}$ \\
\hline $\mathrm{k}=5 \%$ & $\begin{array}{l}\eta=4,812 \\
\kappa=1,967\end{array}$ & $\begin{array}{c}2.721 \\
(.102)\end{array}$ & $\begin{array}{l}30.56 \\
(.24)\end{array}$ & $\begin{array}{c}\eta=1,568 \\
\kappa=606\end{array}$ & $\begin{array}{l}2.528 \\
(.187)\end{array}$ & $\begin{array}{r}31.49 \\
(.48)\end{array}$ & $\begin{array}{c}\eta=1,491 \\
\kappa=592\end{array}$ & $\begin{array}{l}2.705 \\
(.194)\end{array}$ & $\begin{array}{r}29.36 \\
(.43)\end{array}$ & $\begin{array}{l}\eta=563 \\
\kappa=286\end{array}$ & $\begin{array}{c}1.598 \\
(.310)\end{array}$ \\
\hline \multicolumn{12}{|c|}{ Estimation on top $25-\mathrm{k}^{\text {th }}$ percentile of incomes } \\
\hline $\mathrm{k}=1 \%$ & $\begin{array}{c}\eta=7,775 \\
\kappa=394\end{array}$ & $\begin{array}{l}2.512 \\
(.042)\end{array}$ & $\begin{array}{l}31.80 \\
(.35)\end{array}$ & $\begin{array}{c}\eta=2,508 \\
\kappa=124\end{array}$ & $\begin{array}{c}2.374 \\
(.074)\end{array}$ & $\begin{array}{r}31.93 \\
(.54)\end{array}$ & $\begin{array}{c}\eta=2,405 \\
\kappa=117\end{array}$ & $\begin{array}{l}2.505 \\
(.080)\end{array}$ & $\begin{array}{r}30.29 \\
(.51)\end{array}$ & $\begin{array}{c}\eta=946 \\
\kappa=68\end{array}$ & $\begin{array}{l}1.943 \\
(.116)\end{array}$ \\
\hline $\mathrm{k}=3 \%$ & $\begin{array}{l}\eta=6,975 \\
\kappa=1,194\end{array}$ & $\begin{array}{l}2.581 \\
(.059)\end{array}$ & $\begin{array}{l}31.26 \\
(.30)\end{array}$ & $\begin{array}{c}\eta=2,267 \\
\kappa=365\end{array}$ & $\begin{array}{c}2.358 \\
(.104)\end{array}$ & $\begin{array}{r}31.84 \\
(.50)\end{array}$ & $\begin{array}{c}\eta=2,167 \\
\kappa=355\end{array}$ & $\begin{array}{c}2.511 \\
(.111)\end{array}$ & $\begin{array}{r}30.27 \\
(.51)\end{array}$ & $\begin{array}{l}\eta=840 \\
\kappa=174\end{array}$ & $\begin{array}{c}1.826 \\
(.164)\end{array}$ \\
\hline $\mathrm{k}=5 \%$ & $\begin{array}{l}\eta=6,202 \\
\kappa=1,967\end{array}$ & $\begin{array}{c}2.641 \\
(.078)\end{array}$ & $\begin{array}{l}30.76 \\
(.25)\end{array}$ & $\begin{array}{c}\eta=2,026 \\
\kappa=606\end{array}$ & $\begin{array}{c}2.299 \\
(.137)\end{array}$ & $\begin{array}{r}32.28 \\
(.54)\end{array}$ & $\begin{array}{c}\eta=1,930 \\
\kappa=592\end{array}$ & $\begin{array}{c}2.540 \\
(.144)\end{array}$ & $\begin{array}{r}29.82 \\
(.47)\end{array}$ & $\begin{array}{l}\eta=728 \\
\kappa=286\end{array}$ & $\begin{array}{c}1.574 \\
(.237)\end{array}$ \\
\hline
\end{tabular}

Notes: Pareto coefficients are estimated on top expenditures not suspected of contamination (sample size $\eta ; L \leq x<K ; K$ is incor percentile), and are used to replace $\kappa$ potentially-contaminated topmost observations. For example, the first row reports on the es Pareto distribution between the $85^{\text {th }}$ and the $99^{\text {th }}$ percentiles of expenditures, and uses the estimates to replace the topmost $1 \%$ of exp Gini coefficients are computed using 1,000 random draws from the estimated respective Pareto distributions. For clarity, Gini multiplied by 100 . 
Table A5 (cont.). Quasi-nonparametric estimates for household expenditure per capita: truncated Pareto distr

\begin{tabular}{|c|c|c|c|c|c|c|c|c|c|c|c|}
\hline \multicolumn{3}{|c|}{ Palestine '07 } & \multicolumn{3}{|c|}{ Palestine ' 10} & \multicolumn{3}{|c|}{ Palestine '11 } & \multicolumn{3}{|c|}{ Sudan '09 } \\
\hline $\begin{array}{l}\text { Right } \\
\text { truncation }\end{array}$ & $\begin{array}{l}\text { ample size } \eta \\
\kappa \text { obs. } \\
\text { replaced }\end{array}$ & $\alpha$ & Gini & $\begin{array}{c}\text { Sample size } \eta \\
\kappa \text { obs. } \\
\text { replaced }\end{array}$ & $\alpha$ & Gini & $\begin{array}{c}\text { Sample size } \eta \\
\kappa \text { obs. } \\
\text { replaced }\end{array}$ & $\alpha$ & Gini & $\begin{array}{c}\text { Sample size } \eta \\
\kappa \text { obs. } \\
\text { replaced }\end{array}$ & $\alpha$ \\
\hline \multicolumn{12}{|c|}{ Estimation on top $15-\mathrm{k}^{\text {th }}$ percentile of incomes } \\
\hline $\mathrm{k}=1 \%$ & $\begin{array}{c}\eta=234 \\
\kappa=25\end{array}$ & $\begin{array}{l}2.130 \\
(.257)\end{array}$ & $\begin{array}{l}42.85 \\
(1.41)\end{array}$ & $\begin{array}{c}\eta=682 \\
\kappa=66\end{array}$ & $\begin{array}{l}1.797 \\
(.150)\end{array}$ & $\begin{array}{l}41.80 \\
(1.17)\end{array}$ & $\begin{array}{c}\eta=802 \\
\kappa=80\end{array}$ & $\begin{array}{c}2.229 \\
(.173)\end{array}$ & $\begin{array}{r}39.42 \\
(.83) \\
\end{array}$ & $\begin{array}{c}\eta=1,331 \\
\kappa=110\end{array}$ & $\begin{array}{c}2.182 \\
(.138)\end{array}$ \\
\hline $\mathrm{k}=3 \%$ & $\begin{array}{c}\eta=193 \\
\kappa=66\end{array}$ & $\begin{array}{c}2.343 \\
(.409) \\
\end{array}$ & $\begin{array}{l}43.17 \\
(1.29)\end{array}$ & & $\begin{array}{c}1.588 \\
(.251)\end{array}$ & & & & $\begin{array}{r}40.76 \\
(.87)\end{array}$ & $\begin{array}{c}\eta=1,140 \\
\kappa=301\end{array}$ & $\begin{array}{c}2.165 \\
(.216)\end{array}$ \\
\hline $\mathrm{k}=5 \%$ & $\begin{array}{l}\eta=156 \\
\kappa=103\end{array}$ & $\begin{array}{c}3.006 \\
(.619)\end{array}$ & $\begin{array}{l}41.33 \\
(1.04)\end{array}$ & $\begin{array}{l}\eta=486 \\
\kappa=262\end{array}$ & $\begin{array}{c}1.388 \\
(.364)\end{array}$ & $\begin{array}{l}48.32 \\
(1.71)\end{array}$ & $\begin{array}{l}\eta=548 \\
\kappa=334\end{array}$ & $\begin{array}{c}2.045 \\
(.437)\end{array}$ & $\begin{array}{l}41.35 \\
(1.01)\end{array}$ & $\begin{array}{l}\eta= \\
\kappa=\end{array}$ & $\begin{array}{c}2.164 \\
(.340) \\
\end{array}$ \\
\hline \multicolumn{12}{|c|}{ Estimation on top $20-\mathrm{k}^{\text {th }}$ percentile of incomes } \\
\hline $\mathrm{k}=1 \%$ & $\begin{array}{l}\eta=316 \\
\kappa=25\end{array}$ & $\begin{array}{c}1.822 \\
(.182)\end{array}$ & $\begin{array}{l}43.76 \\
(1.61)\end{array}$ & $\begin{array}{c}\eta=904 \\
\kappa=66\end{array}$ & $\begin{array}{c}1.761 \\
(.122)\end{array}$ & $\begin{array}{l}41.94 \\
(1.21)\end{array}$ & $\begin{array}{c}\eta=1,062 \\
\kappa=80\end{array}$ & $\begin{array}{c}1.942 \\
(.124)\end{array}$ & $\begin{array}{r}40.00 \\
(.96) \\
\end{array}$ & $\begin{array}{c}\eta=1,791 \\
\kappa=110\end{array}$ & $\begin{array}{l}2.100 \\
(.109) \\
\end{array}$ \\
\hline $\mathrm{k}=3 \%$ & $\begin{array}{c}\eta=275 \\
\kappa=66\end{array}$ & $\begin{array}{l}1.810 \\
(.261)\end{array}$ & $\begin{array}{l}45.59 \\
(1.63)\end{array}$ & $\begin{array}{l}\eta=797 \\
\kappa=173\end{array}$ & $\begin{array}{c}1.631 \\
(.186)\end{array}$ & $\begin{array}{l}43.32 \\
(1.05)\end{array}$ & $\begin{array}{l}\eta=937 \\
\kappa=205\end{array}$ & $\begin{array}{c}1.709 \\
(.187)\end{array}$ & $\begin{array}{l}42.85 \\
(1.13)\end{array}$ & $\begin{array}{c}\eta=1,600 \\
\kappa=301\end{array}$ & $\begin{array}{c}2.050 \\
(.156)\end{array}$ \\
\hline $\mathrm{k}=5 \%$ & $\begin{array}{l}\eta=238 \\
\kappa=103\end{array}$ & $\begin{array}{c}1.942 \\
(.352)\end{array}$ & $\begin{array}{l}45.43 \\
(1.48)\end{array}$ & $\begin{array}{c}\eta=7,305 \\
\kappa=262\end{array}$ & $\begin{array}{c}1.503 \\
(.125)\end{array}$ & $\begin{array}{r}47.11 \\
(.56) \\
\end{array}$ & $\begin{array}{l}\eta=808 \\
\kappa=334\end{array}$ & $\begin{array}{l}1.531 \\
(.259)\end{array}$ & $\begin{array}{l}46.01 \\
(1.62)\end{array}$ & $\begin{array}{c}\eta=1,395 \\
\kappa=506\end{array}$ & $\begin{array}{c}2.001 \\
(.220)\end{array}$ \\
\hline \multicolumn{12}{|c|}{ Estimation on top $25-\mathrm{k}^{\text {th }}$ percentile of incomes } \\
\hline $\mathrm{k}=1 \%$ & $\begin{array}{l}\eta=386 \\
\kappa=25\end{array}$ & $\begin{array}{c}1.778 \\
(.152)\end{array}$ & $\begin{array}{l}43.93 \\
(1.64) \\
\end{array}$ & $\begin{array}{c}\eta=1,127 \\
\kappa=66\end{array}$ & $\begin{array}{c}1.688 \\
(.100)\end{array}$ & $\begin{array}{l}42.25 \\
(1.28)\end{array}$ & $\begin{array}{c}\eta=1,301 \\
\kappa=80\end{array}$ & $\begin{array}{l}1.901 \\
(0.105)\end{array}$ & $\begin{array}{r}40.11 \\
(.99) \\
\end{array}$ & $\begin{array}{c}\eta=2,209 \\
\kappa=110\end{array}$ & $\begin{array}{c}2.059 \\
(.090) \\
\end{array}$ \\
\hline $\mathrm{k}=3 \%$ & $\begin{array}{c}\eta=345 \\
\kappa=66\end{array}$ & $\begin{array}{c}1.755 \\
(.208) \\
\end{array}$ & $\begin{array}{r}45.97 \\
(1.69)\end{array}$ & $\begin{array}{c}\eta=1,020 \\
\kappa=173\end{array}$ & $\begin{array}{c}1.574 \\
(.143)\end{array}$ & $\begin{array}{l}43.75 \\
(1.11)\end{array}$ & $\begin{array}{c}\eta=1,176 \\
\kappa=205\end{array}$ & $\begin{array}{c}1.721 \\
(.151)\end{array}$ & $\begin{array}{l}42.75 \\
(1.11)\end{array}$ & $\begin{array}{c}\eta=2,018 \\
\kappa=301\end{array}$ & $\begin{array}{c}2.006 \\
(.123) \\
\end{array}$ \\
\hline $\mathrm{k}=5 \%$ & $\begin{array}{l}\eta=308 \\
\kappa=103\end{array}$ & $\begin{array}{c}1.824 \\
(.268)\end{array}$ & $\begin{array}{l}46.31 \\
(1.57)\end{array}$ & $\begin{array}{l}\eta=931 \\
\kappa=262\end{array}$ & $\begin{array}{c}1.504 \\
(.182)\end{array}$ & $\begin{array}{c}46.54 \\
(1.48)\end{array}$ & $\begin{array}{c}\eta=1,047 \\
\kappa=334\end{array}$ & $\begin{array}{c}1.615 \\
(.198)\end{array}$ & $\begin{array}{c}45.03 \\
(1.47)\end{array}$ & $\begin{array}{c}\eta=1,813 \\
\kappa=506\end{array}$ & $\begin{array}{c}1.961 \\
(.163)\end{array}$ \\
\hline
\end{tabular}

Notes: Pareto coefficients are estimated on top expenditures not suspected of contamination (sample size $\eta ; L \leq x<K ; K$ is inco percentile), and are used to replace $\kappa$ potentially-contaminated topmost observations. Quasi-nonparametric Gini coefficients are draws from the estimated respective Pareto distributions. For clarity, Ginis and their standard errors are multiplied by 100. 
Table A5 (cont.). Quasi-nonparametric estimates for household expenditure per capita: truncated Pareto distribution

\begin{tabular}{|c|c|c|c|c|c|c|}
\hline & Tunisia '05 & & & Tunisia '10 & & \\
\hline $\begin{array}{c}\text { Right } \\
\text { truncation }\end{array}$ & $\begin{array}{c}\text { Sample size } \eta \\
\kappa \text { obs. } \\
\text { replaced }\end{array}$ & $\alpha$ & Gini & $\begin{array}{c}\text { Sample size } \eta \\
\kappa \text { obs. } \\
\text { replaced }\end{array}$ & $\alpha$ & Gini \\
\hline \multicolumn{7}{|c|}{ Estimation on top $15-\mathrm{k}^{\text {th }}$ percentile of incomes } \\
\hline $\mathrm{k}=1 \%$ & $\begin{array}{c}\eta=1,878 \\
\kappa=145\end{array}$ & $\begin{array}{c}1.874 \\
(.086)\end{array}$ & $\begin{array}{l}42.56 \\
(.53)\end{array}$ & $\begin{array}{c}\eta=1,623 \\
\kappa=129\end{array}$ & $\begin{array}{l}2.133 \\
(.112)\end{array}$ & $\begin{array}{r}39.36 \\
(.46)\end{array}$ \\
\hline $\mathrm{k}=3 \%$ & $\begin{array}{c}\eta=1,611 \\
\kappa=412\end{array}$ & $\begin{array}{c}1.619 \\
(.138)\end{array}$ & $\begin{array}{l}45.95 \\
(.87) \\
\end{array}$ & $\begin{array}{c}\eta=1,377 \\
\kappa=375\end{array}$ & $\begin{array}{c}2.037 \\
(.172)\end{array}$ & $\begin{array}{r}41.42 \\
(.66) \\
\end{array}$ \\
\hline $\mathrm{k}=5 \%$ & $\begin{array}{c}\eta=1,347 \\
\kappa=676\end{array}$ & $\begin{array}{c}1.574 \\
(.205)\end{array}$ & $\begin{array}{l}47.34 \\
(.90)\end{array}$ & $\begin{array}{c}\eta=1,138 \\
\kappa=614\end{array}$ & $\begin{array}{c}1.539 \\
(.284)\end{array}$ & $\begin{array}{l}46.03 \\
(1.03)\end{array}$ \\
\hline \multicolumn{7}{|c|}{ Estimation on top $20-\mathrm{k}^{\text {th }}$ percentile of incomes } \\
\hline $\mathrm{k}=1 \%$ & $\begin{array}{c}\eta=2,517 \\
\kappa=145\end{array}$ & $\begin{array}{c}1.834 \\
(.068) \\
\end{array}$ & $\begin{array}{l}42.63 \\
(.54) \\
\end{array}$ & $\begin{array}{c}\eta=2,220 \\
\kappa=129\end{array}$ & $\begin{array}{c}2.012 \\
(.084)\end{array}$ & $\begin{array}{r}39.55 \\
(.48) \\
\end{array}$ \\
\hline $\mathrm{k}=3 \%$ & $\begin{array}{c}\eta=2,250 \\
\kappa=412\end{array}$ & $\begin{array}{c}1.661 \\
(.100)\end{array}$ & $\begin{array}{l}45.59 \\
(.83)\end{array}$ & $\begin{array}{c}\eta=1,974 \\
\kappa=375\end{array}$ & $\begin{array}{c}1.891 \\
(.120)\end{array}$ & $\begin{array}{r}42.14 \\
(.74)\end{array}$ \\
\hline $\mathrm{k}=5 \%$ & $\begin{array}{c}\eta=1,986 \\
\kappa=676\end{array}$ & $\begin{array}{l}1.653 \\
(.134)\end{array}$ & $\begin{array}{l}46.39 \\
(.82) \\
\end{array}$ & $\begin{array}{c}\eta=1,735 \\
\kappa=614\end{array}$ & $\begin{array}{l}1.590 \\
(.176)\end{array}$ & $\begin{array}{r}45.38 \\
(.96) \\
\end{array}$ \\
\hline \multicolumn{7}{|c|}{ Estimation on top $25-\mathrm{k}^{\text {th }}$ percentile of incomes } \\
\hline $\mathrm{k}=1 \%$ & $\begin{array}{c}\eta=3,162 \\
\kappa=145\end{array}$ & $\begin{array}{l}1.750 \\
(.055)\end{array}$ & $\begin{array}{l}42.88 \\
(.57)\end{array}$ & $\begin{array}{c}\eta=2,817 \\
\kappa=129\end{array}$ & $\begin{array}{l}1.846 \\
(.067)\end{array}$ & $\begin{array}{r}39.87 \\
(.52)\end{array}$ \\
\hline $\mathrm{k}=3 \%$ & $\begin{array}{c}\eta=2,895 \\
\kappa=412\end{array}$ & $\begin{array}{c}1.593 \\
(.076) \\
\end{array}$ & $\begin{array}{l}46.20 \\
(.89)\end{array}$ & $\begin{array}{c}\eta=2,571 \\
\kappa=375\end{array}$ & $\begin{array}{c}1.687 \\
(.090) \\
\end{array}$ & $\begin{array}{r}43.51 \\
(.91) \\
\end{array}$ \\
\hline $\mathrm{k}=5 \%$ & $\begin{array}{c}\eta=2,631 \\
\kappa=676\end{array}$ & $\begin{array}{c}1.563 \\
(.097) \\
\end{array}$ & $\begin{array}{l}47.45 \\
(.91) \\
\end{array}$ & $\begin{array}{c}\eta=2,332 \\
\kappa=614\end{array}$ & $\begin{array}{c}1.424 \\
(.123)\end{array}$ & $\begin{array}{c}47.81 \\
(1.21)\end{array}$ \\
\hline
\end{tabular}

Notes: Pareto coefficients are estimated on top expenditures not suspected of contamination (sample size $\eta ; L \leq x<$ $K ; K$ is income corresponding to the $100-k^{\text {th }}$ percentile), and are used to replace $\kappa$ potentially-contaminated topmost observations. Quasi-nonparametric Gini coefficients are computed using 1,000 random draws from the estimated respective Pareto distributions. For clarity, Ginis and their standard errors are multiplied by 100. 
Table A6. Parametric and quasi-nonparametric estimates of Ginis: Generalized beta distribution type II

\begin{tabular}{|c|c|c|c|c|c|c|c|c|c|}
\hline & $\begin{array}{c}\text { Egypt } \\
\text { ‘08 }\end{array}$ & $\begin{array}{c}\text { Egypt } \\
\cdot 10 \\
\end{array}$ & $\begin{array}{c}\text { Egypt } \\
\cdot 12 \\
\end{array}$ & $\begin{array}{c}\text { Jordan } \\
\text { '06 } \\
\end{array}$ & $\begin{array}{c}\text { Jordan } \\
' 10 \\
\end{array}$ & $\begin{array}{c}\text { Palestine } \\
\text { ‘07 }\end{array}$ & $\begin{array}{c}\text { Palestine } \\
' 10\end{array}$ & $\begin{array}{c}\text { Palestine } \\
\text { ' } 11\end{array}$ & $\begin{array}{c}\text { Sudan } \\
\text { '09 } \\
\end{array}$ \\
\hline \multirow[t]{2}{*}{$\mathrm{E}(\mathrm{a})$} & 4.008 & 3.527 & 5.162 & 2.218 & 2.045 & 1.657 & 1.167 & 1.353 & 1.8 \\
\hline & $(0.203)$ & $(0.319)$ & $(0.450)$ & $(0.410)$ & $(0.507)$ & $(0.422)$ & $(0.243)$ & $(0.328)$ & $(0.193$ \\
\hline \multirow[t]{2}{*}{$\mathrm{E}(\mathrm{b})$} & 884.212 & 914.705 & $1,154.312$ & $1,353.274$ & $1,295.177$ & $2,013.049$ & $1,053.091$ & $1,810.728$ & 850.215 \\
\hline & $(17.325)$ & (43.916) & $(25.519)$ & $(159.250)$ & $(308.692)$ & (337.498) & (609.263) & (743.082) & (41.658 \\
\hline \multirow[t]{2}{*}{$E(p)$} & 1.346 & 1.805 & 0.965 & 2.252 & 3.528 & 2.374 & 9.741 & 5.471 & 1.59 \\
\hline & $(0.120)$ & $(0.326)$ & $(0.130)$ & $(0.794)$ & (1.949) & (1.104) & $(6.520)$ & (3.518) & $(0.267$ \\
\hline \multirow[t]{2}{*}{$E(q)$} & 0.648 & 0.739 & 0.504 & 1.178 & 1.242 & 1.537 & 2.430 & 2.102 & 1.51 \\
\hline & $(0.040)$ & $(0.083)$ & $(0.053)$ & $(0.297)$ & $(0.422)$ & $(0.569)$ & $(0.725)$ & $(0.728)$ & $(0.249$ \\
\hline \multirow{2}{*}{$\begin{array}{l}\log (\text { pseudo-lik.) } \\
\text { sample size }\end{array}$} & -858.52 & -270.69 & -260.26 & $-46,583$ & $-53,155$ & -70.83 & -210.06 & -240.42 & $-229,74$ \\
\hline & 23,428 & 7,719 & 7,528 & 2,897 & 2,845 & 1,231 & 3,757 & 4,317 & 7,9 \\
\hline \multirow{2}{*}{$\begin{array}{l}\text { nonparametric } \\
\text { Gini }\end{array}$} & 31.32 & 31.42 & 29.60 & 35.81 & 36.21 & 40.83 & 39.18 & 38.43 & 39. \\
\hline & $(0.28)$ & $(0.48)$ & $(0.42)$ & $(0.74)$ & $(1.31)$ & $(1.00)$ & $(0.57)$ & $(0.68)$ & $(0.7$ \\
\hline \multirow[t]{2}{*}{ parametric Gini } & 31.05 & 31.27 & 29.88 & 36.15 & 36.36 & 41.36 & 39.53 & 38.72 & 39. \\
\hline & $(0.26)$ & $(0.47)$ & $(0.46)$ & $(0.79)$ & $(1.04)$ & $(1.17)$ & $(0.66)$ & $(0.74)$ & $(0.6$ \\
\hline \multicolumn{10}{|c|}{ quasi-nonparametric Gini, top $\mathrm{k} \%$ replaced } \\
\hline \multirow[t]{2}{*}{$\mathrm{k}=0.1 \% \times \mathrm{n}$} & 31.40 & 31.47 & 29.88 & 35.97 & 35.86 & 40.94 & 39.33 & 38.65 & 39. \\
\hline & $(0.31)$ & $(0.55)$ & $(0.49)$ & $(0.81)$ & $(0.85)$ & $(1.09)$ & $(0.61)$ & $(0.75)$ & $(0.6$ \\
\hline \multirow[t]{2}{*}{$\mathrm{k}=0.2 \% \times \mathrm{n}$} & 31.39 & 31.45 & 30.00 & 35.95 & 36.11 & 41.26 & 39.51 & 38.67 & 39. \\
\hline & $(0.30)$ & $(0.57)$ & $(0.51)$ & $(0.92)$ & $(0.85)$ & (1.19) & $(0.70)$ & $(0.72)$ & $(0.6$ \\
\hline \multirow[t]{2}{*}{$\mathrm{k}=0.5 \% \times \mathrm{n}$} & 31.29 & 31.42 & 30.15 & 36.21 & 36.50 & 41.41 & 39.68 & 38.79 & 39. \\
\hline & $(0.32)$ & $(0.57)$ & $(0.55)$ & (1.07) & (0.99) & (1.19) & $(0.83)$ & $(0.77)$ & (0.6 \\
\hline \multirow[t]{2}{*}{$\mathrm{k}=1 \% \times \mathrm{n}$} & 31.19 & 31.33 & 29.98 & 36.20 & 36.58 & 41.71 & 39.74 & 38.70 & 39. \\
\hline & $(0.33)$ & $(0.55)$ & $(0.55)$ & $(0.82)$ & (1.56) & $(1.82)$ & $(0.76)$ & $(0.71)$ & $(0.6$ \\
\hline \multirow[t]{2}{*}{$\mathrm{k}=2 \% \times \mathrm{n}$} & 31.04 & 31.26 & 29.89 & 36.27 & 36.92 & 41.43 & 39.78 & 38.72 & 39. \\
\hline & $(0.32)$ & $(0.56)$ & $(0.55)$ & $(0.82)$ & $(2.89)$ & $(1.32)$ & $(0.80)$ & $(0.74)$ & $(0.6)$ \\
\hline \multirow[t]{2}{*}{$\mathrm{k}=5 \% \times \mathrm{n}$} & 30.91 & 31.15 & 29.85 & 36.39 & 36.60 & 41.31 & 39.76 & 38.82 & 39. \\
\hline & $(0.30)$ & $(0.63)$ & $(0.58)$ & $(0.94)$ & (1.18) & $(1.31)$ & $(0.88)$ & $(0.79)$ & (0.6 \\
\hline \multirow[t]{2}{*}{$\mathrm{k}=10 \% \times \mathrm{n}$} & 30.91 & 31.17 & 29.85 & 36.16 & 36.57 & 41.47 & 39.55 & 38.81 & 39. \\
\hline & $(0.30)$ & $(0.54)$ & $(0.57)$ & $(0.89)$ & $(1.22)$ & $(1.52)$ & $(0.83)$ & $(0.88)$ & $(0.6$ \\
\hline \multirow[t]{2}{*}{$\mathrm{k}=20 \% \times \mathrm{n}$} & 31.05 & 31.16 & 30.05 & 36.14 & 36.51 & 41.18 & 39.54 & 38.68 & 39. \\
\hline & $(0.31)$ & $(0.53)$ & $(0.63)$ & $(1.17)$ & (1.79) & $(1.50)$ & $(0.95)$ & $(0.84)$ & $(0.6$ \\
\hline
\end{tabular}

Notes: year-2005 purchasing-power parity international dollars are used (UNSD 2015). For clarity, Ginis and their standard errors errors are in parentheses. Parametric Ginis are calculated by numerical integration with 5,000 integration points. Quasi-nonparan equations 2 and 4. Standard errors of quasi-nonparametric Ginis are computed by bootstrapping and using 100 random draws from as in equation 5 . 
Figure A1. Uncorrected vs. corrected Ginis using an alternative adult-equivalent household-size scale

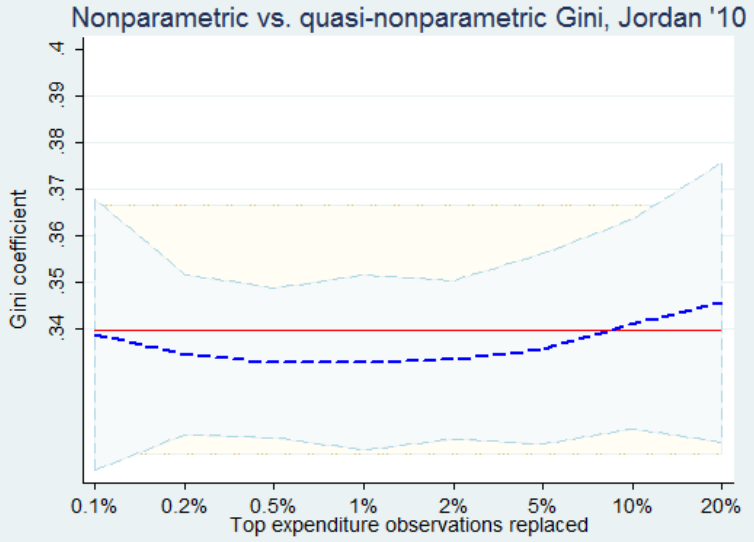

a. Pareto distribution correction, Jordan '10

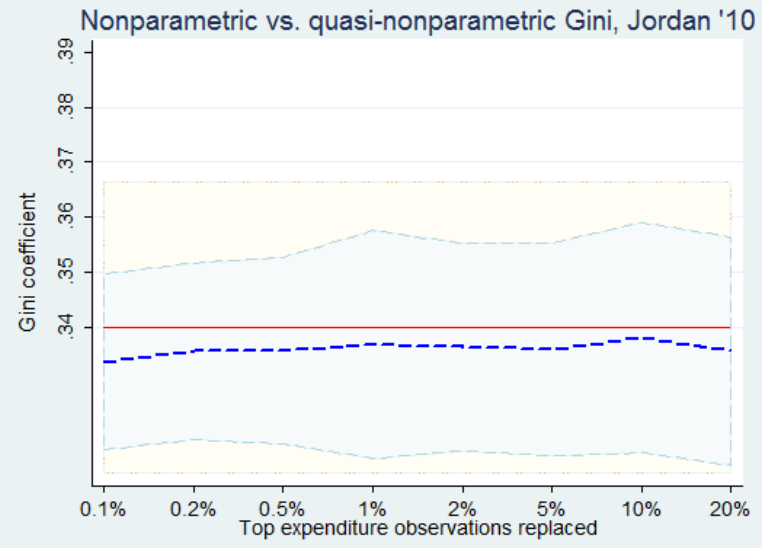

b. GB2 distribution correction, Jordan '10

Note: Expenditure per capita is computed using a modified OECD adult-equivalence scale with household size taken as $\left[1+0.7\left(N_{\text {adults }}-1\right)+0.3 N_{\text {children }}+0.3 N_{\text {elderly }}\right]$ to account for a lesser role played by children under the age of 14 and the elderly aged 65+ years (Glewwe and Twum-Baah, 1991, as cited in Haughton and Khandker 2009:29). 
Figure A2. Gini uncorrected vs. corrected for potentially mismeasured highest expenditures, Generalized Beta distribution type 2
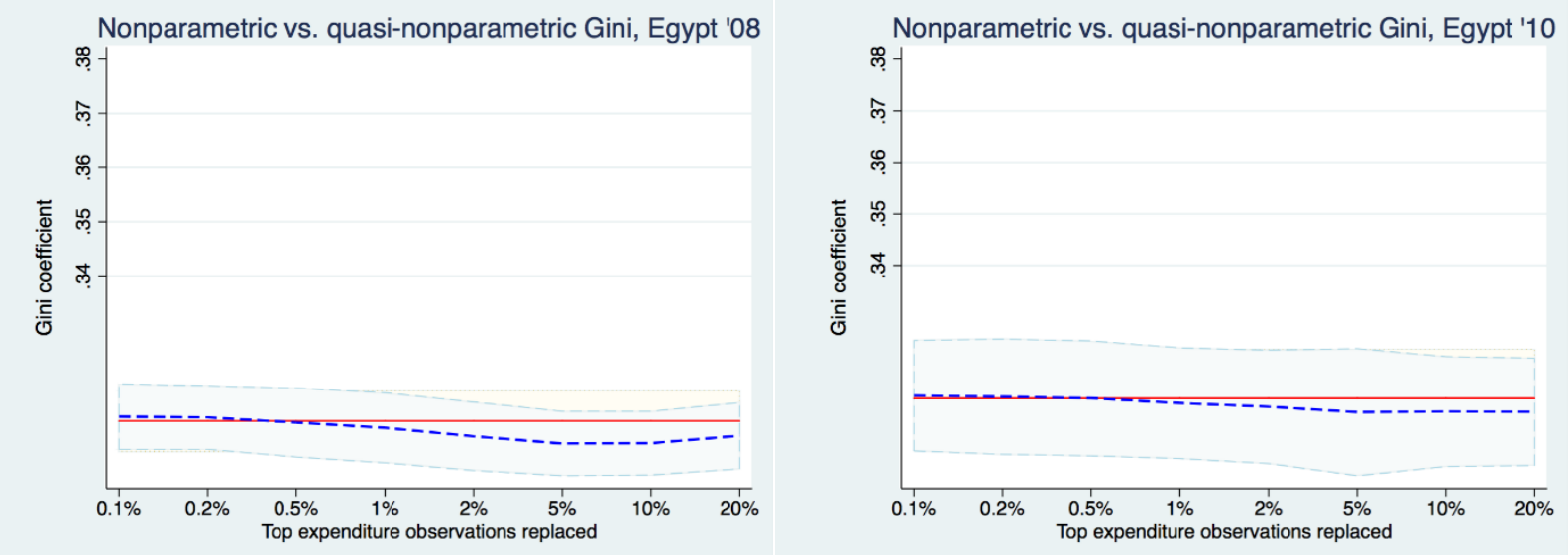

a. Egypt '08

b. Egypt ' 10
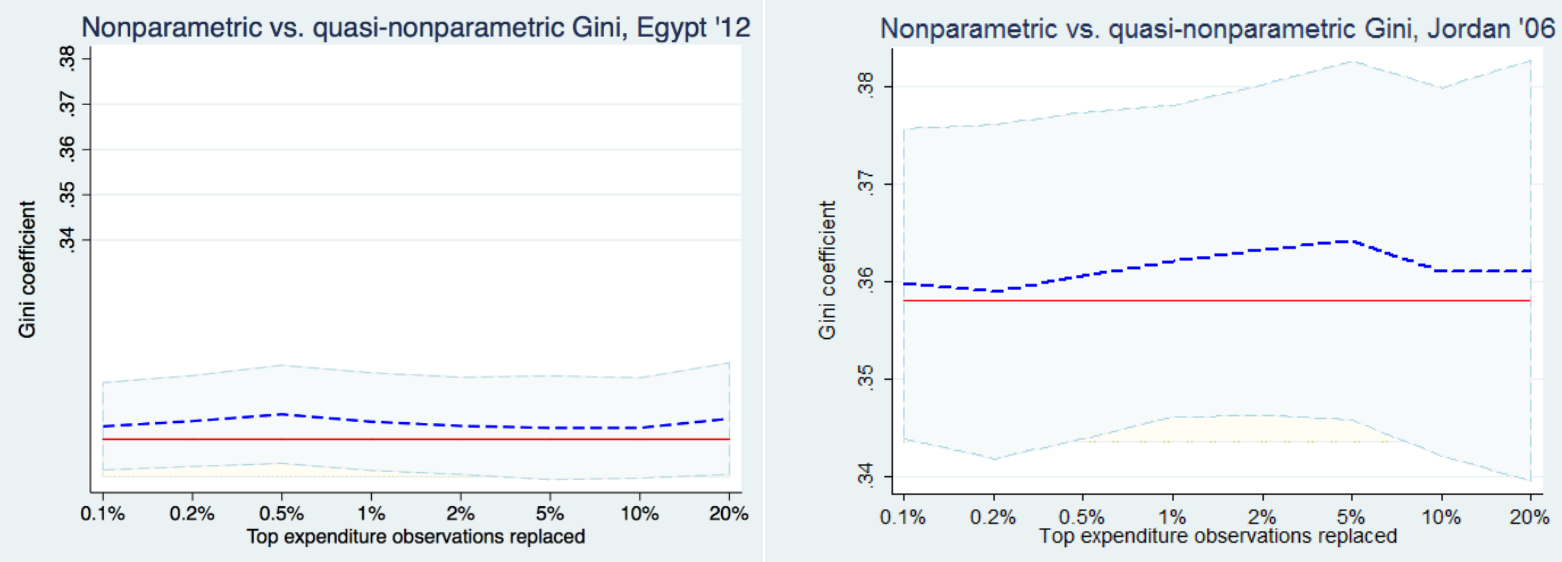

c. Egypt' 12

d. Jordan '06

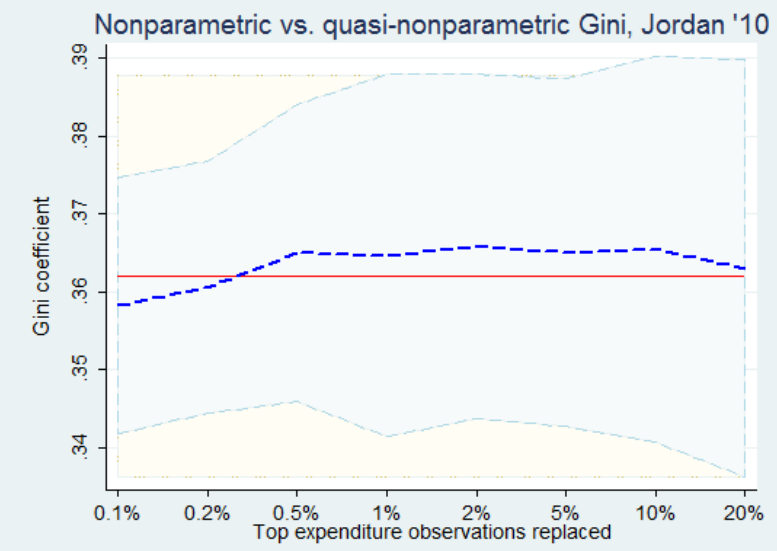

e. Jordan '10

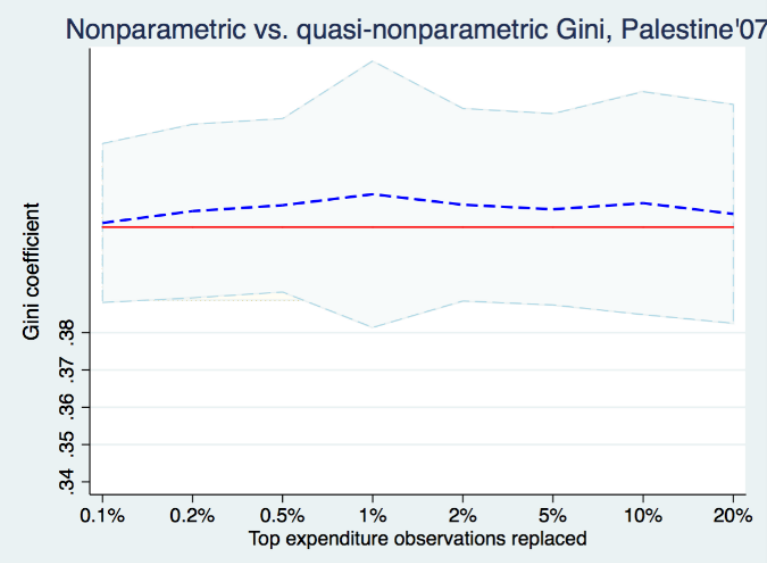

f. Palestine '07 
Figure A2 (cont.). Ginis, Generalized Beta distribution type 2
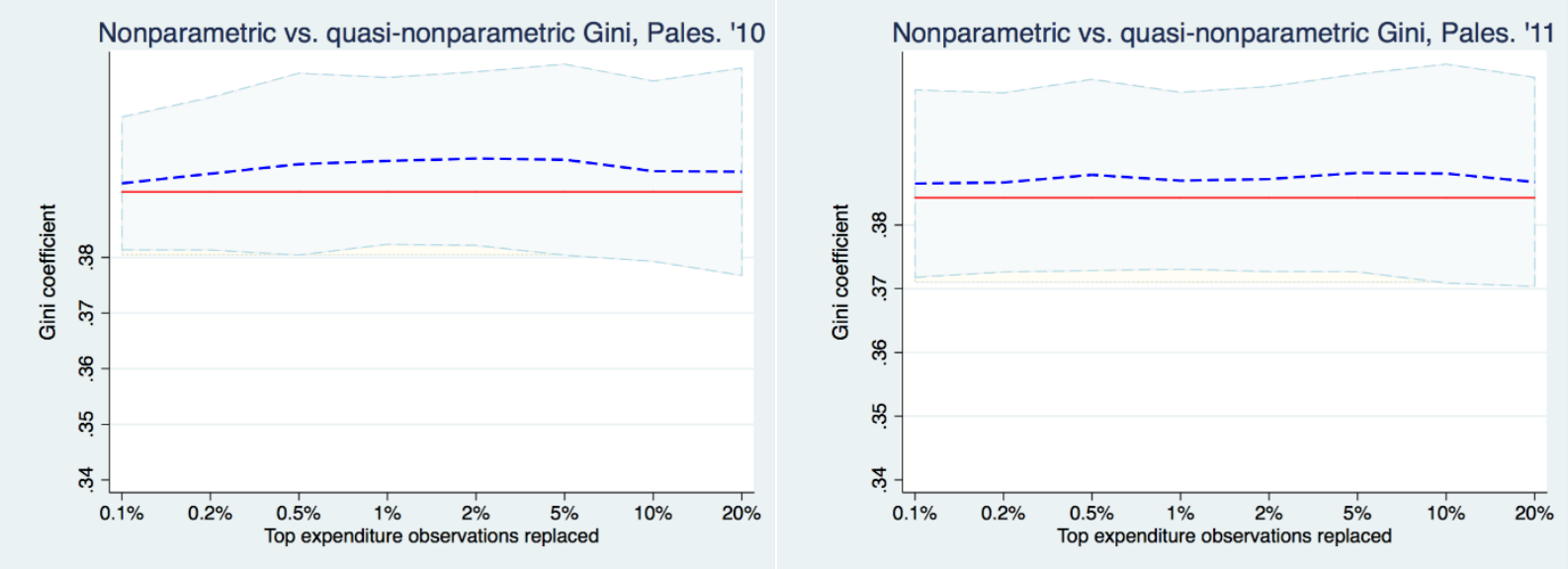

g. Palestine ' 10

h. Palestine ' 11

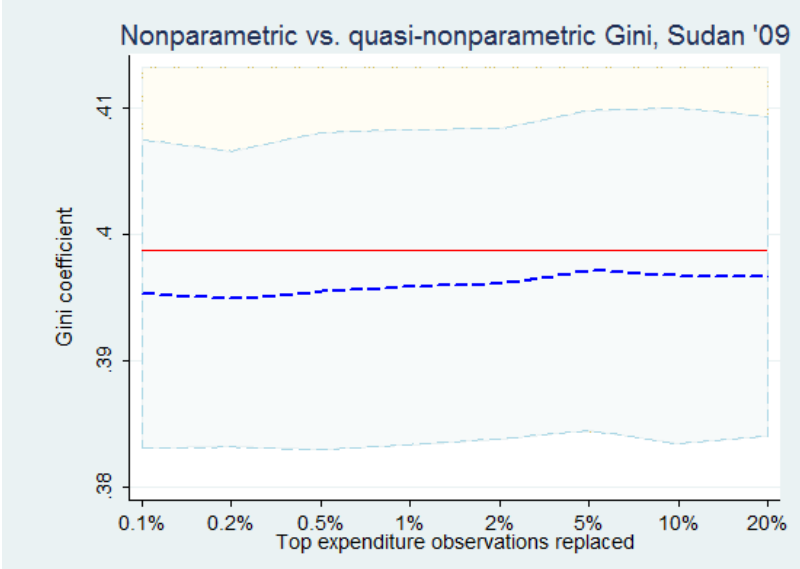

i. Sudan '09

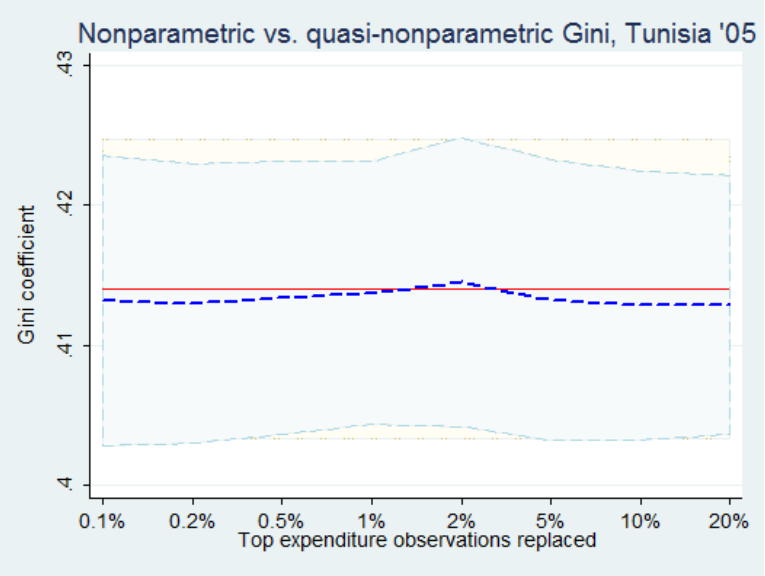

j. Tunisia '05

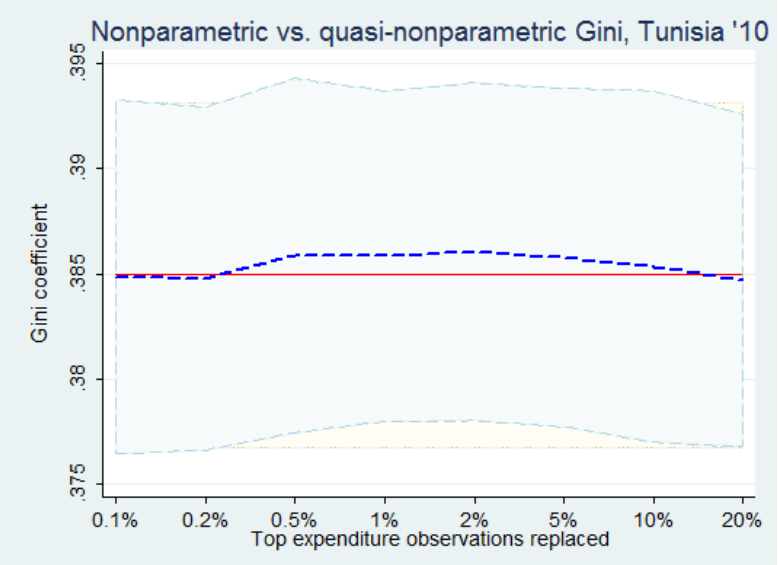

k. Tunisia ' 10

Notes: These Ginis correspond to those reported in table A6. Blue dashed lines show the estimated quasinonparametric Ginis and 95\% confidence intervals using bootstrap standard errors aggregated across 100 random draws as in equation 5, for alternative delineations of top $k$ expenditures. Red solid lines show non-parametric Ginis with their 95\% confidence intervals using bootstrap standard errors. 
Figure A3. Pareto coefficient of the top expenditure distribution from table 1

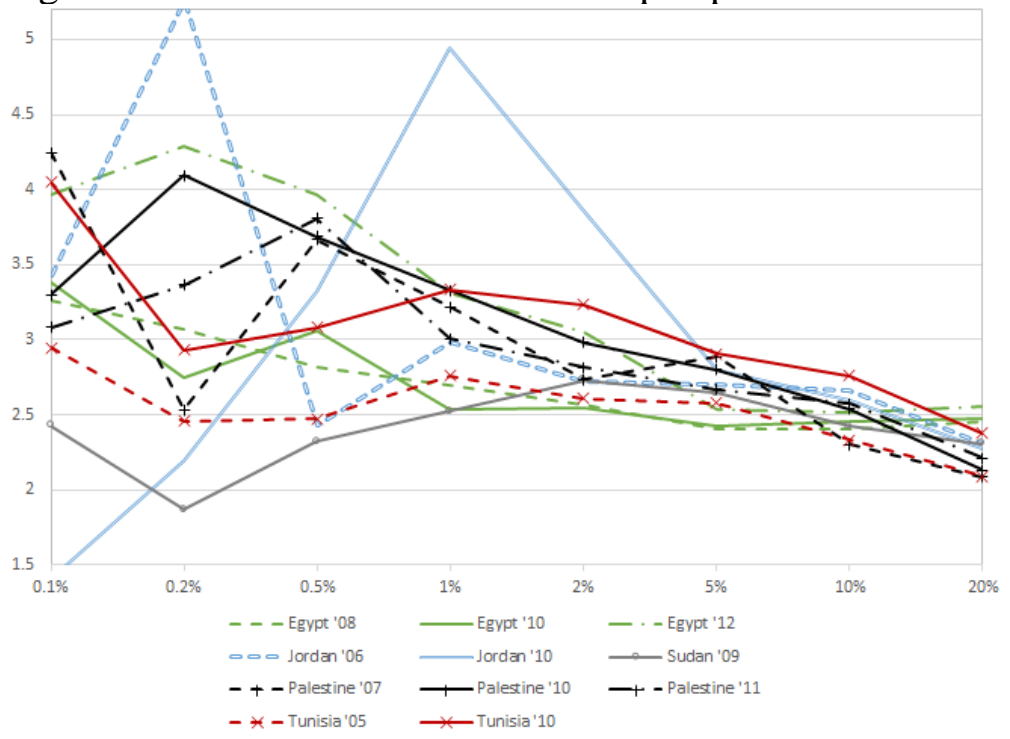


Figure A4. Quantile-quantile plots of actual vs. Pareto-predicted distribution of the top 5\% of expenditures
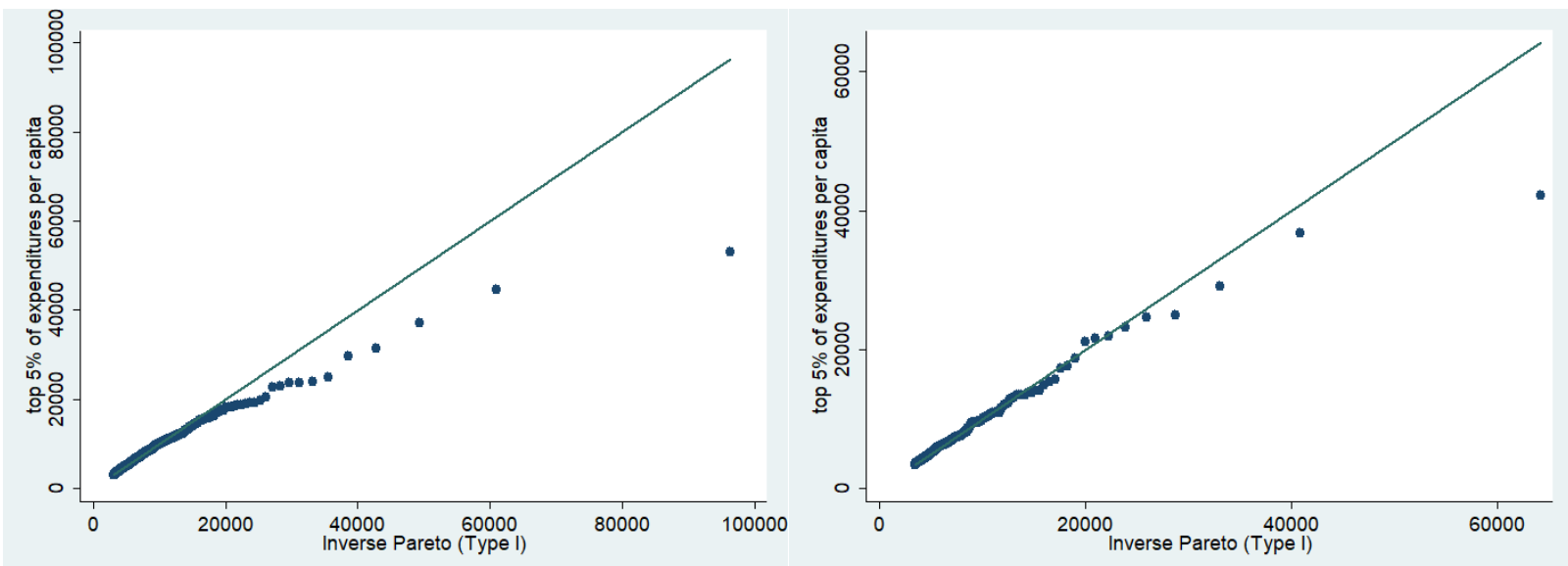

a. Egypt '08

b. Egypt ' 10
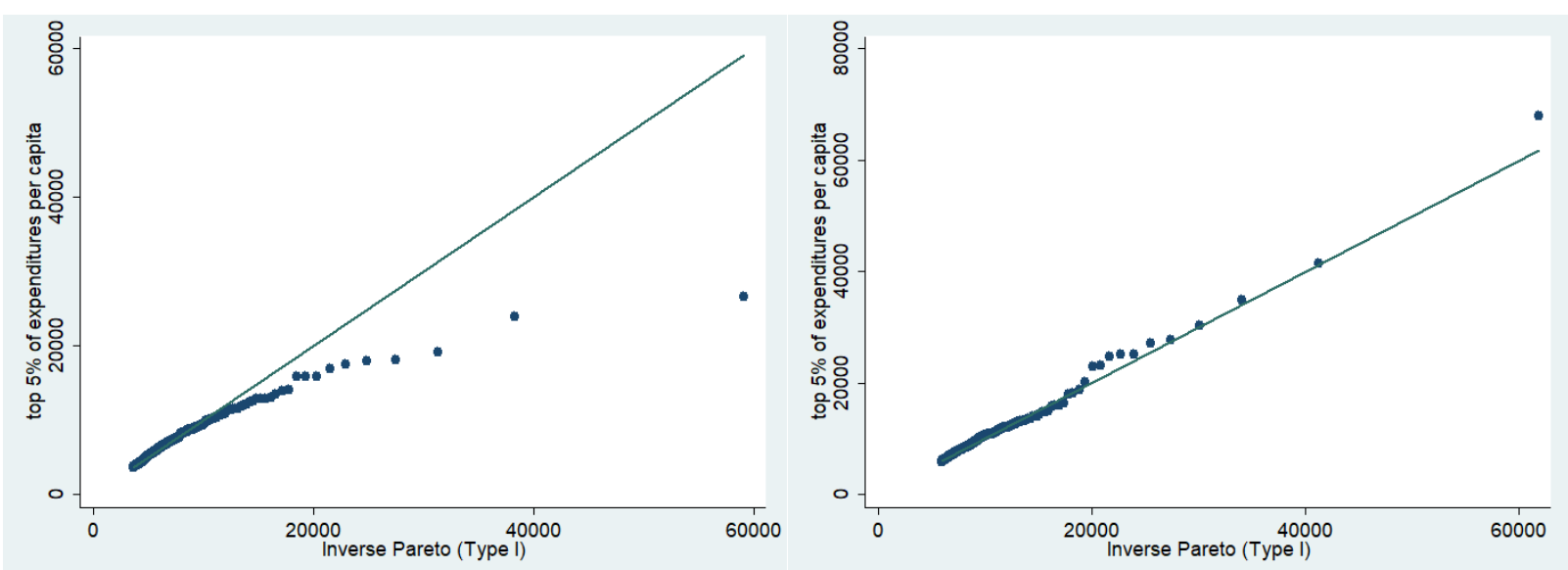

c. Egypt ' 12

d. Jordan '06

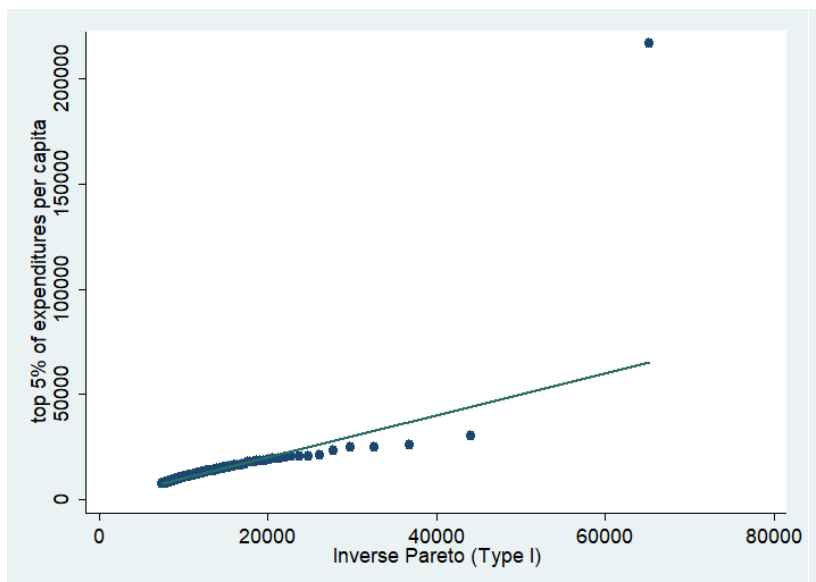

e. Jordan '10

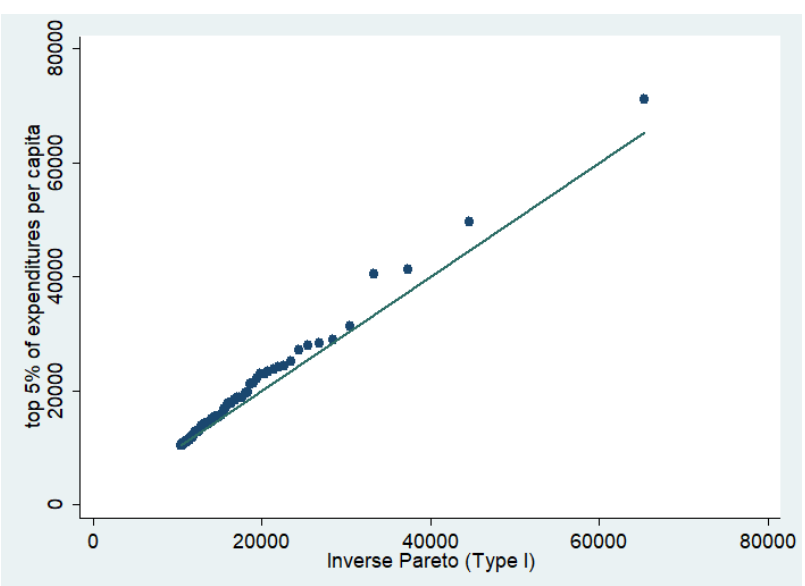

f. Palestine ' 07 
Figure A4 (cont.). Quantile-quantile plots of actual vs. Pareto-predicted distribution of the top 5\% of expenditures
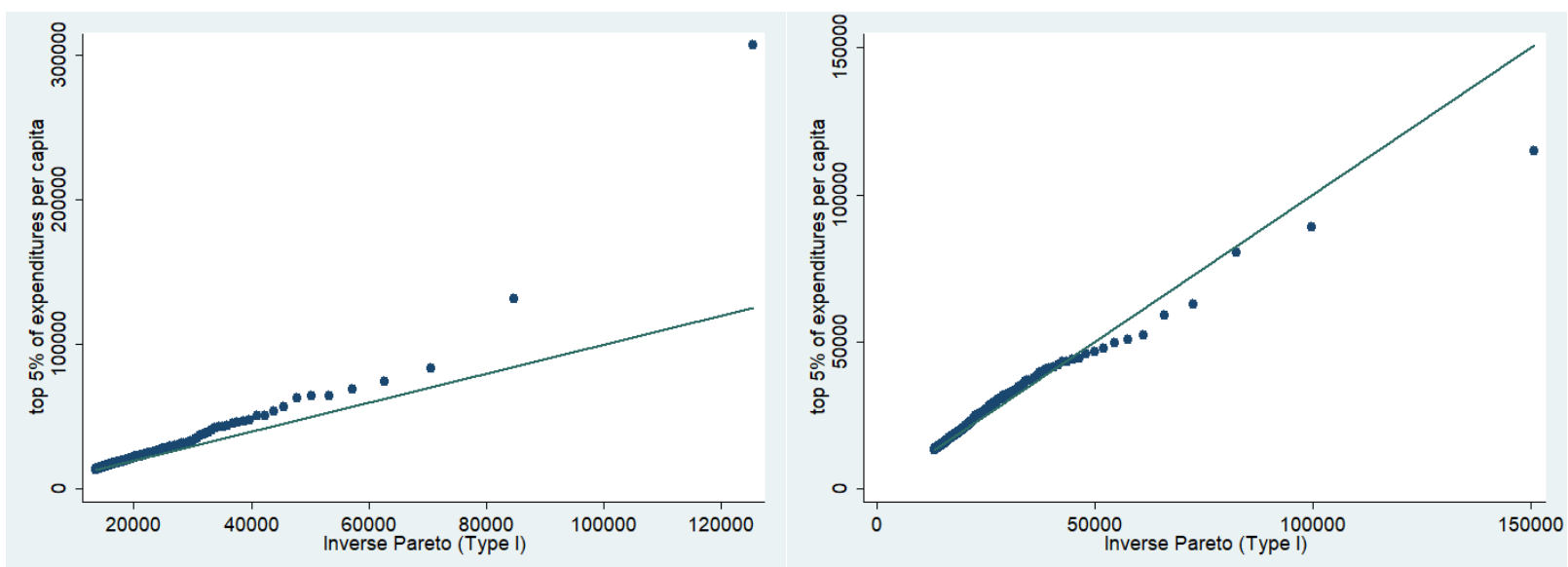

g. Palestine '10

h. Palestine ' 11
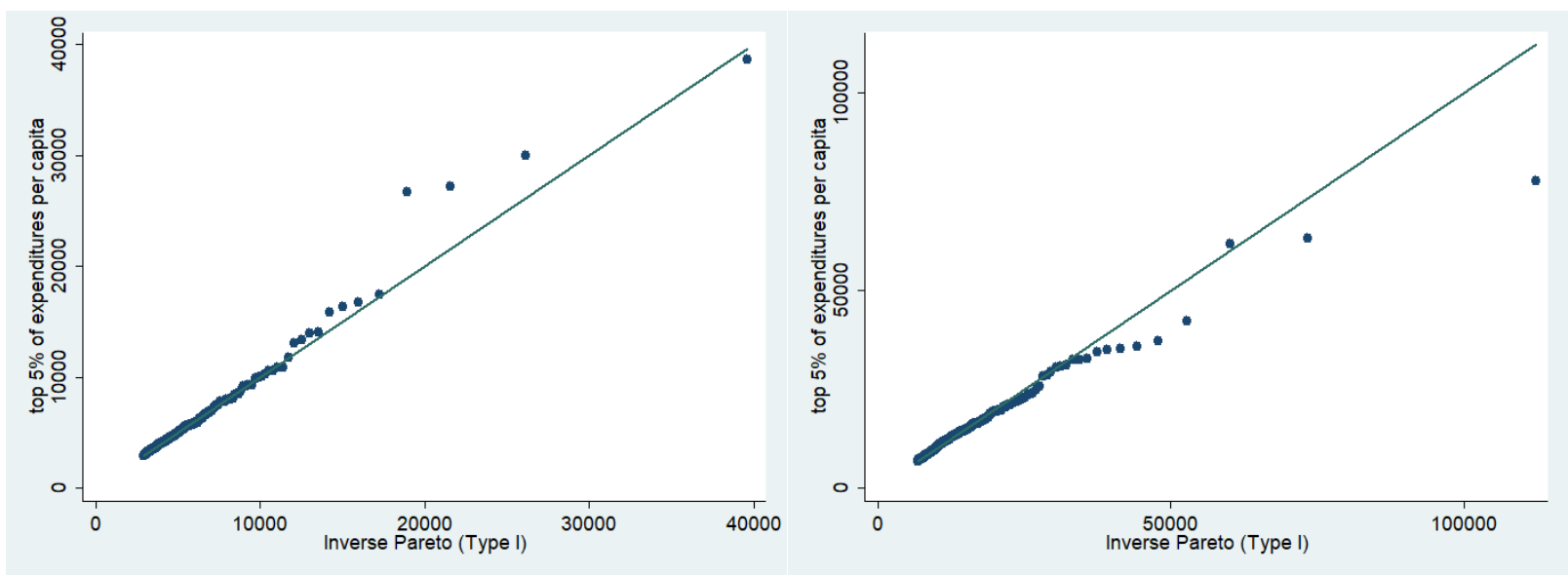

i. Sudan '09

j. Tunisia '05

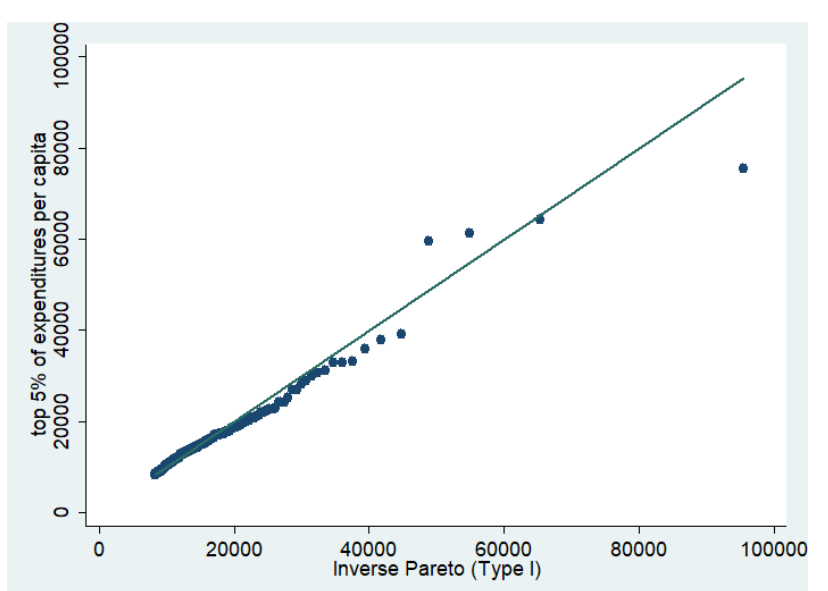

k. Tunisia '10

Notes: Solid lines show the predicted expenditure values under the Pareto distribution estimated among the same top $5 \%$ of expenditures (Pareto coefficients in table 1). Dots show the actual observations (Van Kerm and Cox 2007). 
Figure A5. Quantile-quantile plots of actual vs. Pareto-predicted distribution of the top $20 \%$ of expenditures

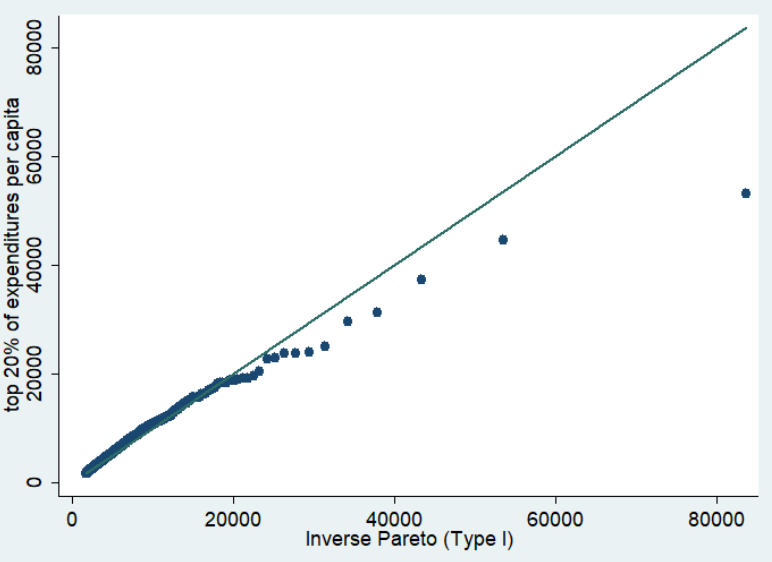

a. Egypt '08

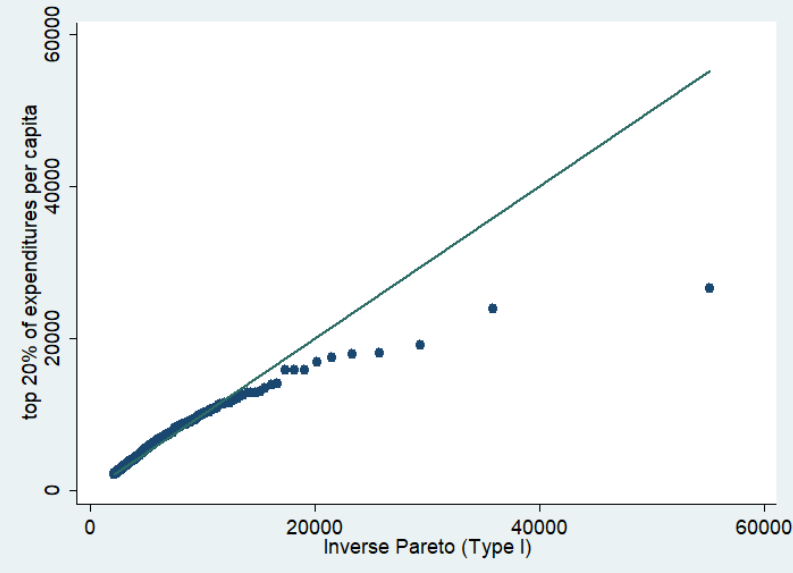

c. Egypt '12

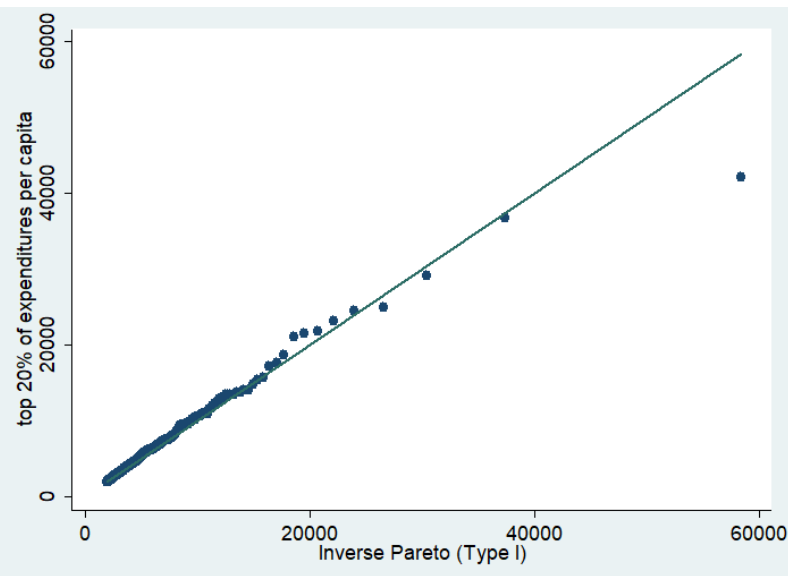

b. Egypt ' 10

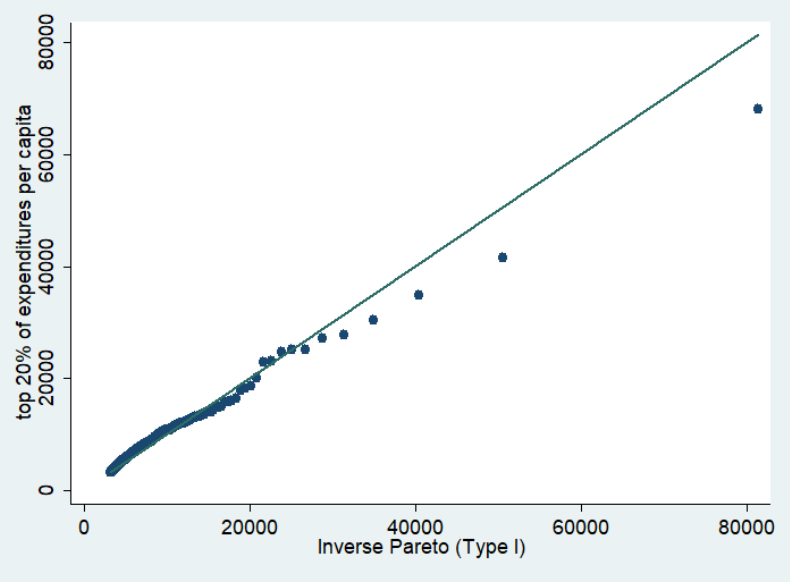

d. Jordan '06

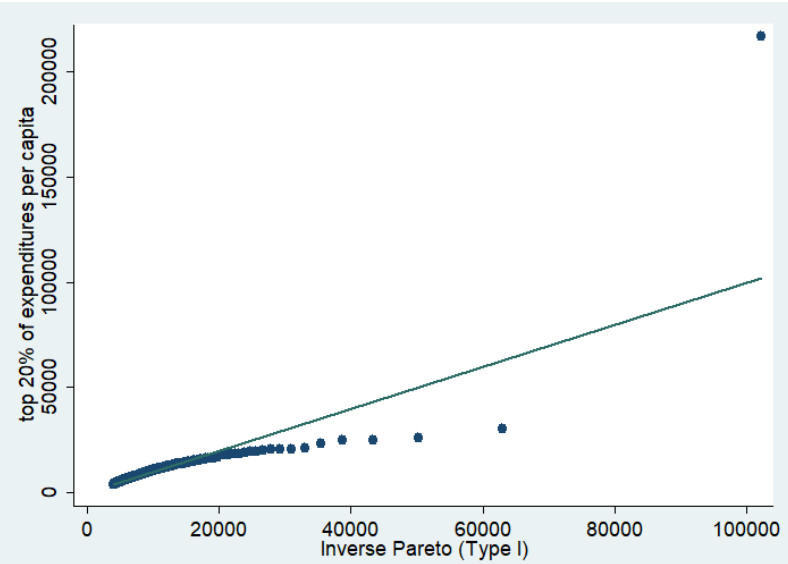

e. Jordan '10

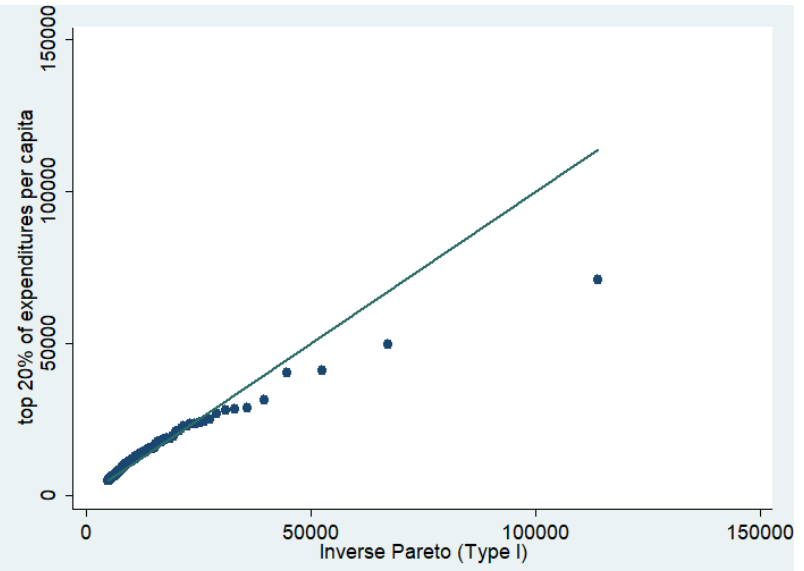

f. Palestine '07

43 
Figure A5 (cont.). Quantile-quantile plots of actual vs. Pareto-predicted distribution of the top 20\% of expenditures
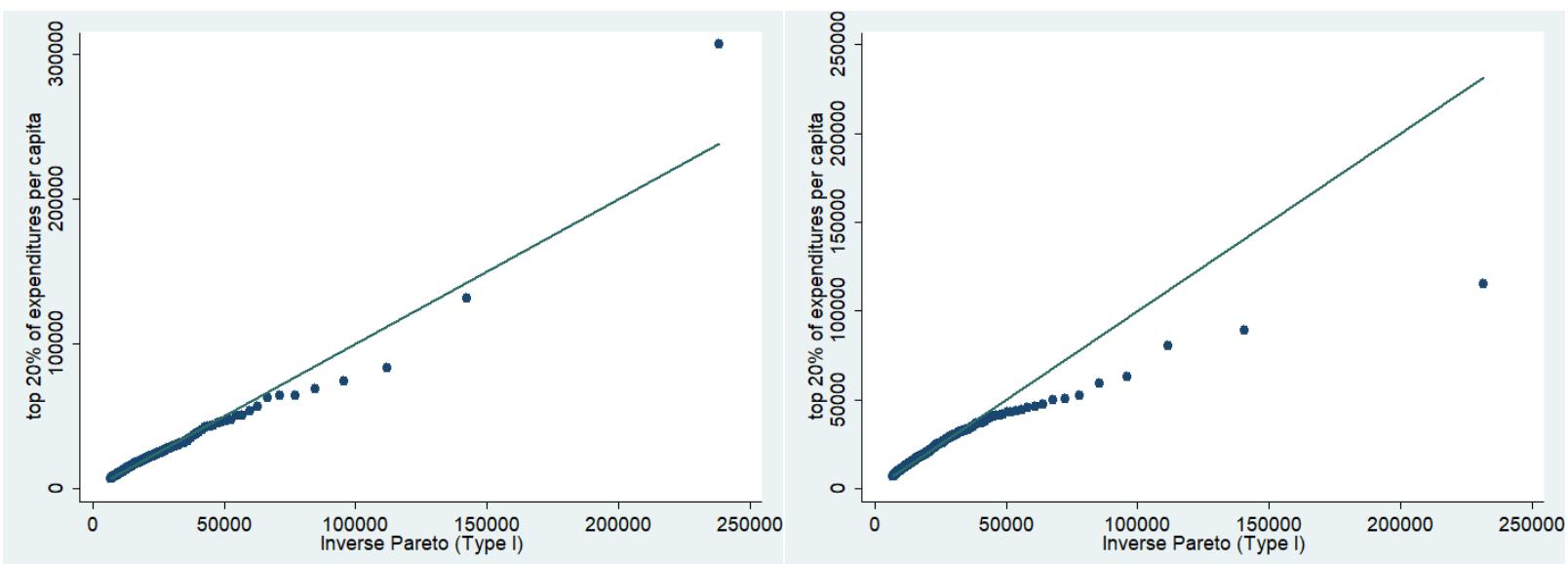

g. Palestine '10

h. Palestine ' 11
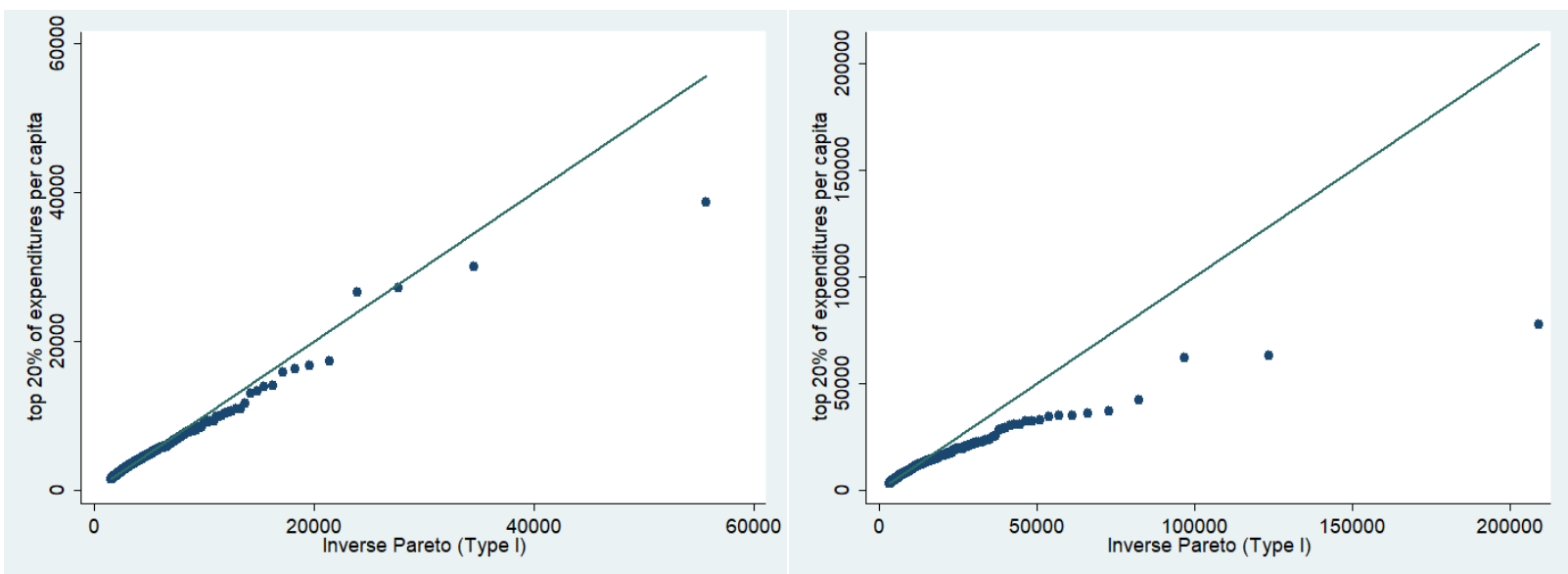

i. Sudan '09

j. Tunisia '05

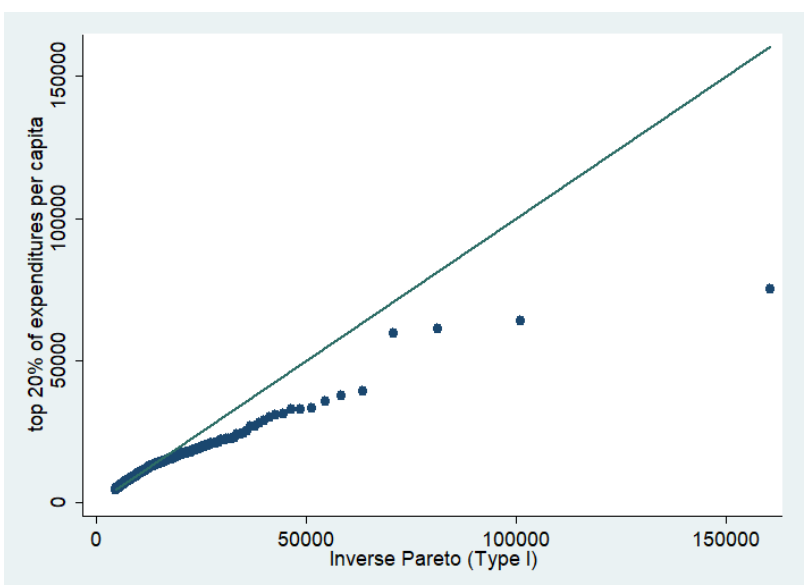

k. Tunisia '10

Notes: Solid lines show the predicted expenditure values under the Pareto distribution estimated among the same top $20 \%$ of expenditures (Pareto coefficients in table 1). Dots show the actual observations (Van Kerm and Cox 2007). 
Figure A6. Hill plots for expenditure per capita
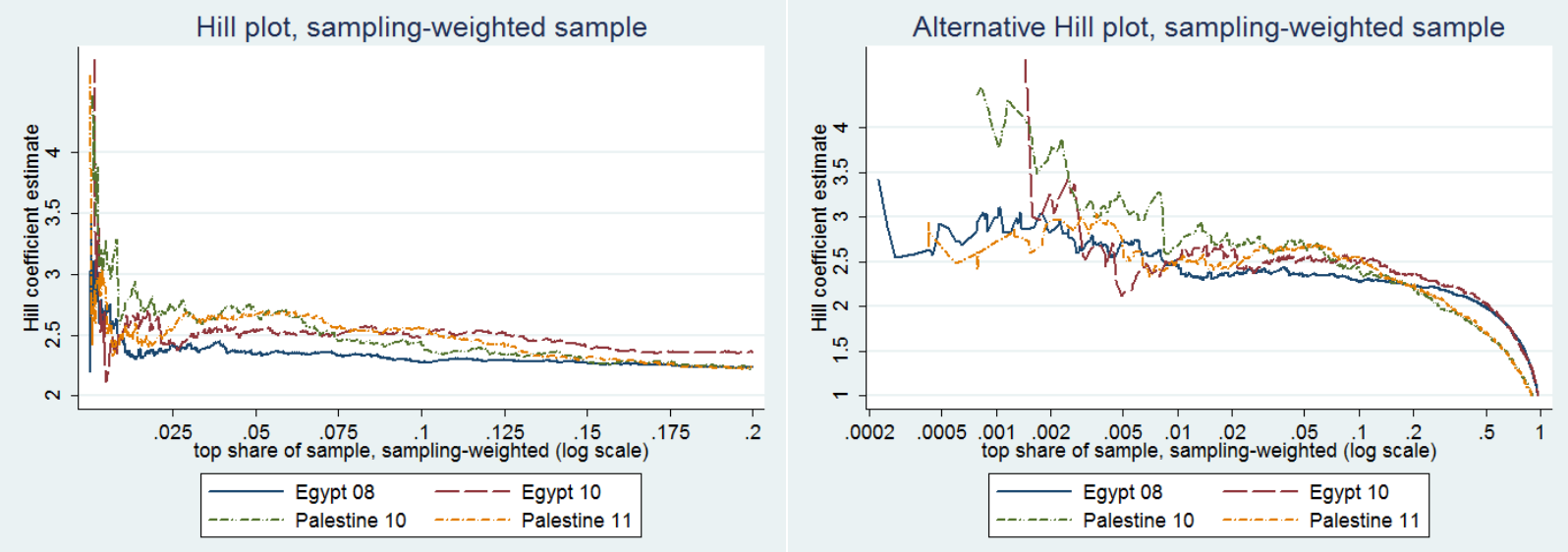

(a) Hill plots: Egypt and Palestine

(b) Alternative Hill plots: Egypt and Palestine

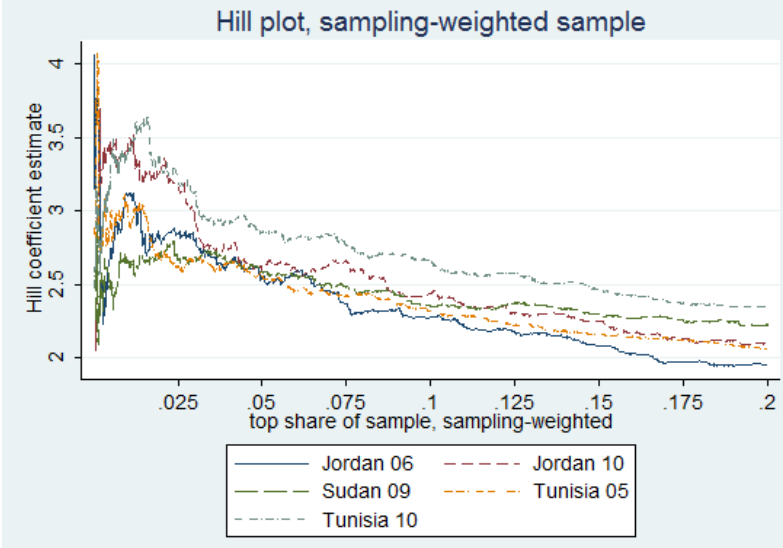

(c) Hill plots: Jordan, Sudan and Tunisia

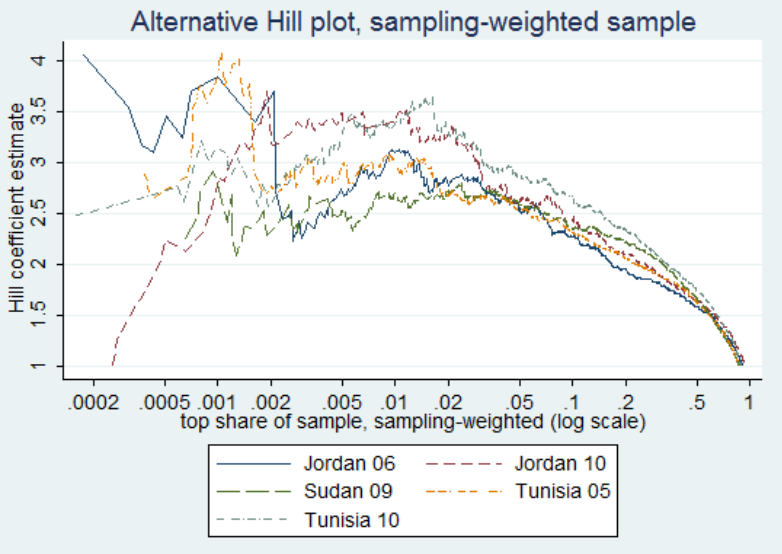

(d) Alternative Hill plots: Jordan, Sudan and Tunisia

Notes: Sample size in all eleven surveys is normalized to $100 \%$ and the Hill plots truncated at top $20 \%$ of sample to facilitate comparison. The alternative Hill plots use a logarithmic scale for sample size (Drees et al. 2000).

\section{Supplementary Material References}

Dagum, C. (1980) The generation and distribution of income, the Lorenz curve and the Gini ratio, Economie Appliquee, 33, 327-367.

Drees, H., de Haan, L., and Resnick, S.I. (2000) How to make a Hill plot. Annals of Statistics 28:254-274.

Glewwe, P., and Twum-Baah, K.A. (1991) The Distribution of Welfare in Ghana, 1987-88, Living Standards Measurement Study Paper No. 75, World Bank, Washington, DC.

Haughton, J., and Khandker, S.R. (2009) Handbook on Poverty and Inequality, World Bank, Washington, DC.

Jenkins, S.P. (2009) GB2LFIT: Stata module to fit a GB2 distribution to unit record data, Institute for Social and Economic Research, University of Essex, Colchester, UK. 
McDonald, J.B. (1984) Some generalized functions for the size distribution of income, Econometrica 52:647-63.

Singh, S.K. and Maddala, G.S. (1976) A function for the size distribution of income, Econometrica 44:963-970.

United Nations Statistics Division (UNSD, 2015) Millennium Development Goals Indicators: Purchasing power parities (PPP) conversion factor, local currency unit to international dollar, 1990-2012, updated 6-July 2015.

Van Kerm, P., and Cox, N.J. (2007), Qpareto. http://medim.ceps.lu/stata/.

World Bank (2015), PPP conversion factor, GDP (LCU per international \$), International Comparison Program database, World Development Indicators catalog, http://data.worldbank.org/indicator/PA.NUS.PPP. 